\title{
IDEO - Integrador de dados da Execução Orçamentária Brasileira: Um estudo de caso da integração de dados das receitas e despesas nas Esferas Federal, Estadual - Governo de São Paulo, e Municipal - Municípios do Estado de São Paulo
}


JOSÉ RODOLFO BELUZO

\section{IDEO - Integrador de dados da Execução Orçamentária Brasileira: Um estudo de caso da integração de dados das receitas e despesas nas Esferas Federal, Estadual - Governo de São Paulo, e Municipal - Municípios do Estado de São Paulo}

Dissertação apresentada à Escola de Artes, Ciências e Humanidades da Universidade de São Paulo para obtenção do título de Mestre em Ciências pelo Programa de Pós-graduação em Sistemas de Informação.

Área de Concentração: Sistemas de Informação

Versão corrigida contendo as alterações solicitadas pela comissão julgadora em 30 de Setembro de 2015. A versão original encontrase em acervo reservado na Biblioteca da EACH-USP e na Biblioteca Digital de Teses e Dissertações da USP (BDTD), de acordo com a Resolução CoPGr 6018, de 13 de Outubro de 2011.

Orientadora: Profa. Dra. Gisele da Silva Craveiro

São Paulo

2015 
Autorizo a reprodução e divulgação total ou parcial deste trabalho, por qualquer meio convencional ou eletrônico, para fins de estudo e pesquisa, desde que citada a fonte.

Beluzo, José Rodolfo

IDEO - Integrador de dados da Execução Orçamentária Brasileira : um estudo de caso da integração de dados das receitas e despesas nas Esferas Federal, Estadual - Governo de São Paulo, e Municipal - Municípios do Estado de São Paulo / José Rodolfo Beluzo ; orientadora, Gisele da Silva Craveiro. São Paulo, 2015

126 f. : il.

Dissertação (Mestrado em Ciências) - Programa de Pós-Graduação em Sistemas de Informação, Escola de Artes, Ciências e Humanidades, Universidade de São Paulo

Versão corrigida

1. Governo eletrônico. 2. Orçamento público. 3. Dados abertos Integração. 4. Administração pública. I. Craveiro, Gisele da Silva, orient. II. Título

CDD 22.ed. -350.0285 
Dissertação de autoria de José Rodolfo Beluzo, sob o título " IDEO - Integrador de dados da Execução Orçamentária Brasileira: Um estudo de caso da integração de dados das receitas e despesas nas Esferas Federal, Estadual - Governo de São Paulo, e Municipal Municípios do Estado de São Paulo", apresentada à Escola de Artes, Ciências e Humanidades da Universidade de São Paulo, para obtenção do título de Mestre em Ciências pelo Programa de Pós-graduação em Sistemas de Informação, na área de concentração Sistemas de Informação, aprovada em 30 de Setembro de 2015 pela comissão julgadora constituída pelos doutores:

Profa. Dra. Gisele da Silva Craveiro

Presidente

Instituição: Escola de Artes, Ciências e Humanidades - USP

Prof. Dr. Jaime Crozatti

Instituição: Escola de Artes, Ciências e Humanidades - USP

Prof. Dr. Seiji Isotani

Instituição: Instituto de Ciências Matemáticas e de Computação - USP 
Dedico este trabalho ao meu pai José Paulo Beluzo (in memoriam) que sempre trabalhou muito e se esforçou em vida para sempre me oferecer uma boa educação 


\section{Agradecimentos}

Agradeço inicialmente à minha mãe e irmãos por sempre me apoiarem e me ampararem em minhas decisões. Agradeço também aos meus amigos, em especial os grandes amigos Eduardo, Ricardo e Daniel que sempre proporcionaram discussões políticas proveitosas em nossos momentos de descontração, as quais influenciaram-me a iniciar este trabalho. Agradeço por último aos professores do programa de pós-graduação do PPGSI da EACH-USP pelo ótimo trabalho realizado durante a minha passagem pelo programa, e em especial à Profa. Dra. Gisele da Silva Craveiro por me acompanhar e me auxiliar durante todo o processo deste projeto. 


\section{Resumo}

Beluzo, José Rodolfo. IDEO - Integrador de dados da execução orçamentária: Um estudo de caso da integração de dados das receitas e despesas nas Esferas Federal, Estadual Governo de São Paulo, e Municipal - Municípios do Estado de São Paulo. 2015. 126 f. Dissertação (Mestrado em Ciências) - Escola de Artes, Ciências e Humanidades, Universidade de São Paulo, São Paulo, 2015.

Este trabalho apresenta um grupo de processos para a integração de dados e esquemas das receitas e despesas da execução do orçamento público brasileiro nas três esferas governamentais: governo federal, estadual e municípios. Estes processos visam resolver problemas de heterogeneidade encontrados pelo cidadão ao buscar por informações públicas em diferentes entes. Estas informações atualmente são disponibilizadas pelos portais de transparência que seguem a obrigatoriedade definida pelo arcabouço legal brasileiro, no qual estes devem publicar, dentre outras informações, o registro de receitas, despesas, transferências financeiras e processos licitatórios, de forma íntegra, primária, autêntica e atualizada. Porém, apesar das exigências citadas por lei, não existe um padrão para publicação, além de inconsistências e ambiguidades de dados entre os diferentes portais. Assim, este trabalho visa resolver estes problemas de heterogeneidade enfrentados pelo cidadão. Para tal, como prova de conceito foram selecionados os dados de receitas e despesas do governo federal, do governo do estado de São Paulo e de 645 municípios do estado de São Paulo. Este trabalho padronizou um modelo conceitual de receitas e despesas baseado no manual técnico do orçamento redigido pelo governo federal anualmente. A partir deste modelo criou-se esquemas de dados padronizados de acordo com os datasets que estão disponibilizados nos portais de transparência de cada ente federativo, assim como um esquema integrado entre estes. Os dados de execução orçamentária do período de 2010 a 2014 dos governos citados foram extraídos dos portais, passando por um processo de transformação e limpeza, e carregados no sistema integrador. Após os dados carregados no sistema, a partir do protótipo foi possível obter informações a respeito da execução orçamentária as quais não eram possíveis de se realizar de forma direta acessando os portais de transparência, ou, quando possível o trabalho de compilação da informação seria muito elevado. Também foi possível analisar e apontar possíveis falhas sistêmicas nos portais de transparência através dos resultados obtidos no processo, podendo contribuir com a melhoria destes.

Palavras-chave: Dados abertos. Dados abertos governamentais. Integração de dados. Data Warehouse. Orçamento Público. 


\begin{abstract}
BELUZO, Jose Rodolfo. The integration of multi-source heterogeneous data: an open data case study for budgetary execution in Brazil. 2015. 126 p. Dissertation (Master of Science) School of Arts, Sciences and Humanities, University of São Paulo, São Paulo, 2015.

This dissertation presents a process group for data integration and schemes of the Brazilian public budget's revenues and expenditures from all government level spheres (municipalities, states and nationwide). These process group aims to solve some heterogeneity problems to access public information provided by different government entities. Budget information is currently disclosed on e-gov portals, which must comply the requirements set by the Brazilian legal framework. Data about revenues, expenses, financial transfers and bidding processes must be published in a primary, authentic and updated way. However, there is no standards for publication, besides the poor data quality and inconsistencies found in the same data provided by different portals. Thus, this work aims to give some contributions to address these heterogeneity problems. To achieve this, we implemented a proof of concept that gathers revenue and expenditure data from the Brazilian federal government, the state government of São Paulo and 645 municipalities of São Paulo state. As a result, this work has standardized a conceptual model of revenues and expenses based on the technical manual of the budget. From this model, we created standardized data schemas according to the datasets that are available at the website of transparency of each government entity, as well as an integrated scheme between them. Data disclosed from 2010-2014 by all mentioned government were gathered, cleaned and loaded into the prototype. The resulting data warehouse allows queries about budget execution in Brazil that are not possible to perform directly accessing the transparency portals, or, when it is possible, this compilation work is very time consuming. During the validation phase was also possible to analyze and identify possible some failures in the e-gov portals and some recomendations try to give some contribution to their improvement.
\end{abstract}

Keywords: Open data. Open government data. Data integration. Data Warehouse. Public Budget. 


\section{Lista de figuras}

Figura 1 - Adoção das diretrizes de DAG na amostra de dados no Brasil .............................22

Figura 2 - Heterogeneidade local dos dados abertos no País ................................................23

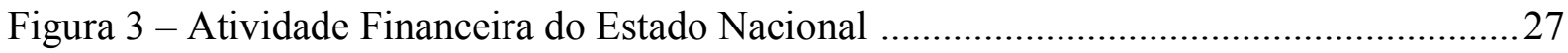

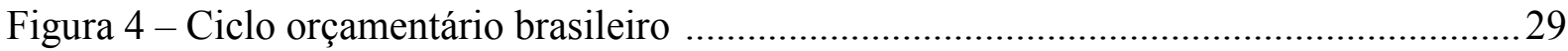

Figura 5 - Exemplo de classificação da receita por "Natureza" ............................................... 30

Figura 6 - Exemplo de classificação por "fonte de recursos" ............................................... 31

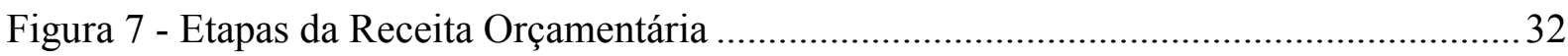

Figura 8 - Classificação Qualitativa - Despesas .................................................................. 33

Figura 9 - Classificação Quantitativa - Despesas ................................................................ 34

Figura 10 - Exemplo da estrutura completa da classificação da despesa ................................35

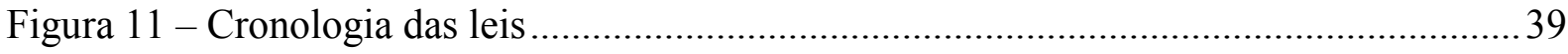

Figura 12 - Datasets disponíveis para consultas no data.gov ................................................. 42

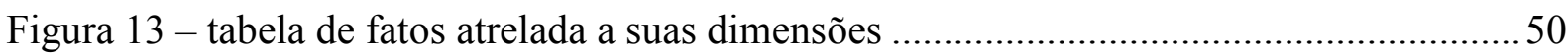

Figura 14 - modelo conceitual de receitas orçamentárias baseado nas descrições do MCASP 2014

Figura 15 - modelo conceitual de receitas orçamentárias - intersecção dos dados de receitas do governo federal com o modelo conceitual baseado nas descrições do MCASP 2014 56

Figura 16 - modelo conceitual de receitas orçamentárias - intersecção dos dados de receitas do governo do estado de São Paulo com o modelo conceitual baseado nas descrições do MCASP 2014

Figura 17 - modelo conceitual de receitas orçamentárias - intersecção dos dados de receitas dos municípios do estado de São Paulo (exceto a Capital São Paulo) com o modelo conceitual baseado nas descrições do MCASP 2014 .............................................58

Figura 18 - esquema lógico de receitas orçamentárias - Governo Federal ............................59

Figura 19 - esquema lógico de receitas orçamentárias - Governo do Estado de São Paulo.... 60 Figura 20 - esquema lógico de receitas orçamentárias - Municípios do Estado de São Paulo (exceto a Capital São Paulo).

Figura 21 - modelo conceitual de receitas orçamentárias - intersecção dos três entes federativos - governo Federal, Estado de São Paulo e dos municípios do estado de São Paulo (exceto a Capital São Paulo) - com o modelo conceitual baseado nas descrições do MCASP 2014 
Figura 22 - esquema lógico de receitas orçamentárias - Intersecção dos três entes federativos - Governo Federal, Governo do Estado de São Paulo e municípios de São Paulo, exceto a capital São Paulo

Figura 23 - modelo conceitual de despesas orçamentárias baseado nas descrições do MCASP

2014

Figura 24 - modelo conceitual: Intersecção de Gastos Diretos - Pagamentos - Governo

Federal com modelo conceitual de despesas de acordo com o MCASP.

Figura 25 - modelo conceitual: Intersecção de Gastos Diretos - Diárias - Governo Federal

com modelo conceitual de despesas de acordo com o MCASP 2014

Figura 26 - modelo conceitual: Intersecção de Gastos Diretos - CPGF - Governo Federal

com modelo conceitual de despesas de acordo com o MCASP 2014 68

Figura 27 - modelo conceitual: Intersecção de Transferências - Pagamentos - Governo

Federal com modelo conceitual de despesas de acordo com o MCASP 2014

Figura 28 - modelo conceitual: Intersecção de Transferências - CPDC - Governo Federal

com modelo conceitual de despesas de acordo com o MCASP 2014 70

Figura 29 - modelo conceitual: Intersecção de Programas Sociais - Bolsa Família e Outros

programas sociais - Governo Federal com modelo conceitual de despesas de

acordo com o MCASP 2014

Figura 30 - modelo conceitual: Intersecção de Programas Sociais - Pescador Artesanal -

Governo Federal com modelo conceitual de despesas de acordo com o MCASP

2014

Figura 31 - esquema lógico: união das intersecções dos datasets do governo Federal - Star

Schema.

Figura 32 - Modelo conceitual: Intersecção Governo Estado de São Paulo com modelo

conceitual de despesas de acordo com o MCASP 2014

Figura 33 - modelo conceitual: Intersecção municípios do Estado de São Paulo (exceto a capital São Paulo) com modelo conceitual de despesas de acordo com o MCASP

2014 .75

Figura 34 - Modelo conceitual: Intersecção município de São Paulo com modelo conceitual de despesas de acordo com o MCASP 2014

Figura 35 - Esquema lógico: Governo do Estado de São Paulo - Star Schema

Figura 36 - Esquema lógico: municípios do Estado de São Paulo (exceto a capital São Paulo)

- Star Schema 78

Figura 37 - Esquema Lógico: Município de São Paulo (Capital) - Star Schema 
Figura 38 - Modelo conceitual: Intersecção das três esferas governamentais (Governo Federal, do Estado de São Paulo e municípios do Estado de São Paulo, incluindo a capital) com o MCASP 2014 80

Figura 39 - Esquema lógico: Intersecção das três esferas governamentais (Governo Federal, do Estado de São Paulo e municípios do Estado de São Paulo, incluindo a capital) com o MCASP 2014 - Star Schema. 81

Figura 40 - exemplo de criação de fluxo de dados para criação dos esquemas físicos das tabelas dimensões e tabela fato para as despesas dos municípios do estado de São Paulo através da ferramenta Pentaho Data Integration

Figura 41 - assistente de criação de fonte de dados do "Pentaho Business Analytics" exemplo de criação do cubo dos dados das receitas dos municípios do estado de São Paulo 89

Figura 42 - Tela inicial da ferramenta Saiku Analytics 90

Figura 43 - Exemplo de consulta OLAP (a) Tabela; (b) Gráfico. 90 


\section{Lista de algoritmos}

Algoritmo 1 - Transformação Parcialmente Automatizada - correção do deslocamento de

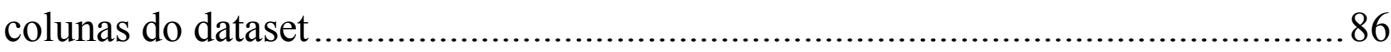

Algoritmo 2 - Carregamento dos dados nos esquemas lógicos do Data Warehouse............... 88 


\section{Lista de tabelas}

Tabela 1 - Totais gerados pelo sistema IDEO - despesas do governo federal - "Gastos

Diretos: Pagamentos"

Tabela 2 - Totais gerados pelo sistema do PTCGU - despesas do governo federal - "Gastos

Diretos: Pagamentos"

Tabela 3 - Diferença de valores / Ausência de dados em PTCGU e IDEO - despesas do governo federal - "Gastos Diretos: Pagamentos". (Observação: valor - "ausente" definido para quando não foi encontrado o dado nos datasets utilizados no sistema IDEO acrescido do valor original disponibilizado apenas na ferramenta de consulta do PTCGU) - 2011 a 94

Tabela 4 - Totais gerados pelo sistema IDEO - despesas do governo federal - "Diárias" ..... 94 Tabela 5 - Totais gerados pelo sistema do PTCGU - despesas do governo federal - "Diárias"

Tabela 6 - Diferença de valores nos dados em PTCGU e IDEO - despesas do governo federal - "Diárias".

Tabela 7 - Totais gerados pelo sistema IDEO - despesas do governo federal - "CPGF"....... 95 Tabela 8 - Totais gerados pelo sistema do PTCGU - despesas do governo federal - "CPGF"

Tabela 9 - Diferença de valores nos dados em PTCGU e IDEO - despesas do governo federal - "CPGF"

Tabela 10 - Totais gerados pelo sistema IDEO - despesas do governo federal -

"Transferências de recursos por Estado e Municípios".

Tabela 11 - Totais gerados pelo sistema do PTCGU - despesas do governo federal -

"Transferências de recursos por Estado e Municípios".....

Tabela 12 - Diferença de valores nos dados em PTCGU e IDEO - despesas do governo federal - "Transferências de recursos por Estado e Municípios". 97

Tabela 13 - Totais gerados pelo sistema IDEO - receitas do governo federal

Tabela 14 - Totais gerados pelo sistema do PTCGU - receitas do governo federal

Tabela 15 - Diferença de valores nos dados em PTCGU e IDEO - receitas do governo federal

Tabela 16 - Totais gerados pelo sistema IDEO - despesas do governo do estado de São Paulo 
Tabela 17 - Totais gerados pelo sistema interno do portal "Prestando Contas" - despesas do governo do estado de São Paulo

Tabela 18 - Diferença / Ausência de dados em Portal "Prestando Contas" e IDEO - despesas do governo do Estado de São Paulo

Tabela 19 - Totais gerados pelo sistema IDEO - receitas do governo do estado de São Paulo

Tabela 20 - Totais gerados pelo sistema interno do portal "Prestando Contas" - receitas do governo do estado de São Paulo

Tabela 21 - Diferença de valores nos dados em Portal "Prestando Contas" e IDEO - receitas do governo do Estado de São Paulo

Tabela 22 - Totais gerados pelo sistema IDEO - despesas dos municípios do estado de São

Paulo (Exceto a Capital)

Tabela 23 - Totais gerados pela ferramenta WEB do TCE SP - despesas dos municípios do estado de São Paulo (Exceto a Capital)

Tabela 24 - Diferença de valores nos dados em ferramenta WEB do TCE SP e IDEO despesas dos municípios do estado de São Paulo (Exceto a Capital)

Tabela 25 - Totais gerados pelo sistema IDEO - receitas dos municípios do estado de São

Paulo (Exceto a Capital)

Tabela 26 - Totais gerados pela ferramenta WEB do TCE SP - receitas dos municípios do estado de São Paulo (Exceto a Capital)

Tabela 27 - Diferença de valores nos dados em ferramenta WEB do TCE SP e IDEO receitas dos municípios do estado de São Paulo (Exceto a Capital) 105

Tabela 28 - Totais gerados pelo Sistema IDEO

Tabela 29 - Totais extraídos dos relatórios - Quadro Detalhado da Despesa, em cumprimento às Leis $n^{\circ} 13.949$ de 21 de janeiro de 2011 e n 14.106 de 28 de junho de 2011106 Tabela 30 - Diferenças entre o sistema IDEO e o Quadro Detalhado da Despesa (QDD).... 106 Tabela 31 - Totais gerados pelo sistema PTCGU x IDEO x SIGA - receitas arrecadadas do governo federal 108

Tabela 32 - Totais gerados pelo sistema PTCGU x IDEO x SIGA - despesas arrecadadas do governo federal - Gastos Diretos + Transferências.

Tabela 33 - Totais gerados pelo sistema IDEO x FINBRA - receitas arrecadadas do governo do estado de São Paulo 110

Tabela 34 - Totais gerados pelo sistema IDEO x FINBRA - despesas pagas pelo governo do estado de São Paulo 
Tabela 35 - Totais gerados pelo sistema IDEO x FINBRA - receitas dos municípios do estado de São Paulo 111

Tabela 36 - Totais gerados pelo sistema IDEO x FINBRA - despesas pagas pelos municípios

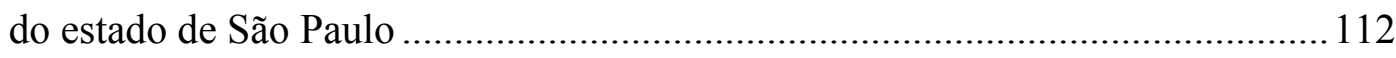

Tabela 37 - Totais gerados pelo sistema IDEO x FINBRA - despesas pagas pelo município de São Paulo 


\section{Lista de gráficos}

Gráfico 1 - Comparativo dos valores de receitas entre 2010 e 2014 entre os sistemas IDEO,

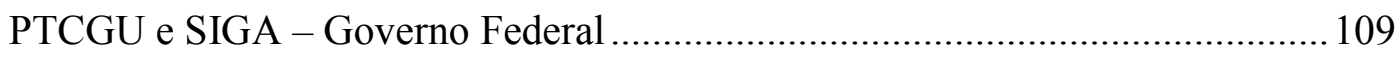

Gráfico 2 - Comparativo dos valores de despesas entre 2010 e 2014 entre os sistemas IDEO, PTCGU e SIGA - Governo Federal ................................................................. 110

Gráfico 3 - Comparativo dos valores de receitas entre 2010 e 2014 entre os sistemas IDEO, PTCGU e SIGA - Municípios

Gráfico 4 - Comparativo dos valores de despesas entre 2010 e 2014 entre os sistemas IDEO, PTCGU e SIGA - Municípios

Gráfico 4 - Comparativo dos valores de despesas entre 2010 e 2014 entre os sistemas IDEO, PTCGU e SIGA - Município SP 115 


\section{Lista de Quadros}

Quadro 1 - levantamento dos portais e respectivas localizações na internet para os dados da execução orçamentária dos entes federativos utilizados neste projeto ....................53

Quadro 2 - Diferença na granularidade das publicações de dados .................................... 120

Quadro 3 - Corretude dos dados dos entes federativos de acordo com os próprios portais .. 121

Quadro 4 - Corretude dos dados dos entes federativos de acordo com outras fontes............ 122 


\section{Lista de abreviaturas e siglas}

$\mathrm{BD}$

CF

CPDC

CPGF

CSV

DAG

DCL

DDL

DIGO

DML

$\mathrm{DM}$

DW

DWB

ETL

FINBRA

GND

HTML

IDEO

IDOC

IDUSO

LAI

LDO

LOA

LOD

LRF

MCASP

MDB

MTO

OGD

OGP

$\mathrm{OKF}$

OLAP
Banco de Dados

Constituição Federal

Cartão de Pagamento da Defesa Civil

Cartão de Pagamento do Governo Federal

Comma-separated values

Dados abertos governamentais

Data Control Language

Data Definition Language

Delivering Information of Government

Data Manipulation Language

Data Mart

Data Warehouse

Data Warehouse Bus

Extract, Transform and Load

Finanças do Brasil

Grupo de Natureza de Despesa

Hipertext Markup Language

Integrador de dados da Execução Orçamentária

Identificador de doação e operação de crédito

Identificador de uso

Lei de Acesso à Informação

Lei de Diretrizes Orçamentárias

Lei Orçamentária Anual

Linked Open data

Lei de Responsabilidade Fiscal

Manual de Contabilidade Aplicada ao Setor Público

Microsoft Access Database

Manual Técnico do Orçamento

Open Government Data

Open Government Partnership

Open Knowledge Foudation

Online Analytical Processing 
PDF

PDI

PHP

PPA

PTCGU

QDD

RDF

SAD

SGBD

SIAFI

SIC

SICONFI

SIGA

STN

TCE SP

TXT

WEB

XLS

ZIP
Portable Document Format

Pentaho Data Integration

Hypertext Preprocessor

Planejamento Plurianual

Portal da Transparência da Controladoria Geral da União

Quadro detalhado da despesa

Resource Description Framework

Sistema de Apoio a Decisão

Sistema Gerenciador de Banco de Dados

Sist. Integrado de Administração Financeira do Governo Federal

Sistema de Informação de Custos do Governo Federal

Sist. de Info. Contábeis e Fiscais do Setor Público Brasileiro

Sistema de informações sobre orçamento público

Secretária do Tesouro Nacional

Tribunal de Contas dos municípios do Estado de São Paulo

Arquivo de texto

Rede mundial de computadores

Extensão de arquivos Spreadsheet

Extensão de arquivo compactado 


\section{Sumário}

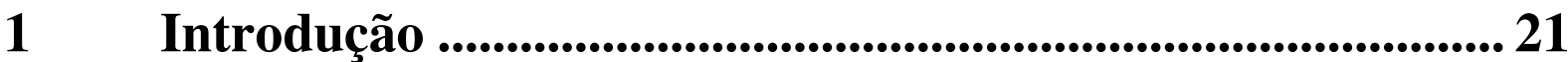

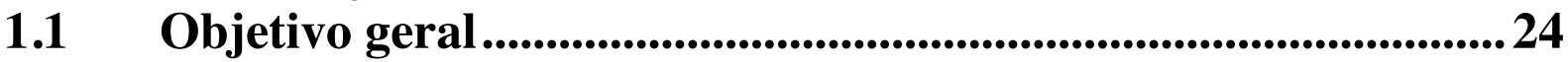

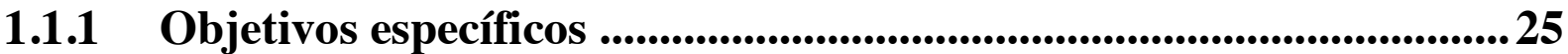

1.2 Organização do texto ............................................................... 25

2 Orçamento Público Brasileiro .................................................... 27

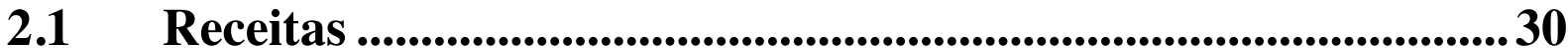

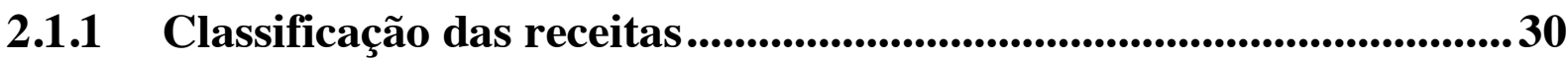

2.1.2 Etapas da Receita Orçamentária ...................................................................32

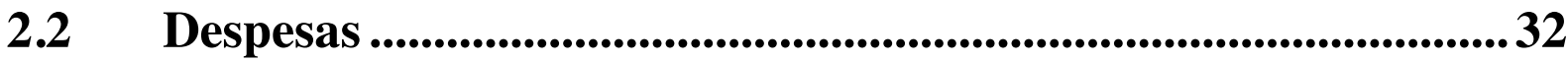

2.2.1 Classificação das despesas ..........................................................................334

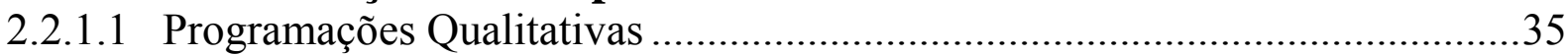

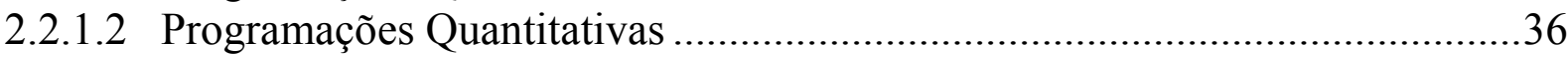

2.2.2 Etapas da Despesa Orçamentária ...............................................................37

3 Transparência pública de dados ............................................ 38

3.1 Dados Abertos Governamentais..............................................40

3.1.1 Dados Abertos Governamentais no mundo .........................................41

3.1.2 Dados Abertos Governamentais no Brasil ............................................ 42

4 Conceitos técnicos de um processo integrador .................... 44

4.1 Arquitetura de dados ...............................................................45

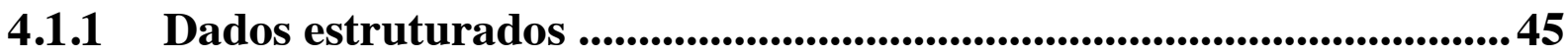

4.1.2 Dados semiestruturados................................................................45

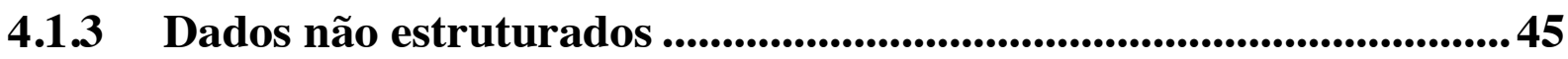

4.2 Procedência de dados .............................................................................. 46

4.3 Integração de dados e esquemas ...................................................46

4.3.1 Heterogeneidade entre SGBD's .......................................................4 47

4.3.2 Heterogeneidade estrutural ..................................................................47

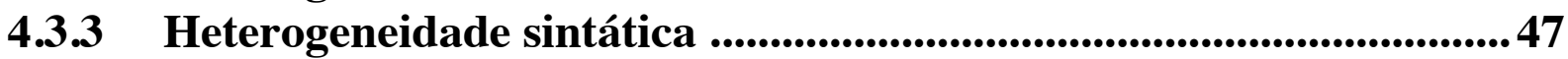

4.3.4 Heterogeneidade semântica .............................................................48

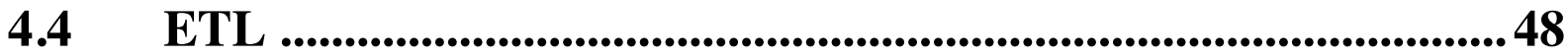

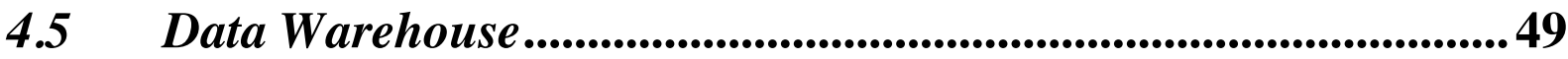

4.6 Sistemas de Apoio a Decisão (SAD) ...............................................50

5 Desenvolvimento do trabalho ................................................. 52

5.1 Padronização e Integração...............................................................552

5.1.1 Esquemas conceituais e esquemas lógicos - Receitas ............................55

5.1.2 Esquemas conceituais e esquemas lógicos - Despesas .........................63

5.2 Processo ETL ....................................................................81 
5.2.1 Extração ....................................................................................................................8 81

5.2.2 Transformação .............................................................................82

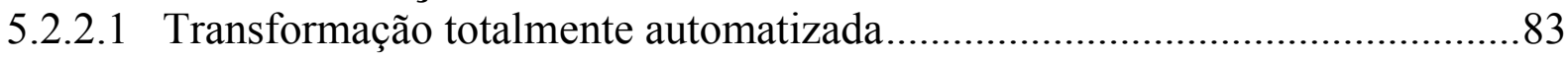

5.2.2.1.1 Transformações comuns a todos os entes federativos ............................................... 83

5.2.2.1.2 Transformações específicas para o governo federal - receitas ................................... 83

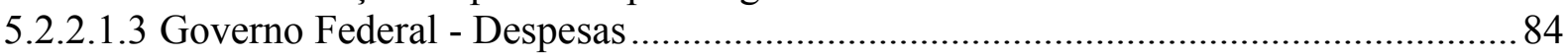

5.2.2.1.4 Governo do Estado de São Paulo - receitas e despesas ............................................... 84

5.2.2.1.5 Municípios do Estado de São Paulo - receitas ............................................................ 84

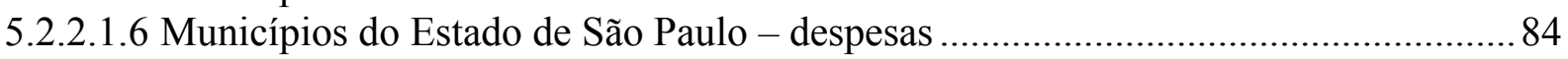

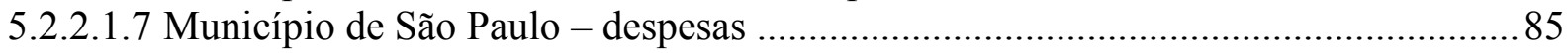

5.2.2.2 Transformação parcialmente automatizada ........................................................85

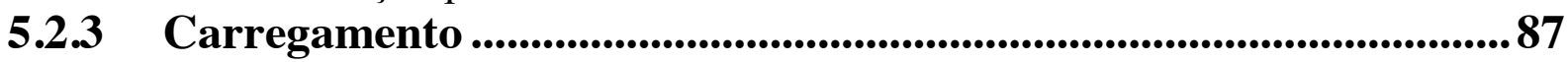

5.3 Visualização de dados......................................................................88

5.4 Validação do sistema .....................................................................91

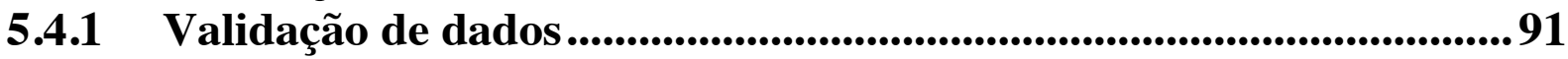

5.4.1.1 Validação de dados - Governo Federal.........................................................92

5.4.1.2 Validação de dados - Governo do estado de São Paulo..................................100

5.4.1.3 Validação de dados - Municípios do estado de São Paulo (Exceto a Capital)

5.4.1.4 Validação de dados - Município de São Paulo ....

5.4.2 Validação com fontes externas ...................................................................107

5.4.2.1 Validação de dados - Governo do Federal ...................................................107

5.4.2.2 Validação de dados - Governo do estado de São Paulo.................................110

5.4.2.3 Validação de dados - Municípios do estado de São Paulo (exceto a capital)

5.4.2.4 Validação de dados - Município de São Paulo (Capital) ..............................113

5.4.3 Validação com especialista de dados .................................................115

6 Discussão dos Resultados ....................................................... 117

6.1 Esquemas conceituais e modelos lógicos ..................................117

$6.2 \quad$ ETL .................................................................................................... 118

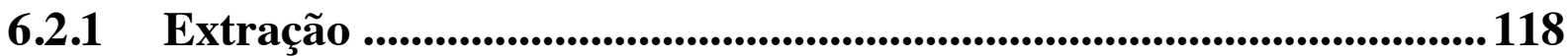

6.2.2 Transformação ............................................................................119

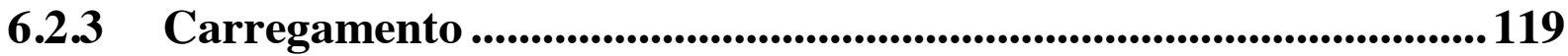

6.2.4 Visualização ......................................................................................120

6.2.5 Validação .................................................................................................................... 120

7 Conclusão e trabalhos futuros ............................................... 122

Referências ................................................................................124 


\section{Introdução}

O acesso à informação pública é essencial para a transparência das ações de governo e a transparência orçamentária é fator chave em maior accountability (OECD, 2002). Este acesso é regido por leis de acordo com cada país. No Brasil as leis têm tornado favorável este contexto.

Na Constituição Federal de 1988 (Brasil, 1988, Art. 5), diz que "Todos têm direito a receber dos órgãos públicos informações de seu interesse particular, ou de interesse coletivo ou geral, que serão prestadas no prazo da lei, sob pena de responsabilidade, ressalvadas aquelas cujo sigilo seja imprescindível à segurança da sociedade e do Estado”. Esta lei é o marco inicial da situação de transparência pública em que encontramos no Brasil.

A legislação evoluiu nos últimos anos, tornando-se obrigatoriedade a publicação de dados orçamentários na internet. No dia 5 de maio de 2000 entrou em vigor a lei complementar $\mathrm{n}^{\mathrm{o}} 101$ - a LRF (Lei de Responsabilidade Fiscal) - que estabelece normas de gestão fiscal e obriga a União, os Estados, o Distrito Federal e os municípios, assim como autarquias, fundações e empresas estatais dependentes, a planejar o orçamento de modo equilibrado e transparente e apresenta-lo detalhadamente ao Tribunal de Contas.

Em 2009, a Lei Complementar $n^{\circ} 131$ - Lei Capiberibe - modificou a redação da LRF acrescentando a obrigação da "liberação ao pleno conhecimento e acompanhamento da sociedade, em tempo real, de informações pormenorizadas sobre a execução orçamentária e financeira, em meios eletrônicos de acesso público" (BRASIL, 2009, Art. $1^{\text {o }}$ ).

Em 2010, O Decreto no 7.185 (BRASIL, 2010, Art. $2^{\circ}$ ) estabeleceu padrões mínimos de qualidade do que deve ser publicado das informações públicas. Dentre estes padrões, estão os critérios do que deve ser obrigatoriamente publicado com relação a classificação das receitas e despesas da execução orçamentária.

Em 2011 foi aprovada a Lei - Lei de Acesso à Informação - a qual reforça a obrigação de publicação de informações de interesse coletivo na rede mundial de computadores - a Internet - incluindo o registro de despesas, transferências financeiras e processos licitatórios (BRASIL, 2011, art. 8), de forma "íntegra, primária, autêntica e atualizada" (BRASIL, 2011, art. $\left.7^{\circ}\right)$.

Este processo de mudança nas leis, os quais vieram sob demandas sociais desde o passado, despertam ainda mais em diversos atores o interesse em saber o que os governos fazem e a que preço fazem (Loureiro et al, 2008). Este interesse tem impulsionado a comunidade desenvolvedora de software, que já produz diversas aplicações computacionais utilizando informações que já estão disponibilizadas na internet seguindo estas leis. Dentre as aplicações 
produzidas atualmente, algumas delas possuem enfoque em facilitar análises dos dados gerando indicativos de como, quando e onde o dinheiro público está sendo utilizado. São exemplos destas aplicações: "Orçamento ao seu alcance" 1 e "Cuidando do meu Bairro"2.

Porém, ainda que a obrigatoriedade destes dados se cumpra pelos portais de transparência espalhados pela WEB, a forma de se obter as informações é complexa, pois estas não seguem os princípios básicos de dados abertos ${ }^{3}$ definidos por um grupo de ativistas que estipula oito princípios mínimos que facilitam o consumo dos dados pelas aplicações computacionais ${ }^{4}$.

Baseado nestas diretrizes, em 2013 (último ano de adequação à Lei Capiberibe) o estudo de Craveiro et al (2013) que coletou e analisou 54 portais de transparência de execução orçamentária nos três níveis governamentais e 34 portais de tribunais de contas, baseando-se nos oito princípios de dados abertos governamentais (DAG, 2007) e nas leis Capiberibe e LAI, detectou que grande parte dos portais não se enquadravam nos padrões de DAG e também não atendiam às necessidades exigidas pela lei. A figura 1 demonstra os percentuais encontrados para cada um dos princípios de dados abertos governamentais nas amostras estudadas:

Figura 1 - Adoção dos princípios de DAG na amostra de dados no Brasil

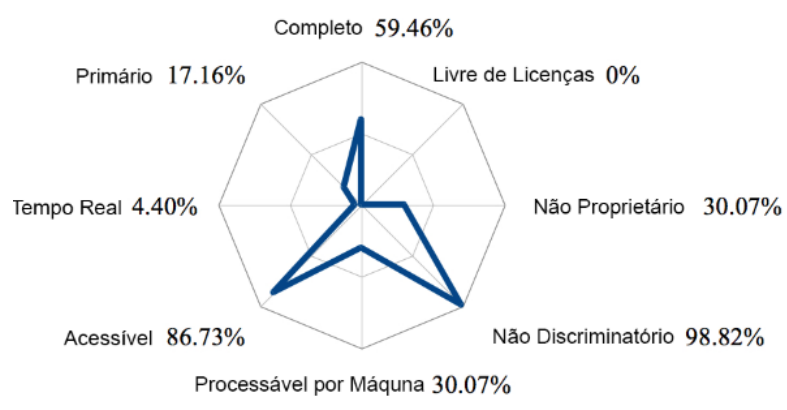

Fonte: Adaptado de Craveiro et al, 2013

Outro problema encontrado é com relação a padronização de nomenclatura de campos e domínio de valores. No Brasil existe uma compilação do arcabouço legal e normativo da contabilidade pública em um Manual de Contabilidade Aplicada ao Setor Público (MCASP,

\footnotetext{
${ }^{1} \mathrm{http}: / /$ orcamento.inesc.org.br

2 http://cuidando.org.br/

${ }^{3} \mathrm{http}$ ://opendefinition.org/

${ }^{4} \mathrm{http}$ ://opengovdata.org/
} 
2014) atualizado anualmente desde 2001, que define (dentre outras informações) como receitas e despesas devem ser classificadas. Apesar de existirem regras, algumas das classificações possuem domínio de valor específico para cada ente federativo. Além disso, cada ente federativo possui autonomia para criar novos elementos em uma mesma classificação ou alterar existentes. Desta forma, o modo em que os dados são publicados dependerá de como funciona o modelo de cada ente federativo.

Outro grande problema está na falta de padronização dos dados: desde a publicação até o formato em que estes são publicados. Esta diferença pode ocorrer na estrutura apresentada (campos disponíveis de detalhamento, por exemplo), formato de arquivo (aberto para leitura por máquinas - CSV e TXT -, ou fechado - PDF e XLS), localização da informação no portal (sempre disponíveis no mesmo padrão de diretórios), nível de agregação do dado (valor gasto no mês, ou disponibilizado detalhadamente por dia, por exemplo), dentre outros. Assim, um cidadão que deseja realizar uma comparação entre dados de diferentes fontes federativas precisa entender todo o processo que foi utilizado para a publicação do dado em todas as fontes que este deseja comparar, e criar mecanismos de extração, transformação e carregamento de dados para cada fonte.

Para ilustrar o que foi citado, veja o seguinte exemplo da figura 2: um cidadão deseja comparar o quanto é gasto em educação pelos três níveis de governo (federal, estadual e municipal) em duas cidades de diferentes estados.

Figura 2 - Heterogeneidade local dos dados abertos no País

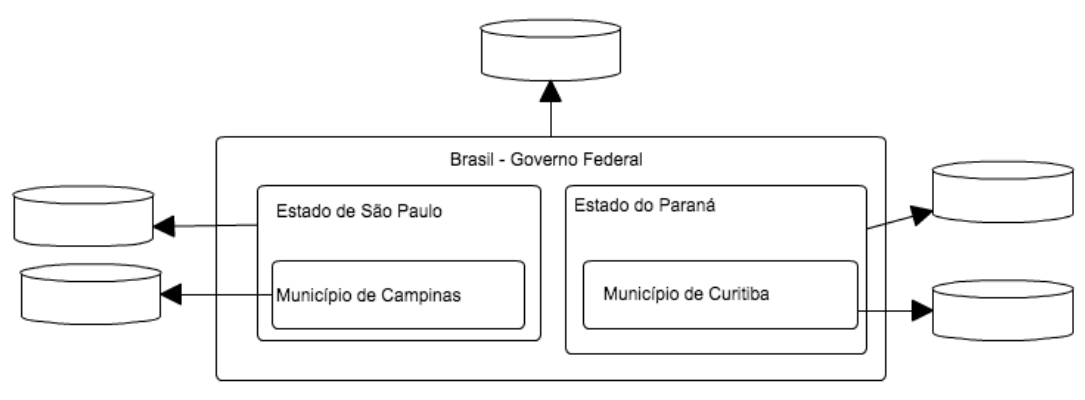

Fonte: José Rodolfo Beluzo, 2015.

Na forma em que a publicação dos dados atualmente é realizada, este deverá extrair um dataset em formato CSV (compactado em formato ZIP) do portal de transparência do governo federal ao qual irá conseguir o total gasto em educação para as duas cidades filtrando a informação pelo campo "UF" e "município" e em seguida pelo campo "função" - elemento de 
classificação de despesa que estabelece a função básica do gasto de uma determinada despesa. Em seguida, irá realizar o mesmo procedimento para as despesas dos governos do Estado de São Paulo e Paraná (2 datasets diferentes) filtrando pela informação "município" e "função". Para o governo do estado de São Paulo o formato do dataset também está em CSV (compactado em formato ZIP); para o governo do Paraná o formato do dataset está em XLS. Na sequência irá realizar a consulta pelo campo "função" para as despesas dos munícipios de Campinas e Curitiba (2 datasets diferentes). No portal da transparência de Curitiba o formato do dataset está em XLS; para o município de Campinas o dataset está no formato CSV.

Desta forma, para este exemplo é necessário que o cidadão acesse 5 portais de transparência, com caminhos de acessos aos dados e formatos das fontes diferentes. Como não existe um padrão para a nomenclatura, os nomes de campos de dados também não são exatamente iguais. Há também uma diferença no domínio de valores dos dados com escritas de formas diferentes como por exemplo datasets que utilizam acentuação e outros que não utilizam, ou que utilizam caixa alta nos dados e outros não.

O caso anterior é um exemplo de informações públicas referentes ao orçamento público brasileiro que podem ser obtidas com dados na web; porém possui um grau de complexidade elevado para se chegar a um resultado de compilação dos dados para se obter a informação comparativa, pois cada base de dados possui a sua peculiaridade referente às diferenças que podemos encontrar, como citado anteriormente.

Para situações como estas uma arquitetura computacional de integração de dados pode melhorar a interação do usuário com relação ao nível de dificuldade encontrado para a obtenção dos dados. Um modelo de integração de dados, como por exemplo, o modelo Data Warehouse - modelo temporal de depósito de dados correlacionados, com a finalidade de geração de relatórios para tomadas de decisões nas organizações (Kimball, 1999) - pode atingir este objetivo. É baseado nesta premissa que este trabalho foi realizado.

\subsection{Objetivo geral}

Este trabalho tem como objetivo principal criar um repositório de informações de fontes de dados heterogêneas referentes à execução orçamentária nas três esferas governamentais no Brasil - federal, estadual e municipal em um repositório de dados integrado no modelo Data Warehouse. Para fins de prova de conceito, o escopo do trabalho foi restringido no nível estadual ao Estado de São Paulo e no nível municipal todos os 645 municípios do Estado de 
São Paulo. Também foi definido um período de cinco anos de dados para os datasets selecionados (de 2010 a 2014).

\subsubsection{Objetivos específicos}

Os objetivos específicos deste trabalho são:

- Criar um modelo relacional conceitual dos dados da execução orçamentária baseado em documentos formais que definem as classificações orçamentárias para receitas e despesas a fim de facilitar o entendimento de forma sistêmica dos dados da execução orçamentária;

- definir um esquema único de dados da execução orçamentária a partir da intersecção dos dados existentes nos portais de transparência no escopo selecionado, em um modelo de dados multidimensional a fim de facilitar o processo de geração de informações gerenciais a partir dos dados;

- identificar as falhas de publicação nos dados no escopo selecionado e corrigi-las, quando possível;

- definir um processo de extração, transformação e carregamento destes dados no modelo a partir das bases de dados selecionadas a fim de disponibilizar os dados de forma padronizada em um único local.

\subsection{Organização do texto}

A organização do texto deste trabalho será dividida e estruturada seguindo o seguinte formato: no Capítulo 2 será apresentado os conceitos referentes ao orçamento público brasileiro, possibilitando o entendimento dos elementos de receitas arrecadas e despesas realizadas, assim como suas classificações. No Capítulo 3 iremos tratar sobre transparência orçamentária, elencando o estado da arte referente à transparência orçamentária no mundo e principalmente no Brasil e em quais aspectos a ferramenta integradora pode ser útil neste contexto; no Capítulo 4 iremos apresentar os conceitos técnicos que irão fazer parte do processo de integração proposto nos objetivos deste trabalho; no Capítulo 5 será descrito a metodologia utilizada para se desenvolver este trabalho, assim como as dificuldades encontradas; no Capítulo 6 é apresentado os resultados obtidos em cada etapa do projeto, assim como o resultado final; no Capítulo 7 encontra-se a conclusão do trabalho com as respectivas considerações que 
devem ser levadas em conta referente ao problema estudado, assim como as possibilidades de estudos para trabalhos futuros baseados nos resultados obtidos por este trabalho. 


\section{Orçamento Público Brasileiro}

O orçamento público, de acordo com o Ministério do Planejamento, Orçamento e Gestão (MPOG) "é um instrumento de planejamento governamental em que constam as despesas da administração pública para um ano, em equilíbrio com a arrecadação das receitas previstas. É o documento onde o governo reúne todas as receitas arrecadadas e programa o que de fato vai ser feito com esses recursos. É onde aloca os recursos destinados a hospitais, manutenção das estradas, construção de escolas, pagamento de professores. É no orçamento onde estão previstos todos os recursos arrecadados e onde esses recursos serão destinados" (MPOG, 2015). Através das previsões de receitas, pode-se organizar o que será possível realizar de benfeitorias nas diversas cidades do país (Giacomoni, 2012), assim como demonstrar uma transparência orçamentária para a população, de acordo com o que rege a lei na Constituição Brasileira de 1988 - Artigo 5º citado na introdução deste trabalho.

O elemento principal do orçamento são as contas a pagar e a receber. Através destas podemos antecipar situações patrimoniais, registrar movimentação patrimonial e demonstrar resultados patrimoniais. Desta forma o Governo, por meio de suas esferas federal, estadual e municipal tem a obrigatoriedade de exercer as atividades financeiras necessárias com o intuito de garantir o bem comum da sociedade. Estas atividades consistem em: arrecadação de recursos (receita pública), a aplicação destes recursos mediante a elaboração de programas para a prestação de serviços públicos (despesa pública); a gestão e planejamento de como estes recursos serão gastos (orçamento público) e criação de crédito para a população (empréstimo público) (Paludo, 2013). A figura 3 representa estas ações fundamentais para a atividade financeira do Estado nacional:

Figura 3 - Atividade Financeira do Estado Nacional

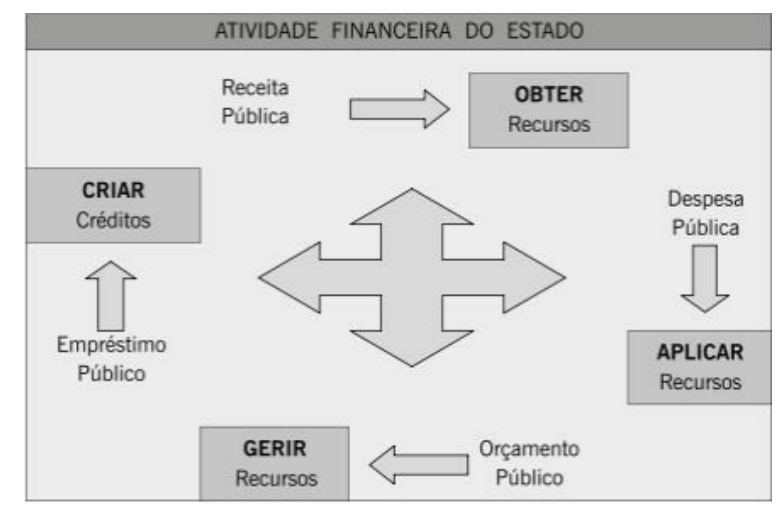

Fonte: Paludo, 2013. 
As contas podem ter diversas classificações. Cada classificação irá facilitar as análises das definições acima citadas em várias áreas. Estas áreas podem ser: políticas, administrativas, econômicas, jurídicas, financeiras, contábeis, etc.

Como cada área específica possui um objetivo, consequentemente haverá vários critérios para realizar cada classificação das contas. Por exemplo: Data de aquisição; item de despesa; programa utilizador da despesa; feito econômico; etc.

A classificação das contas tem como objetivo a realização de uma organização das contas. Segundo Jesse Burkhead (Burkhead, 1971), esta organização tem a finalidade de: facilitar a formulação de programas; contribuir para a efetiva execução do orçamento, apresentação, de modo a servir ao objetivo da prestação de contas; organizar de forma que seja possível analisar os efeitos econômicos das atividades governamentais.

Ainda com relação à classificação, Martner (apud. Giacomoni, 2012) diz que tem a finalidade de: serem estruturadas de maneira a facilitar as análises de efeitos econômicos e sociais das atividades do governo; facilitar a formação dos programas elaborados pelo governo para cumprir suas funções; contribuir para a efetiva execução do orçamento; facilitar a contabilidade fiscal.

As regras de classificação do orçamento servirão como base para se produzir as leis que regerão a utilização do orçamento público. Existem três leis que servem como guia para o planejamento e execução do orçamento: O Planejamento Plurianual (PPA), a Lei de Diretriz Orçamentária (LDO) e a Lei Orçamentária anual (LOA).

O PPA é um planejamento estratégico de longo prazo, ao qual estabelece objetivos que devem ser atingidos no período de 4 anos, iniciando-se no segundo ano do mandato do chefe do poder executivo e vai até o primeiro ano do mandato seguinte, estabelecendo "de forma regionalizada as diretrizes, objetivos e metas da administração pública Federal para as despesas de capital e outras delas decorrentes, e para os programas de duração continuada" (Giacomoni, 2012).

A LDO, Baseado no PPA, serve para definir as prioridades e metas que devem ser atingidas ano a ano, de acordo com o que foi definido no PPA, de forma a orientar a produção da LOA (Lei Orçamentária Anual), além de alterações na legislação tributária, a fim de suprir as necessidades de aumento de receita para conseguir cumprir os novos orçamentos. A LDO divide as metas do PPA em quatro anos, de tal forma que o somatório das metas da LDO nos quatro anos deve estar de acordo com as metas estabelecidas no PPA (Giacomoni, 2012). 
A LOA define a programação das ações a serem executadas, visando atingir as diretrizes, objetivos e metas estabelecidas nas etapas do PPA em consonância com a LDO e a LRF - Lei de Responsabilidade Fiscal. É nesta fase em que se é desenvolvido o orçamento propriamente dito. São definidos valores fixados de investimento para os planos definidos no PPA, baseados nas metas definidas na LDO (Giacomoni, 2012).

Com base nas definições do PPA e da LDO, o Orçamento Público é elaborado pelo Poder Executivo e aprovado pelo poder Legislativo, dando origem à LOA, que estima as receitas fixas e as despesas de toda a administração pública para o ano subsequente.

Estes três elementos estão presentes e definem as fases do ciclo orçamentário ilustrado na Figura 4 ilustrado por Paludo (PALUDO, 2013), que corresponde ao período em que as atividades do orçamento são realizadas, desde a sua concepção - fase de elaboração e aprovação - até a execução e apreciação final do orçamento público - fase de controle e avaliação.

Figura 4 - Ciclo orçamentário brasileiro

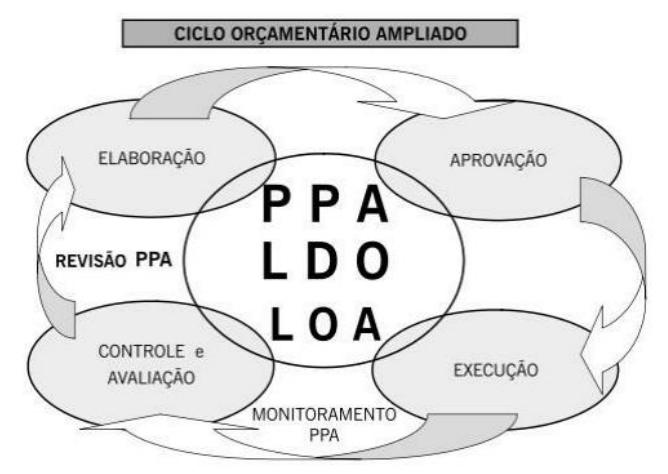

Fonte: Paludo, 2013.

As previsões das receitas e a fixação das despesas são fundamentais para a fase de elaboração e aprovação citada na figura acima, pois nestas fases os responsáveis pela elaboração do planejamento precisam de dados que irão os guiar como base para o desenvolvimento do plano de execução orçamentária.

A fase de execução consiste em colocar o plano em prática. Esta é a fase da "execução orçamentária", quando os planos de arrecadação se iniciam e as ações governamentais começam a realizar seus gastos, de acordo com o que foi planejado anteriormente. É nesta fase que este trabalho possui enfoque. 
A fase de avaliação consiste em analisar os dados da execução orçamentária do ciclo orçamentário encerrado e proporcionar novas informações para a fase de elaboração, criando aqui o elo do ciclo orçamentário.

As Seções 2.1 e 2.2 irão contextualizar os elementos de receitas e despesas respectivamente, que compõem a execução orçamentária.

\subsection{Receitas}

"Disponibilidades de recursos financeiros que ingressam durante o exercício e constituem elemento novo para o patrimônio público. Instrumento por meio do qual se viabiliza a execução das políticas públicas, a receita orçamentária é fonte de recursos utilizada pelo Estado em programas e ações cuja finalidade precípua é atender às necessidades públicas e demandas da sociedade", (MCASP, 2014). A seção 2.1.1 irá definir as três formas de classificação da receita orçamentária e na seção 2.1.2, as quatro etapas que a compõe.

\subsubsection{Classificação das receitas}

As receitas orçamentárias podem ser classificadas por: Natureza; Indicador de Resultado Primário e Fonte de Recursos.

A receita por natureza representa o menor nível de detalhamento das informações orçamentárias (MCASP, 2014) e é identificada pelo seu fato gerador. É composta por um identificador numérico de oito dígitos que categorizam seis níveis de detalhamento da receita: $\mathrm{o} 1^{\circ}$ dígito define a categoria econômica; o $2^{\circ}$ digito define a origem; o $3^{\circ}$ digito define a espécie; o $4^{\circ}$ digito define a rubrica; o $5^{\circ}$ e $6^{\circ}$ digito definem a alínea e o $7^{\circ}$ e $8^{\circ}$ digito definem a sub alínea. A figura 5 demostra um exemplo de como é realizada este tipo de classificação:

Figura 5 - Exemplo de classificação da receita por "Natureza"

\begin{tabular}{|c|l|c|l|}
\hline C & Categoria Econômica & $\mathbf{1}$ & Receita Corrente \\
\hline O & Origem & $\mathbf{1}$ & Receita Tributária \\
\hline E & Espécie & $\mathbf{1}$ & Impostos \\
\hline R & Rubrica & $\mathbf{2}$ & Impostos sobre o Patrimônio e a Renda \\
\hline AA & Alínea & $\mathbf{0 4}$ & Impostos sobre a Renda e Proventos de Qualquer Natureza \\
\hline SS & Subalínea & $\mathbf{1 0}$ & Pessoas Físicas \\
\hline
\end{tabular}


“A Classificação por Natureza é a de nível mais analítico da receita; por isso, auxilia na elaboração de análises econômico-financeiras sobre a atuação estatal”, (MCASP, 2014). O detalhamento e domínio de valores de cada um dos seis níveis que servirá de auxílio na construção do esquema do modelo integrado proposto no trabalho encontram-se no MCASP, 2014.

A classificação por Identificador de Recurso Primário tem o objetivo de definir quais são as receitas que compõem o resultado primário do governo - somatório das Receitas Correntes com as de Capital e, depois, exclui-se da conta as receitas: de operações de crédito e seus retornos (juros e amortizações), de aplicações financeiras, de empréstimos concedidos e do superávit financeiro (MCASP, 2014). É Classificada como "P" quando esta é "Primária" faz parte do cálculo citado acima; e "F" quando esta é "Financeira" - quando não faz parte do cálculo.

A classificação Por Fonte de Recursos é a classificação de conexão entre receitas e despesas. Esta demonstra as fontes financiadoras dos gastos públicos. Na receita, esta denomina a destinação do recurso; na despesa, denomina a origem do recurso utilizado. É composta por um grupo numérico de três dígitos: o $1^{\circ}$ digito denomina o grupo de Fonte de Recursos e o $2^{\circ} \mathrm{e}$ $3^{\circ}$ digito denominam a especificação das Fontes de Recursos. O Manual técnico do Orçamento Público (MTO, 2014), utilizado na esfera federal exemplifica a utilização desta classificação. A figura 6 mostra um exemplo de como ela é realizada:

Figura 6 - Exemplo de classificação por "fonte de recursos"

\begin{tabular}{l|l|c}
\hline \multicolumn{1}{c|}{$1^{\circ}$ DÍGITO (Grupo da Fonte) } & \multicolumn{1}{|c}{$2^{\underline{0} \text { e } 3^{\circ} \text { DÍGITOS (Especificação da Fonte) }}$} & FONTE \\
\hline $\begin{array}{l}1-\text { Recursos do Tesouro - Exercício } \\
\text { Corrente }\end{array}$ & $\begin{array}{l}12 \text { - Recursos Destinados à Manutenção e } \\
\text { Desenvolvimento do Ensino }\end{array}$ & 112 \\
\hline $\begin{array}{l}\text { 2- Recursos de Outras Fontes - Exercício } \\
\text { Corrente }\end{array}$ & $\begin{array}{l}93 \text { - Produto da Aplicação dos Recursos à Conta do } \\
\text { Salário-Educação }\end{array}$ & 293 \\
\hline
\end{tabular}

Fonte: MTO, 2014.

De acordo com o Decreto 7.185 de 2010 (Brasil, 2010), no ato de publicação da receita orçamentária, é discriminado que deve ser publicado, no mínimo, a classificação das unidades gestoras responsáveis pela receita e a classificação por "Natureza da receita", que compreende a categoria econômica, origem, espécie, rubrica, alínea e subalínea da receita arrecada pelo órgão governamental. Os códigos e domínios de valores da classificação por natureza da receita 
possuem um padrão definido para todos os níveis de governo no MCASP (MCASP 2014), documento utilizado como base neste trabalho. Esta classificação deve ser realizada para todas as etapas da receita - previsão, lançamento e arrecadação - que serão descritas na próxima seção.

\subsubsection{Etapas da Receita Orçamentária}

A receita orçamentária é composta de quatro fases: previsão, lançamento, arrecadação e recolhimento (MCASP, 2014) - figura 7.

Figura 7 - Etapas da Receita Orçamentária

\begin{tabular}{|l|l|}
\hline \multicolumn{2}{|c|}{ Etapas da Receita Orçamentária } \\
\hline Planejamento & Previsão \\
\hline \multirow{4}{*}{ Execução } & Lançamento \\
\cline { 2 - 2 } & Arrecadação \\
\cline { 2 - 2 } & Recolhimento \\
\hline
\end{tabular}

Fonte: MCASP, 2014.

A fase de previsão consiste no planejamento e levantamento inicial da arrecadação das receitas que estarão na proposta orçamentária; a fase de lançamento verifica a procedência do crédito fiscal e o elemento (pessoa física ou jurídica) que é devedora e registra este futuro débito; a fase de arrecadação consiste na entrega do recurso por parte dos elementos (pessoa física ou jurídica) para os agentes arrecadadores ou instituições financeiras autorizadas pelo ente arrecadador; por fim, a fase de recolhimento consiste na transferência dos valores arrecadados à conta específica do Tesouro Nacional. Este trabalho possui como enfoque a última fase - valor recolhido.

\subsection{Despesas}

Os gastos públicos realizados em todo país são de interesse geral: população, órgãos públicos e privados e poder público. A estrutura de classificação dos gastos públicos - despesas - tem o propósito de atender a demanda de informação a todos os interessados. Na estrutura atual, as programações orçamentárias estão organizadas em programas de trabalho, que contêm informações qualitativas e quantitativas, sejam físicas ou financeiras (MTO, 2014). 
A Programação Qualitativa responde às perguntas clássicas que caracterizam o ato de orçar, sendo, do ponto de vista operacional, composto dos seguintes blocos de informação: classificação por esfera, classificação institucional, classificação funcional, estrutura programática e principais informações do Programa e da Ação (MTO, 2014), ilustrado na figura $8:$

Figura 8 - Classificação Qualitativa - Despesas

\begin{tabular}{|c|c|c|}
\hline $\begin{array}{l}\text { BLOCOS DA } \\
\text { ESTRUTURA }\end{array}$ & ITEM DA ESTRUTURA & PERGUNTA A SER RESPONDIDA \\
\hline Classificação por Esfera & Esfera Orçamentária & Em qual Orçamento? \\
\hline $\begin{array}{l}\text { Classificação } \\
\text { Institucional }\end{array}$ & $\begin{array}{c}\text { Órgão } \\
\text { Unidade Orçamentária }\end{array}$ & Quem é o responsável por fazer? \\
\hline Classificação Funcional & $\begin{array}{c}\text { Função } \\
\text { Subfunção }\end{array}$ & $\begin{array}{l}\text { Em que áreas de despesa a ação } \\
\text { governamental será realizada? }\end{array}$ \\
\hline Estrutura Programática & Programa & Qual o tema da Política Pública? \\
\hline \multirow{2}{*}{$\begin{array}{l}\text { Informações Principais } \\
\text { do Programa }\end{array}$} & Objetivo & $\begin{array}{l}\text { O que se pretende alcançar com a } \\
\text { implementação da Política Pública? }\end{array}$ \\
\hline & Iniciativa & O que será entregue pela Política Pública? \\
\hline \multirow{6}{*}{$\begin{array}{l}\text { Informações Principais } \\
\text { da Ação }\end{array}$} & Ação & $\begin{array}{l}\text { O que será desenvolvido para alcançar o } \\
\text { objetivo do programa? }\end{array}$ \\
\hline & Descrição & O que é feito? Para que é feito? \\
\hline & Forma de Implementação & Como é feito? \\
\hline & Produto & O que será produzido ou prestado? \\
\hline & Unidade de Medida & Como é mensurado? \\
\hline & Subtítulo & $\begin{array}{c}\text { Onde é feito? } \\
\text { Onde está o beneficiário do gasto? }\end{array}$ \\
\hline
\end{tabular}

Fonte: MTO, 2014.

A Programação Quantitativa das despesas possui uma dimensão física e uma financeira. A dimensão física define a quantidade de bens e serviços a serem entregues (MTO, 2014). A dimensão financeira estima o montante necessário para o desenvolvimento da ação orçamentária de acordo com os seguintes classificadores: Natureza da Despesa, Identificador de Uso (IDUSO), Fonte de Recursos, Identificador de Doação e de Operação de Crédito (IDOC), Identificação de Resultado Primário e Dotação. A figura 9 exemplifica as perguntas a serem respondidas com cada tipo de classificação para a dimensão financeira: 
Figura 9 - Classificação Quantitativa - Despesas

\begin{tabular}{c|c}
\hline ITEM DA ESTRUTURA & PERGUNTA A SER RESPONDIDA \\
\hline Natureza da Despesa & \\
\hline Categoria Econômica da Despesa & Qual o efeito econômico da realização da despesa? \\
\hline Grupo de Natureza de Despesa (GND) & Em qual classe de gasto será realizada a despesa? \\
\hline Modalidade de Aplicação & De que forma serão aplicados os recursos? \\
\hline Elemento de Despesa & Quais os insumos que se pretende utilizar ou adquirir? \\
\hline Identificador de Uso (IDUSO) & Os recursos são destinados para contrapartida? \\
\hline Fonte de Recursos & De onde virão os recursos para realizar a despesa? \\
\hline Identificador de Doação e de Operação de & A que operação de crédito ou doação os recursos se \\
relacionam? (IDOC)
\end{tabular}

Fonte: MTO, 2014

A seção 2.2.1 irá definir as sete formas de classificação da despesa orçamentária e na seção 2.2.2, as quatro etapas que a compõe.

\subsubsection{Classificação das despesas}

As classificações das despesas orçamentárias citadas acima nos programas qualitativos e quantitativos são definidas neste tópico segundo o Manual Técnico do Orçamento (MCASP, 2014). Segue, na figura 10, um exemplo de codificação de um elemento de despesa na programação, encontrado no MCASP de 2014, para que facilite o entendimento de cada componente classificador: 
Figura 10 - Exemplo da estrutura completa da classificação da despesa

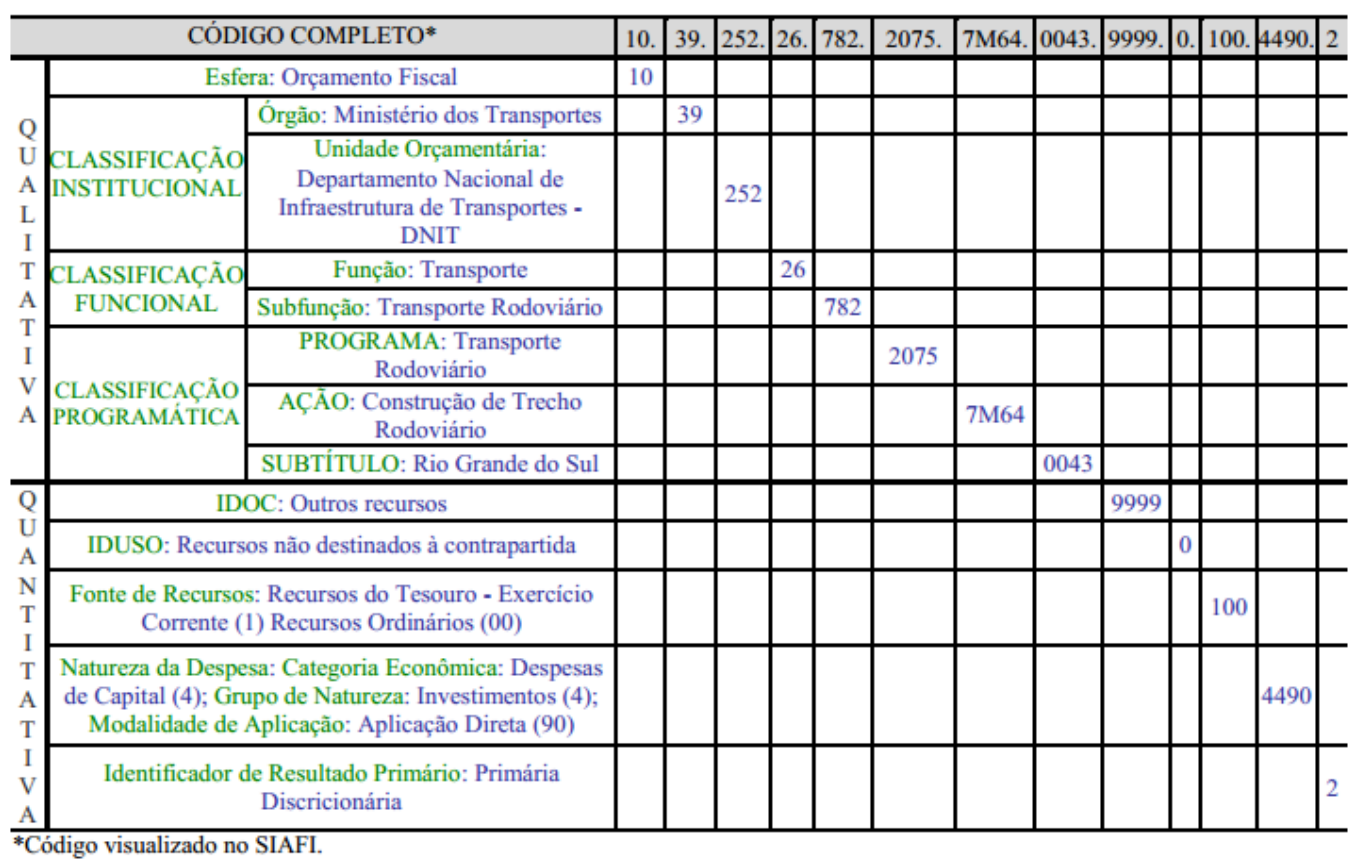

Fonte: MTO, 2014.

A seção 2.2.1.1 irá tratar sobre as classificações nos programas qualitativos e a seção 2.2.1.2 irá tratar sobre as classificações nos programas quantitativos.

\subsubsection{Programações Qualitativas}

A classificação por Esfera Orçamentária tem por finalidade identificar se a despesa pertence ao Orçamento Fiscal (F), da Seguridade Social (S) ou de Investimento das Empresas Estatais (I), conforme disposto no $\S 50$ do art. 165 da CF.

A classificação Institucional, definida por um código numérico de cinco dígitos, fornece informação sobre qual órgão e unidade orçamentária realiza a despesa. Os dois primeiros dígitos representam o órgão e os três restantes, a unidade orçamentária.

A classificação Funcional é dividida em função e subfunção, definida por um código numérico de cinco dígitos. Esta classificação define a área de ação que a despesa será realizada. Os dois primeiros dígitos representam a função e os três restantes, a subfunção.

A classificação programática está estruturada em programas orientados para atingir os objetivos definidos no PPA. Os programas podem ser temáticos ou de gestão, manutenção e serviços ao Estado. São identificados por um código numérico de quatro dígitos e contém uma ou mais ações. As ações são os elementos concretos (projetos, atividades ou operações 
especiais) que irão realizar os objetivos de um programa. Cada ação é identificada por um código alfanumérico de oito dígitos. $\mathrm{O} 1^{\circ}$ dígito identifica o tipo da ação; do $2^{\circ}$ ao $4^{\mathrm{o}}$ é detalhada a ação; os quatro últimos identificam o subtítulo da ação assim como a localização da mesma.

De acordo com o Decreto 7.185 de 2010 (Brasil, 2010), no ato de publicação da despesa orçamentária para a programação qualitativa, se enquadra como mínimo para publicação a classificação institucional, classificação funcional, classificação programática e, não descrito no MCASP, porém também qualifica, o procedimento licitatório realizado (assim como sua dispensa ou inexigibilidade, quando for o caso) do pagamento de todas as etapas da despesa, que será descrita na seção 2.2.2. Os códigos e domínio de valor da classificação funcional são padronizados pelo MCASP (MCASP, 2014). A classificação institucional e programática possui classificação livre, de acordo com o órgão.

\subsubsection{Programações Quantitativas}

O identificador de Doação e de Operação de Crédito (IDOC) é composto por um código numérico de quatro dígitos e tem como objetivo identificar as doações de entidades internacionais ou operações de crédito contratuais.

O Identificador de Uso (IDUSO) é composto por um código numérico de um dígito e indica se os recursos compõem contrapartida nacional de empréstimos ou de doações ou destinam-se a outras aplicações.

A classificação Por Fonte de Recursos, como citado na Seção 2.1.1 é a classificação de conexão entre receitas e despesas. Na despesa, esta denomina a origem do recurso utilizado. Seu código é definido da mesma forma que na receita - um grupo numérico de três dígitos: o $1^{\circ}$ digito denomina o grupo de Fonte de Recursos e o $2^{\circ}$ e $3^{\circ}$ digito denomina a especificação das Fontes de Recursos.

A classificação por Natureza da Despesa, semelhante à Natureza da Receita, também é definida por um código numérico de oito dígitos, porém, subdivididos em cinco níveis: categoria econômica ( $1^{\circ}$ dígito), grupo de natureza da despesa (GND) $\left(2^{\circ}\right.$ dígito), modalidade da aplicação ( $3^{\circ}$ e $4^{\circ}$ dígitos), elemento de despesa ( $5^{\circ}$ e $6^{\circ}$ dígitos $)$ e subelemento $\left(7^{\circ}\right.$ e $8^{\circ}$ dígitos).

O identificador de Resultado Primário é composto por um código numérico de um dígito e tem como finalidade auxiliar a apuração do resultado primário previsto na LDO.

De acordo com o Decreto 7.185 de 2010 (Brasil, 2010), no ato de publicação da despesa orçamentária para a programação quantitativa, se enquadra como mínimo para publicação a 
classificação por natureza da despesa, por fonte de recursos e, não descrito no MCASP, porém também quantifica, a pessoa física ou jurídica beneficiária do pagamento de todas as etapas da despesa, que será descrita na seção 2.2.2. A classificação por natureza da despesa possui codificação e domínio de valor definido pelo MCASP; as outras são de codificação e domínio de valores livre.

\subsubsection{Etapas da Despesa Orçamentária}

As etapas da despesa orçamentária compreendem as fases de previsão, licitação, empenho, liquidação e pagamento (MCASP, 2014). A previsão consiste no levantamento das necessidades dos gastos; a licitação compreende um conjunto de procedimentos administrativos que objetivam adquirir materiais, contratar obras e serviços, alienar ou ceder bens a terceiros, bem como fazer concessões de serviços públicos com as melhores condições para o Estado; o empenho consiste na aprovação do gasto e direcionamento do gasto ao elemento (Pessoa Física ou Jurídica); a liquidação consiste na aprovação do pagamento ao elemento (Pessoa Física ou Jurídica) e o pagamento consiste na transferência do valor da conta pública para o elemento recebedor. Esta última será o alvo deste trabalho no quesito “despesas". 


\section{Transparência pública de dados}

Existem diversos movimentos ao redor do mundo que influenciaram o estado atual da transparência pública de dados. Podemos citar como entre os principais a "Nova Administração Pública", a qual teve seu inicio fortemente iniciado pelo Reino Unido e influenciado outros movimentos. Este movimento visava a adaptação e a transferência dos conhecimentos gerenciais desenvolvidos no setor privado para o público, pressupondo a redução do tamanho da máquina administrativa, uma ênfase crescente na competição e o aumento de sua eficiência (Pieranti et al, 2007).

Sendo influenciado por este movimento, no Brasil o estado atual de transparência também se deve pela "Reforma da Administração Pública" de 1995, que visava um aparelho de Estado mais eficiente. Dentre suas dimensões de visão para estas mudanças, destaca-se "uma dimensão de gestão, definida pela maior autonomia e a introdução de três novas formas de responsabilização dos gestores - a administração por resultados, a competição administrada por excelência, e o controle social - em substituição parcial dos regulamentos rígidos, da supervisão e da auditoria, que caracterizam a administração burocrática" 5 .

A transparência pública tem como objetivo divulgar as ações governamentais para a população e propiciar mecanismos que possibilitem a participação cidadã tanto no exercício da democracia, fazendo com que este possa entender como o seu dinheiro está sendo investido, assim como na auditoria cidadã, podendo este fazer suas próprias análises e eventualmente realizar suas sugestões de projetos e apontar possíveis erros aos seus candidatos eleitos para representa-los.

Desde a Constituição de 1988, no Brasil a transparência pública em geral, incluindo-se a orçamentária, já era uma obrigatoriedade por lei, porém foi a partir do ano de 2000 que está começou a se consolidar e incorporar melhores leis que lhe dessem apoio e respaldo legal para que a obrigatoriedade se cumpra, além de facilidade para a população em obter os dados referentes ao orçamento público. Em seu projeto, Santana (2013) realiza um levantamento da cronologia de leis que desde o ano 2000 vieram se aperfeiçoando para chegar até o ponto atual da transparência pública no Brasil (figura 11):

\footnotetext{
${ }^{5}$ http://www.bresserpereira.org.br/rgp.asp
} 
Figura 11 - Cronologia das leis

\begin{tabular}{|c|c|}
\hline Legislação & Requisitos \\
\hline $\begin{array}{l}\text { Lei de Responsabilidade Fiscal(2000) e } \\
\text { Lei Capiberibe(2009) }\end{array}$ & $\begin{array}{l}\text { informações pormenorizadas publica- } \\
\text { das em tempo real em meios eletrônicos }\end{array}$ \\
\hline Decreto $7.185(2010)$ & $\begin{array}{l}\text { - tempo real equivale a um dia útil; } \\
\text { - publicação na Internet; } \\
\text { - verificação de integridade, confia- } \\
\text { bilidade e disponibilidade da in- } \\
\text { formação; } \\
\text { - atender a e-PING e a e-MAG; } \\
\text { - da despesas publicar empenho, li- } \\
\text { quidação, pagamento, número de } \\
\text { processo, classificação orçamen- } \\
\text { tária, beneficiário, procedimento } \\
\text { licitatório e bem ou serviço for- } \\
\text { necido; } \\
\text { - da receita publicar previsão, lan- } \\
\text { çamento e arrecadação }\end{array}$ \\
\hline $\begin{array}{l}\text { Lei de Acesso à Informação(2011) e De- } \\
\text { creto } 7.724(2012)\end{array}$ & $\begin{array}{l}\text { - ferramentas de pesquisa; } \\
\text { - gravar relatórios em diversos for- } \\
\text { matos não proprietários; } \\
\text { - possibilitar acesso automatizado; } \\
\text { - utilizar formatos abertos legíveis } \\
\text { por máquina; } \\
\text { - fornecer informação primária, ín- } \\
\text { tegra, autêntica, atualizada e gra- } \\
\text { tuita: }\end{array}$ \\
\hline
\end{tabular}

Fonte: Santana, 2013.

Assim, torna-se obrigatório, a partir da Lei de Acesso à Informação e do Decreto 7.724 de 2012, que regulamenta a LAI, o estabelecimento de que os Sites Governamentais contenham ferramentas de pesquisa de conteúdo; possibilitem a gravação de relatórios em diversos formatos eletrônicos não-proprietários; possibilitem o acesso automatizado por sistemas externos em formatos abertos, estruturados e legíveis por máquina; divulguem em detalhes os formatos utilizados para estruturação da informação e utilizem linguagem de fácil compreensão no fornecimento de informação primária, íntegra, autêntica, atualizada, de forma gratuita e independente de requerimentos no caso de repasses, transferências ou despesas (Santana, 2013). 
O Brasil é um dos cofundadores de uma organização internacional denominada OGP Open Government Partnership - ao qual "os países participantes endossam uma Declaração de Princípios e apresentam Planos de Ação Nacionais, comprometendo-se a adotar medidas concretas para o fortalecimento da transparência das informações e atos governamentais, combate à corrupção, fomento à participação cidadã, gestão dos recursos públicos, integridade nos setores público e privados, entre outros objetivos" ${ }^{6}$ (OGP, 2011).

Assim, o Brasil possui atualmente leis que visam atender às medidas de fortalecimento de transparência das informações e atos governamentais obrigando a publicação das informações em formato aberto na Internet, ao qual este formato segue como diretrizes as leis e princípios definidos por um grupo de ativistas que definiram a OGP. A seção 3.1 contextualiza qual o estado da arte do conceito DAG em alguns países (seção 3.1.1) e, mais especificamente, no Brasil (seção 3.1.2).

\subsection{Dados Abertos Governamentais}

O conceito de dados abertos segundo a Open Knowledge Foudation (OKF), organização sem fins lucrativos criada no Reino Unido e que atualmente possuí diversas cedes em outros países, dentre eles o Brasil, e que tem por missão a promoção do conhecimento livre em todo o mundo, diz que um dado é aberto quando qualquer pessoa possa utilizá-lo, reutiliza-lo e redistribui-lo estando sujeito no máximo a exigência de creditar a sua autoria e compartilha-lo sob a mesma licença. Assim, três requisitos que estão presentes nas definições dos oito princípios de DAG (2007) são importantes para esta definição: os dados devem estar publicados na Internet; devem ser disponibilizados em formato de arquivo aberto e processável por máquina (Eaves, 2009).

Ao redor do mundo diversos são os trabalhos que já utilizam os dados abertos em seus países para criar aplicações computacionais que auxiliem a população no dia a dia com aplicativos informativos, de utilidade pública, no combate à corrupção, dentre outros. Porém, muitas vezes os dados que estão abertos, seguindo os três requisitos citados no parágrafo anterior, precisam passar por transformações computacionais a fim de deixá-los utilizáveis para as aplicações. Transformações estas que poderiam em alguns casos serem desnecessárias se todos os princípios fossem seguidos.

\footnotetext{
${ }^{6}$ http://www.governoaberto.cgu.gov.br/a-ogp/como-funciona
} 
Assim, enquanto os dados abertos governamentais não seguem todas as diretrizes propostas pela Open Government Working Group (OGWG, 2007), para alguns tipos de aplicações ainda é necessário estabelecer uma arquitetura de sistemas prévia para dispor os dados no formato necessário para a aplicação. A seção 2.4.1.1 aponta algumas aplicações computacionais que utilizam dados abertos governamentais de orçamento público no mundo, assim como arquiteturas computacionais criadas para atender as necessidades de dados destas aplicações; a seção 2.4.1.2 aponta as mesmas aplicações, porém com enfoque no Brasil.

\subsubsection{Dados Abertos Governamentais no mundo}

Nos Estados Unidos, o projeto Midas (Sala, 2010) criou uma arquitetura de centralização de dados orçamentários provenientes de vários portais de transparência. O projeto tem como base dados de informações estruturadas sobre os membros do Congresso dos Estados Unidos, de distritos eleitorais, agências federais, fornecedores do governo e os seus próprios gastos. Por meio de uma ferramenta de buscas na web, é possível retornar e exportar dados das bases de dados de forma integrada referentes aos dados destes contextos governamentais.

Na Grécia, o projeto "DIAVGEIA" (Theocharis, 2013) é um caso de sucesso. Atualmente é utilizado pela administração pública no país e centraliza todas as leis e decisões emitidas por todos os órgãos em um único local. O seu objetivo é proporcionar através de uma arquitetura de sistemas provedora de dados o máximo possível de informação governamental e ações administrativas do governo. Através deste portal é possível encontrar informações de dados dos ministérios, regiões, municípios, ações administrativas de todo o país, dentre outras.

Outros países ainda não possuem uma arquitetura provedora de dados integrada implementada, porém já possuem estudos iniciados que demonstram a viabilidade de integração dos dados que já são publicados. Na indonésia um estudo (Aryan, et al, 2014) propõe criar um framework de republicação dos dados que já estavam publicados em outros portais de forma integrada. O framework utiliza o formato RDF - Resource Description Framework - a fim de criar as ligações dos mesmos pela LOD - Linked Open Data. LOD é um conjunto de práticas proposta por Tim Bernes-Lee (Bernes-Lee, 2006) que diz respeito a publicar dados na WEB de forma relacionada. Desta forma, as relações possibilitam que pessoas ou máquinas possam explorar a rede de dados e descobrir novos conhecimentos.

Um trabalho semelhante a LOD proposta na indonésia já é realidade em países como Estados Unidos (Hendler et al, 2012) e Inglaterra (Shadbolt et al, 2012). A LOGD - Linked Open Government Data - dos Estados Unidos possibilita extração de dados de forma integrada 
em diversas áreas (ver figura 12). A arquitetura a qual provê estes dados possui um framework padrão para que os dados nas diversas áreas sejam publicados e ligados na rede. Assim, um usuário ou máquina programada pode realizar consultas e gerar relatórios de dados combinados, como por exemplo correlações de dados governamentais com empresas, saúde ou segurança pública.

Figura 12 - Datasets disponíveis para consultas no data.gov

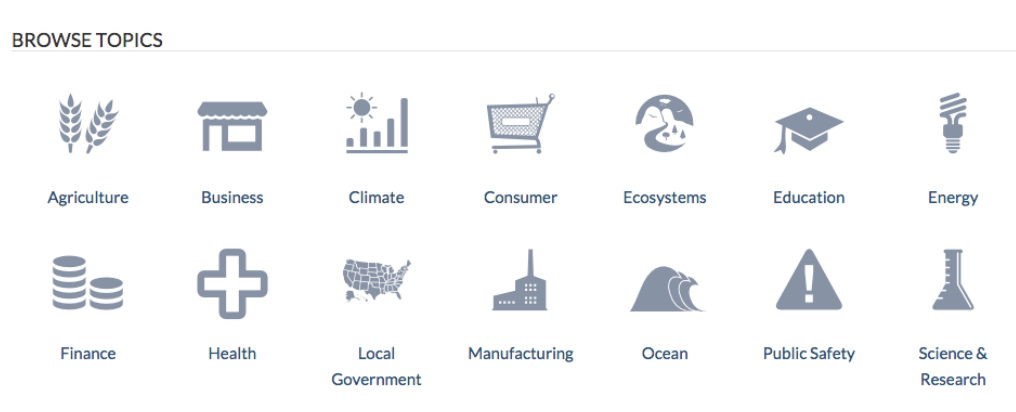

Fonte: http://data.gov, 2015.

\subsubsection{Dados Abertos Governamentais no Brasil}

No Brasil, as aplicações computacionais estão ganhando espaço. São exemplos destas os portais "Meu Município" 7, que possibilita levantar informações de receitas e despesas e realizar comparativos entre os municípios brasileiros utilizando como fonte de dados as informações de dados encontrados no portal da Secretaria do Tesouro Nacional (STN); outra aplicação que segue uma linha de raciocínio próxima, possibilitando a fiscalização cidadã é o portal "Cuidando do Meu Bairro" 8 , que possibilita a visualização em um mapa dos locais onde estão previstos, empenhados e gastos do dinheiro público marcando com respectivamente pontos com cores vermelhas, amarelas e verdes. Para este tipo de aplicação os dados são provenientes de uma mesma fonte, no mesmo padrão de publicação.

Outros trabalhos governamentais preveem a integração dos dados na esfera governamental Federal (Santos, 2011) - SIC (Sistema de Informação de Custos do Governo Federal). Este trabalho propõe a interação entre as ações de desenvolvimento da gestão de

\footnotetext{
${ }^{7} \mathrm{http}: / /$ www.meumunicipio.org.br/

${ }^{8}$ http://cuidando.org.br/
} 
custos na administração pública brasileira e aquelas vinculadas às políticas de promoção da excelência da gestão no setor público brasileiro; porém o foco do sistema é voltado a apenas gestores governamentais (Santos, 2011), excluindo a população. Assim esta ferramenta não se enquadra em OGD (OGWG, 2007).

Seguindo a mesma linha de raciocínio do sistema descrito por Santos, Brito (2014) propõe sistemas de informação integrados para melhor apresentar os dados de fontes de dados heterogêneas como o sistema "Meu congresso Nacional" que integra fontes de dados abertos a respeito de deputados federais e senadores; e o "Cidadão Recifense", que integra fontes de dados de transparência governamental, serviços públicos e participação da sociedade com dados de redes sociais. Este trabalho prevê uma integração de dados nas três esferas governamentais: Federal, Estadual e Municipal, além de possibilitar o acesso a informação amplo para tanto gestores, pesquisadores e cidadãos em geral.

Observando este cenário, outros trabalhos vieram com o intuito de organizar as informações governamentais de forma a possibilitar melhor acesso a estes dados aos cidadãos. “DIGO” (Machado et al, 2011) propõe uma arquitetura semelhante à proposta na seção anterior por Aryan (2014). A arquitetura propõe um sistema que extrai informações de várias bases de dados e republica-los em Linked data. O problema é que este processo exige um esquema de publicação inicial dos dados com uma padronização mínima de metadados para que seja possível a transformação deste dado no formato RDF. A realidade no Brasil ainda não é esta, pois diversos portais não publicam seus dados de acordo com os padrões (Craveiro et al, 2013) sugeridos pela OGD (OGWG, 2007) inviabilizando esta atividade nestes casos.

Complementar ao trabalho anterior, Santana (2013) propõe uma taxonomia de publicação de dados abertos governamentais da execução orçamentária. Esta taxonomia visa atender trabalhos como o "DIGO" de Machado, facilitando o processo de integração e ligação dos dados, porém esta é uma etapa que depende da disponibilidade dos governos se adequarem para publicar os dados. 


\section{Conceitos técnicos de um processo integrador}

A construção de um repositório de dados dependerá de vários elementos tecnológicos que irão compor um fluxo operacional até chegar a um resultado final - um sistema computacional capaz de prover dados para uma ferramenta de visualização de dados de forma analítica em um modelo Data Warehouse.

Para isso será necessário a criação de um esquema capaz de armazenar dados de várias bases de dados heterogêneas. A primeira etapa é entender estas heterogeneidades e como resolve-las.

A segunda etapa consiste em um procedimento que é composto de três novas etapas: extração dos dados, transformação destes para o novo esquema de armazenamento e carregamento dos dados transformados no esquema. Além disso, devem ser armazenadas para diversos fins (auditoria, rastreamento, dentre outros) informações relativas aos dados originais como localização e data e horário da extração, além das regras de transformação que foram realizadas sobre os dados originais.

Neste capítulo serão detalhados os conceitos e termos fundamentais necessários para o entendimento da proposta deste trabalho. Assim, iremos descrever inicialmente na Seção 4.1 sobre o projeto da arquitetura de dados que irá facilitar a compreensão de arquitetura em que os dados utilizados estão, assim como a arquitetura que será definida no projeto; na Seção 4.2 será descrito o conceito de procedência de dados, elemento importante para garantia da auditoria futura dos dados, assim como na manutenção de melhorias e correção do sistema; na Seção 4.3 serão discutidos os conceitos de integração de dados e esquemas assim como os problemas de heterogeneidades encontrados nesta etapa; na Seção 4.4 serão descritos as características e formas de realização do processo ETL - extract, transform and load - em um sistema, assim como os pontos críticos que devem ser levados em conta durante o desenvolvimento desta etapa; na Seção 4.5 são detalhadas as características de um sistema data warehouse (DW) e o seu objetivo, assim como as duas metodologias possíveis de seguir para a criação de um sistema DW e a metodologia escolhida para este trabalho; na Seção 4.6 é descrito o conceito de sistemas de apoio a decisão - tipo de sistema que será utilizado no processo de validação do projeto. 


\subsection{Arquitetura de dados}

Um projeto de arquitetura de dados visa demonstrar a estrutura de todos os níveis de abstração dos componentes de dados em um sistema computacional (Elmasri, 2010). Neste sistema inclui-se a arquitetura conceitual, física e lógica do projeto de dados, que irão facilitar correções, modificações e novas funcionalidades em um sistema computacional. Um Sistema de apoio a decisão (SAD) deve ter uma arquitetura de dados definida em seu projeto.

Esta arquitetura de dados descreve todo o processo, desde como os dados serão coletados, processados e armazenados. Sobre a coleta, está ligada diretamente ao formato em que o dado se encontra. Definiremos aqui, segundo (Elmasri, 2010) e (Kent, 2000) os formatos de dados como estruturados, semiestruturados e não estruturados.

\subsubsection{Dados estruturados}

Dados estruturados são aqueles organizados de acordo com um critério rígido e prédefinido, respeitando vários campos (ou atributos) de dados, que delimitam o escopo, domínio (valores possíveis) de dado, tipo de dado, e relacionamento entre os dados. Este é o caso, por exemplo, com dados envolvidos em tabelas de banco de dados relacional utilizados em Sistemas Gerenciadores de Bancos de Dados (SGBD).

\subsubsection{Dados semiestruturados}

Dados semiestruturados são dados que possuem uma determinada organização com relação a qual atributo de dado este representa. Alguns dos seus atributos gerais podem ser conhecidos com antecedência, outros adicionados mais tarde, dependendo das circunstâncias. Porém o seu relacionamento e o seu tipo (numérico, booleano, texto, etc.) nem sempre é definido. Exemplos de dados semiestruturados são os dados descritos no padrão Comma Separated Value (CSV).

\subsubsection{Dados não estruturados}

Dados não estruturados são aqueles para os quais não é especificado nenhum esquema, contendo apenas o conteúdo e a forma de apresentá-lo. Normalmente caracterizado por 
documentos textos, imagens, áudios, etc. Uma página HTML (apesar de possuir uma determinada estrutura de apresentação para os dados) é considerada também como um conjunto de dados não estruturados, pois não define informações sobre o que são os dados; somente como devem ser apresentados.

\subsection{Procedência de dados}

Procedência de dados é um conceito relacionado ao armazenamento de um conjunto de metadados - dados sobre um outro dado - para identificação da fonte original dos dados aos quais um sistema utiliza, assim como as transformações realizadas nestes dados. Simmhan (2005) e Tan (2004) dizem que o motivo para se armazenar a procedência dos dados tem ao menos oito utilidades necessárias: garantia da qualidade dos dados; verificação dos dados; auditoria e autoria dos dados; manutenção de banco de dados; informação sobre os dados; reenvio de dados para a fonte; análise de tendências e reprodução de experimentos científicos.

Neste trabalho, a procedência de dados será incorporada no projeto de arquitetura de dados com a finalidade de armazenar as fontes utilizadas, datas de extração e transformações necessárias para o processo de integração.

\subsection{Integração de dados e esquemas}

As organizações são compostas por diversos sistemas transacionais de informação, muitas vezes utilizando-se de diferentes formatos, sistemas, modelos e localidades dos dados. Esta heterogeneidade gera um problema de integração a ser solucionado para a resolução de sistemas de apoio a decisão, quando os dados utilizados nas diferentes fontes de dados são necessários para a geração de uma nova informação para tomadas de decisões.

A integração de bancos de dados é definida como a atividade de criar um esquema global unificado composto pelos bancos de dados existentes na organização (Batini, 1986), gerando assim um relacionamento semântico sobre estes dados. Sheth e Larson (Sheth, 1990) discutem os problemas de integração que são encontrados em bancos de dados heterogêneos. Esta heterogeneidade é classificada como heterogeneidade entre SGBDs, estrutural, sintática e/ou semântica. 


\subsubsection{Heterogeneidade entre SGBD's}

Em uma organização, diferentes requisitos em diferentes setores são solicitados para atender as necessidades especificas de cada setor. Neste caso, cada setor poderá ter implementado uma solução com diferentes tipos de SGBDs. Cada SGBD tem um modelo de dados próprio usado para definir estruturas de dados e regras. Além disso, pode haver a diferença nas linguagens de programação de desenvolvimento de cada uma, e linguagens DML (Data Manipulation Language), DDL (Data Definition Language) e DCL (Data Control Language). Desta forma, esta é uma das heterogeneidades ao qual se deve tratar quanto à resolução de integração de dados.

\subsubsection{Heterogeneidade estrutural}

Assim como diferentes requisitos são implementados utilizando-se de diferentes SGBD's, estes requisitos também podem utilizar diferentes esquemas e estruturas para armazenar os dados das aplicações. Os modelos de dados podem utilizar recursos próprios ao qual o paradigma do modelo suporta, como por exemplo, a utilização de herança e generalização em modelos de dados orientados a objetos, não suportados em modelos de dados relacionais (não estendidos). Há também o problema onde um elemento é caracterizado como uma entidade em um determinado modelo, e como atributo de uma entidade em outro modelo, como por exemplo, o cadastro de endereço em um determinado esquema de banco de dados pode ser um atributo da entidade "cliente" e em outro esquema de banco de dados pode ser uma entidade "endereço", composta pelos atributos "logradouro", "numero", "bairro", "cidade", "uf" e "país".

\subsubsection{Heterogeneidade sintática}

Bases de dados de diferentes setores de uma Organização podem armazenar resultados iguais ou semelhantes, porém descritos sintaticamente diferentes. Um exemplo é o caso de cadastro de clientes ao qual em determinada base esta entidade é definida como "Cliente", e em outra base a denominação sintática para esta entidade é definida como "Usuario". Ambas trazem informações iguais (ou semelhantes) do tipo dados pessoais do cliente (ou usuário) da Organização. 


\subsubsection{Heterogeneidade semântica}

A semântica de um dado descreve o significado deste. Em duas bases distintas, pode haver duas entidades (ou atributos de entidades) com o mesmo nome, porém com significados e interpretações diferentes. Um exemplo referente a este tipo de heterogeneidade é com relação a bases de dados sobre valores financeiros. Seja dois bancos de dados distintos com as seguintes tabelas TB1 e TB2, e ambas com um atributo de nome comum - valor. A tabela TB1 define valores sobre o detalhamento dos gastos da empresa, e a tabela TB2 define valores sobre o detalhamento de faturamento de produtos da empresa. Em ambas, há um valor final referente ao seu gasto ou lucro, chamado "valor". A má interpretação destas tabelas pode gerar uma integração de dados errônea referente aos tipos de dados, onde uma tem interpretação semântica de gasto e a outra tem interpretação semântica de lucro, porém ambas com o mesmo nome do atributo.

\subsection{ETL}

ETL é um acrônimo dos termos "Extract, Transform and Load". Este procedimento é uma fase crítica da construção de um Data Warehouse (apesar de não ser um procedimento único para carga somente em DW; pode ser utilizado para outros serviços em sistemas de informação. Consideraremos aqui a aplicabilidade deste sobre os DWs). As subfases de extração e carregamento são obrigatórias, pois é nestas subfases que os dados serão recuperados de sistemas transacionais e carregados diretamente no DW. A subfase de transformação é a fase mais crítica do processo: é nesta fase que os dados passarão por correção, adaptação e transformações para se adequarem ao novo modelo e esquema de banco de dados ao qual este dado passará a fazer parte (passos de integração de dados). Segundo Kimball (2004), as características mais relevantes para garantir a qualidade dos dados são:

- Unicidade: removendo qualquer duplicação de informação;

- Precisão: Os dados não podem perder suas características originais assim que são carregados para o DW;

- Completude: não gerando dados parciais de todo o conjunto relevante às análises;

- Consistência: ou seja, os fatos devem apresentar consistência com as dimensões que o compõem. 
É necessário que os dados fiquem em uma forma homogênea para serem carregados no DW. As regras de transformação devem ser guardadas para futuras auditorias de verificação dos processos de integração, para garantir que os dados que estão armazenados no DW passaram pelo procedimento correto de transformação.

\subsection{Data Warehouse}

Um Data Warehouse é um "armazém” de dados ao qual o objetivo é armazenar informações temporais e/ou espaciais para apoio à tomada de decisões. Normalmente estas informações são séries temporais, possibilitando uma análise em determinados períodos ou ciclos de um determinado processo, gerando informações importantes para as tomadas de decisões, ao invés de tomar uma decisão apenas por intuição do negócio.

Estes dados são extraídos de sistemas transacionais, que podem estar integrados ou não; no mesmo espaço físico, ou em diferentes regiões do planeta; armazenados em uma mesma tecnologia, ou em diversas tecnologias de código aberto e/ou tecnologias privadas.

O DW não é uma ferramenta específica. Este pode ser considerado como um modelo de desenvolvimento ao qual pode ser baseado em várias arquiteturas e metodologias, dentre elas as quais se destacam dois autores principais: Inmon ou Kimball.

Inmon (2005) é considerado como o criador do modelo DW. Em sua publicação "Building the Data Warehouse", ele descreve uma arquitetura lógica para o primeiro passo da construção de um DW: a extração dos dados de BDs operacionais dispersos; a transformação dos dados em uma série temporal em um único BD integrado e em seguida passa por uma nova transformação em unidades menores departamentais, conhecidas como Data Marts (DM), ponto final para iniciar a extração de informação pelos gestores departamentais criarem seus relatórios. Logo, a metodologia Inmon é conhecida como metodologia top-down, onde primeiro se constrói o geral, e a partir deste gera sistemas menores que compõem o todo.

A abordagem descrita por Kimball (Kimball, 1998) possuí uma visão inversa. Em sua publicação "The Data Warehouse Toolkit" ele descreve que a extração dos dados deve ser “departamentais", construindo os DM's que são ligados por um canal de comunicação denominado Data Warehouse bus (DWB), somando-se os DM's para a construção final do DW. Esta abordagem é conhecida como metodologia Bottom-up, que parte de vários subsistemas que serão agregados a fim de montar o sistema principal.

Dentre estas abordagens, o problema principal está na extração dos dados. O primeiro passo é estar certo de que os dados dos passos anteriores (local de onde será extraído os dados) 
estão sendo persistidos de forma correta. De nada adianta despender tempo com modelagem e criação da infraestrutura do DW se a fonte dos dados está inconsistente; feito isso, o próximo passo é a extração dos dados dos bancos de dados operacionais para carregamento no sistema DW (ou subsistemas DM, caso a abordagem tomada for a Kimball) - procedimentos de ETL, citados anteriormente.

Ainda sobre o modelo da estrutura de dados do DW, a mais utilizada atualmente é a metodologia de Kimball, utilizando-se do modelo "estrela" ou "snowflake". Estes modelos consistem basicamente em uma tabela fato e as tabelas dimensões (e dimensões auxiliares, no caso do modelo snowflake).

"A tabela de fatos é a tabela principal em um modelo dimensional, onde os valores numéricos de medições de desempenho do Negócio são armazenados”, (Kimball, 1998). Esta será uma tabela ao qual conterá a intersecção de todas as chaves de campos (das dimensões) aos quais influenciam diretamente na medição deste valor armazenado, como exemplificado na figura 13.

Figura 13 - tabela de fatos atrelada a suas dimensões

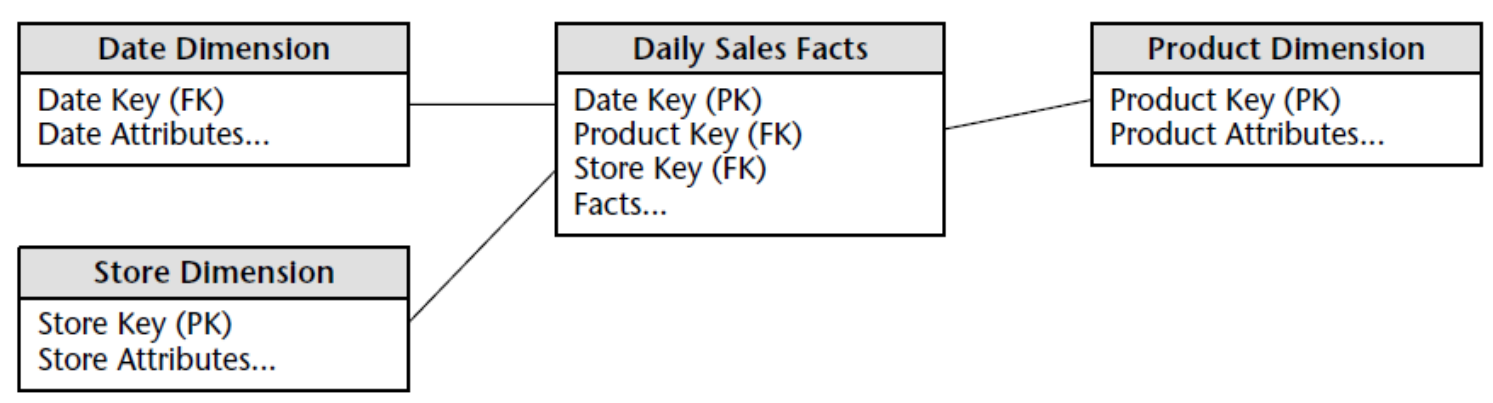

Fonte: Kimball, 1998.

“As tabelas de dimensões contêm os descritores textuais do negócio" (Kimball, 1998). É nestas tabelas que armazenamos os elementos aos quais irão estar representados por chaves na tabela de fatos. Estes elementos irão ser únicos em cada tabela dimensão.

\subsection{Sistemas de Apoio a Decisão (SAD)}

O conceito de SAD - Sistemas de Apoio a Decisão - é abordado inicialmente na literatura na década de 70, quando Keen e Scott Morton (Keen; Morton, 1978) definiram este 
como duas grandes áreas de pesquisas: o estudo teórico de tomada de decisões nas organizações e os trabalhos técnicos em sistemas computacionais interativos.

SAD é um subgrupo de Sistemas de Informação (Keen, 1978) que possui a finalidade de, a partir de um conjunto de registro de dados sobre uma determinada organização e passos pré-definidos de processamento sobre estes dados, gerar informações úteis em casos onde o julgamento humano é um passo da resolução de um problema, porém a capacidade humana de análise de grandes massas de dados é limitada. Assim, a informação gerada pelo SAD servirá como apoio ao humano tomador de decisão.

Neste trabalho o conceito de SAD será utilizado para demonstrar os resultados que podem ser gerados com dados abertos governamentais integrados na WEB para análises, mineração de dados e tomadas de decisões. 


\section{Desenvolvimento do trabalho}

Este capítulo irá descrever a metodologia de desenvolvimento para se atingir o objetivo do trabalho. As etapas foram divididas em:

- definição de esquema conceitual dos dados de receitas e despesas;

- definição dos esquemas lógicos dos entes federativos e do modelo integrado;

- criação do processo de extração de dados do processo ETL;

- criação do processo de transformação de dados do processo ETL;

- criação do processo de carregamento de dados do processo ETL;

- configuração de ferramenta OLAP para visualização e análise dos dados;

- validação do protótipo de integração com relação a corretude dos dados e com relação a usabilidade da ferramenta junto a um especialista da área dos dados.

\subsection{Padronização e Integração}

O trabalho de padronização e integração de dados define as duas primeiras etapas do projeto. Para isso, foi definida a seguinte metodologia: criação do esquema conceitual dos dados referentes à receitas e despesas do orçamento público e padronização das nomenclaturas; criação dos esquemas lógicos dos dados já publicados nos portais de transparência (baseado nos esquemas conceituais e nos dados que estão disponíveis nestes conjuntos de dados) e definição do domínio de dados para campos de dados que possuem codificação e nomenclatura específica.

Para a criação dos esquemas conceituais (receitas e despesas) foi utilizado o estudo dos elementos e classificações de receitas e despesas disponíveis no Manual de Contabilidade Aplicada ao setor Público (MCASP, 2014), pois este é aplicado à União, aos estados, ao Distrito Federal e aos municípios.

Os esquemas lógicos de cada ente federativo foram definidos baseados na intersecção das informações disponíveis nos conjuntos de dados dos portais de transparência e o que está descrito pelo modelo conceitual. Os critérios para a escolha das bases de dados após a definição 
do escopo (governo federal, governo do estado de São Paulo e municípios do estado de São Paulo) foram baseados nas três leis de dados abertos governamentais ${ }^{9}$ :

- Se o dado não pode ser encontrado e indexado na Web, ele não existe;

- Se não estiver aberto e disponível em formato compreensível por máquina, ele não pode ser reaproveitado;

- Se algum dispositivo legal não permitir sua replicação, ele não é útil.

Baseado nestes critérios, as bases de dados selecionadas para definição dos esquemas (receitas e despesas) estão representados no quadro 1 com os respectivos portais e localização no portal que possibilita extrair os dados de forma automática por url ou API.

Quadro 1 - levantamento dos portais e respectivas localizações na internet para os dados da execução orçamentária dos entes federativos utilizados neste projeto

Governo Federal: Portal da Transparência - Controladoria Geral da União, Governo Federal

\section{Receitas:}

2010 a 2012

(I) http://www.portaltransparencia.gov.br/planilhas/index.asp

2013 a 2014

(II) http://www.portaltransparencia.gov.br/download

\section{Despesas:}

2010

(III) http://www.portaltransparencia.gov.br/planilhas/index.asp

2011 a 2014

(IV) http://www.portaltransparencia.gov.br/download

Governo do Estado de São Paulo - Portal da Secretária da Fazenda

\section{Receitas:}

2010 a 2014

(V) http://www.fazenda.sp.gov.br/download/default.shtm

\footnotetext{
${ }^{9} \mathrm{http}: / /$ eaves.ca/2009/09/30/three-law-of-open-government-data/
} 


\section{Despesas:}

2010 a 2014

(VI) http://www.fazenda.sp.gov.br/download/default.shtm

Municípios do Estado de São Paulo (Exceto a capital) - Portal do Cidadão: Tribunal de Contas do Estado de São Paulo

\section{Receitas:}

\section{0 a 2014}

(VII) www.portaldocidadao.tce.sp.gov.br/downloads-e-api

\section{Despesas:}

2010 a 2014

(VIII) www.portaldocidadao.tce.sp.gov.br/downloads-e-api

Município do Estado de São Paulo - Secretária Municipal de Planejamento, Orçamento e Gestão

\section{Receitas:}

2010 a 2014

Não disponível

\section{Despesas:}

2010 a 2014

http://sempla.prefeitura.sp.gov.br/orcamento/execucao.html

Fonte: Dados da pesquisa, 2015.

\subsubsection{Esquemas conceituais e esquemas lógicos - Receitas}

Como visto na Seção 2.1.1, as receitas orçamentárias possuem três classificações:

- Por natureza da receita: Define os itens da discriminação da receita, identificando a origem do recurso segundo o fator gerador. Representa o menor nível de detalhamento das informações orçamentárias sobre uma receita (MCASP, 2014);

- Por identificador de resultado primário da receita: Define a receita como primária ou financeira. Receita primária o capital o valor deve ser considerado no cálculo de 
resultado primário. Financeira são receitas que não podem ser contabilizadas neste cálculo (MCASP, 2014);

- Por "fonte / destinação de recurso" da receita: Define uma finalidade específica de aplicação desta receita. É o mecanismo integrador entre receitas e despesas.

A partir dos conceitos definidos para as classificações da receita orçamentária no MCASP, foi criado um esquema conceitual que representa o relacionamento entre um item de receita e seus classificadores, definidos pela figura 14 :

Figura 14 - modelo conceitual de receitas orçamentárias baseado nas descrições do MCASP 2014

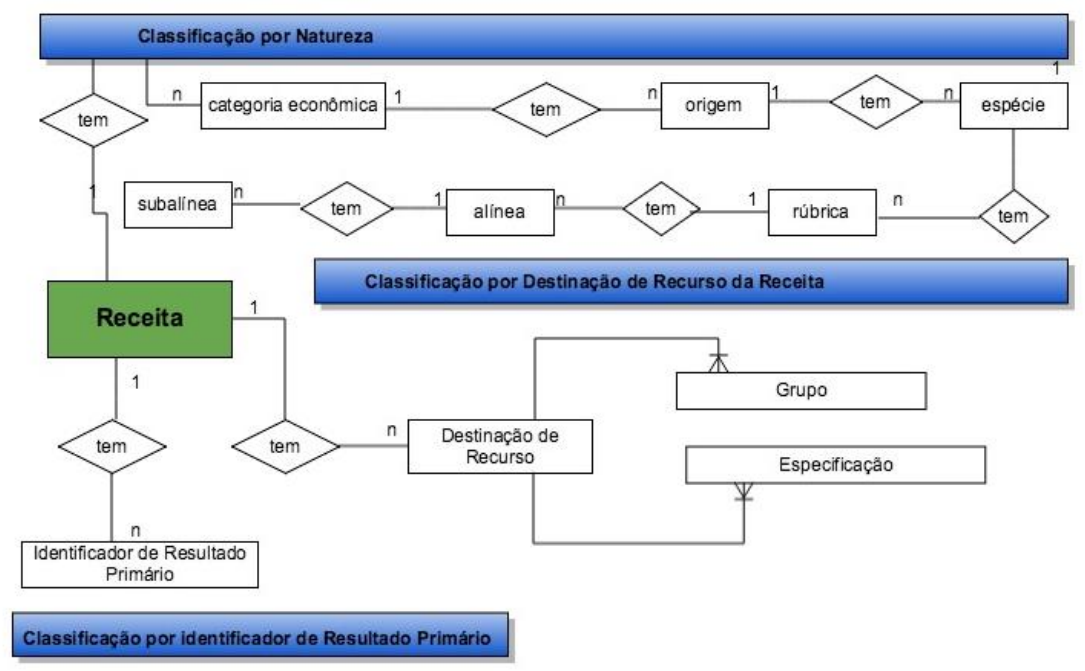

Fonte: José Rodolfo Beluzo, 2015.

A partir do modelo conceitual da figura 14, foi criado um modelo conceitual para cada esquema de dados dos datasets utilizados identificando nas bases de dados extraídas de cada ente federativo qual campo de classificação estava ou não sendo disponibilizado de acordo com o MCASP e qual campo estava sendo disponibilizado e não está denominado no MCASP. Foram utilizadas três marcações para estas identificações: cor vermelha para indicar que a informação é citada no MCASP e não está disponível no conjunto de dados; cor amarela para informar que a informação não está descrita no MCASP, mas está disponível no conjunto de dados (informação extra); e cor verde para informar que o campo está descrito no MCASP e foi disponibilizado no conjunto de dados.

A figura 15 refere-se ao modelo conceitual das receitas orçamentárias do governo federal. Para este grupo de datasets as informações estão condizentes em partes com o MCASP 
(MCASP, 2014), pois não publicam a classificação por destinação de recurso da receita, nem de identificador de resultado primário, porém estão de acordo com as solicitações mínimas do Decreto 7.158 (Brasil, 2010), pois publicam a classificação por natureza da receita e também os elementos da unidade gestora pelos campos "órgão superior", "órgão subordinado" e "unidade gestora". A granularidade dos dados de acordo com o período é diária - possui informação de dia, mês e ano.

Figura 15 - modelo conceitual de receitas orçamentárias - intersecção dos dados de receitas do governo federal com o modelo conceitual baseado nas descrições do MCASP 2014

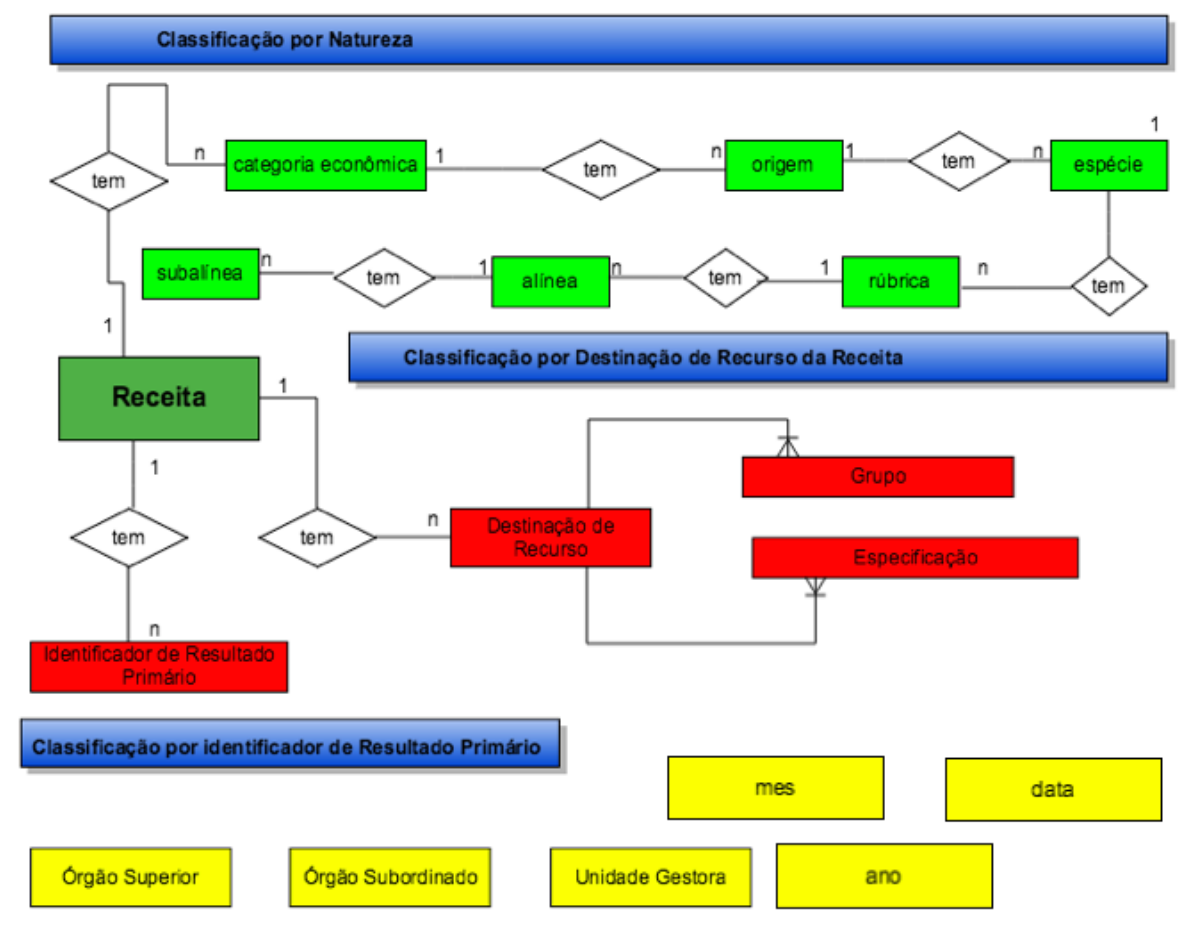

Fonte: José Rodolfo Beluzo, 2015.

A figura 16 refere-se ao modelo conceitual das receitas orçamentárias do governo do estado de São Paulo. Para este caso, os datasets de receitas do governo estadual se enquadram ao exigido por lei no decreto 7.185 (Brasil, 2010) e publicam também a informação de destinação de recurso da classificação por destinação de recursos do MCASP (MCASP, 2014), mas não publicam seu grupo; também não publicam a classificação por identificador de resultado primário. A granularidade da informação é anual. 
Figura 16 - modelo conceitual de receitas orçamentárias - intersecção dos dados de receitas do governo do estado de São Paulo com o modelo conceitual baseado nas descrições do MCASP 2014

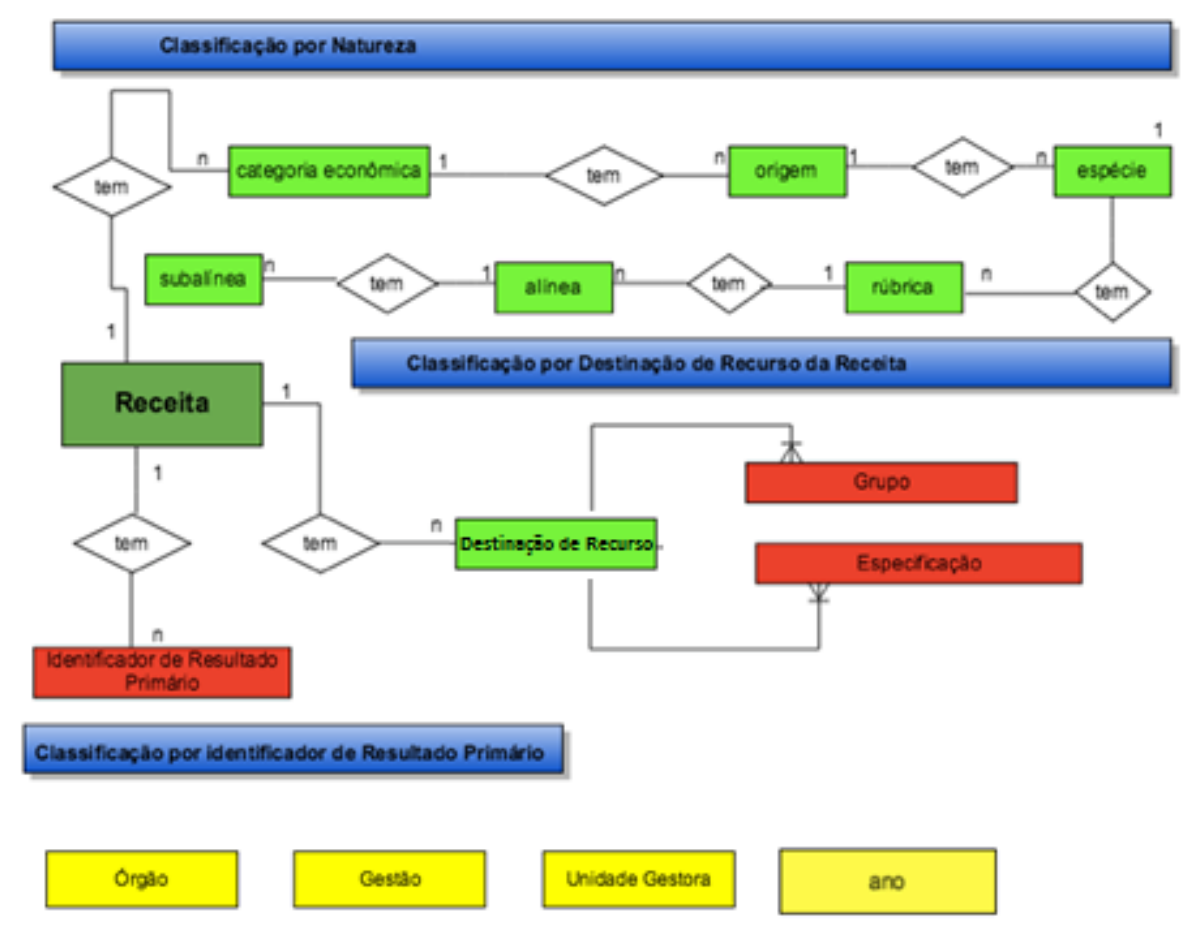

Fonte: José Rodolfo Beluzo, 2015.

A figura 17 refere-se ao modelo conceitual das receitas orçamentárias dos municípios do estado de São Paulo, exceto a capital. Assim como os outros dois casos anteriores, os datasets estão adequados apenas ao Decreto 7.185 (Brasil, 2010), porém nesse caso também existe a informação da destinação de recursos, assim como da cidade que está captando a receita. A granularidade para este grupo é diária - possui a informação dia, mês e ano. 
Figura 17 - modelo conceitual de receitas orçamentárias - intersecção dos dados de receitas dos municípios do estado de São Paulo (exceto a Capital São Paulo) com o modelo conceitual baseado nas descrições do MCASP 2014

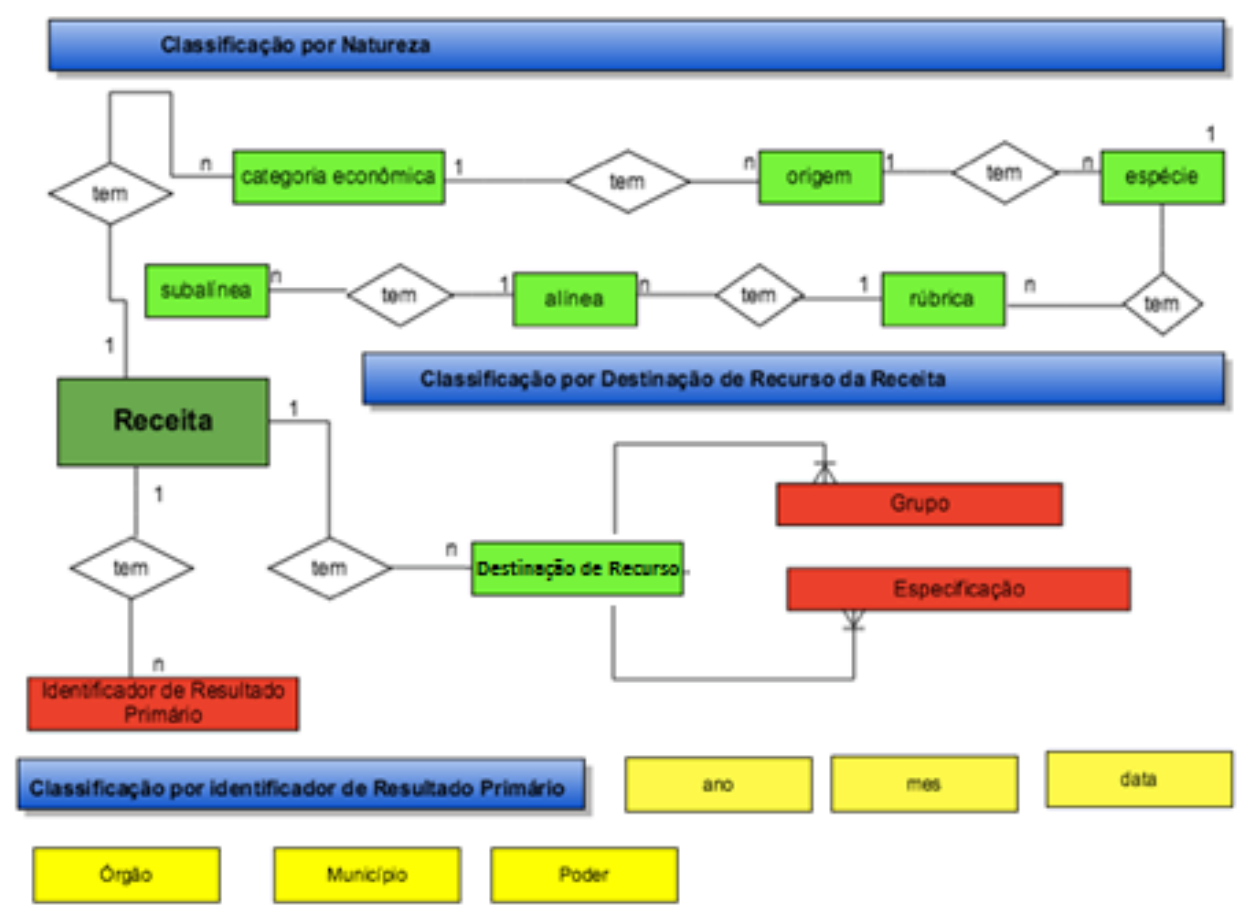

Fonte: José Rodolfo Beluzo, 2015.

Esta etapa serviu de apoio para melhor entendimento e visualização de como é a classificação das receitas orçamentárias. Após a definição dos modelos conceituais, foi criado um esquema lógico para cada modelo conceitual criado a partir das intersecções, seguindo a metodologia de desenvolvimento dos esquemas lógicos "Star Schema" proposto por Kimball (Kimball, 1999), que irá possibilitar consultas analíticas sobre os dados de forma mais eficiente que o modelo relacional convencional.

A figura 18 ilustra o esquema lógico definido para os dados do governo federal baseado nas intersecções observadas na figura 15. Este esquema representa um data mart no sistema principal. A partir dele é possível obter informações multidimensionais a respeito dos valores das receitas arrecadadas pelo governo federal. 
Figura 18 - esquema lógico de receitas orçamentárias - Governo Federal

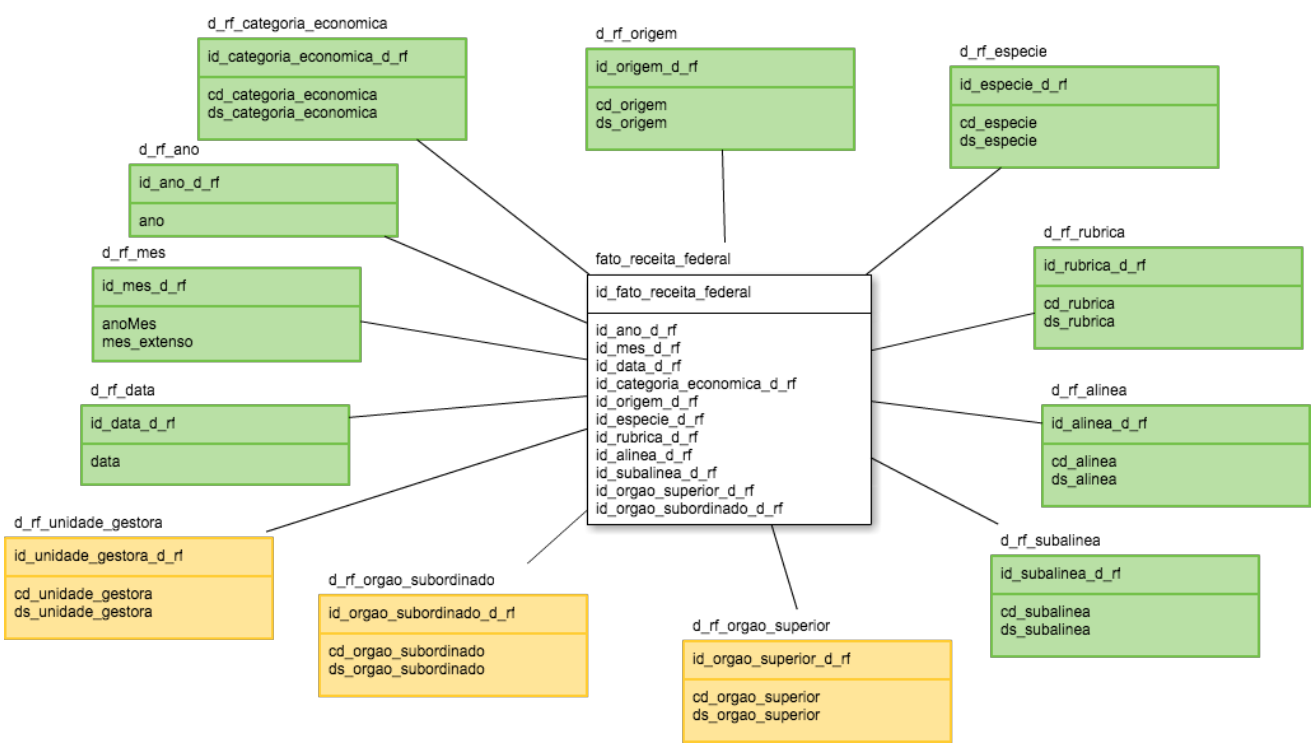

Fonte: José Rodolfo Beluzo, 2015.

A figura 19 ilustra o esquema lógico definido para o governo do estado de São Paulo baseado nas intersecções observadas na figura 16. Este representará outro data mart no sistema principal. A partir dele é possível obter informações multidimensionais a respeito dos valores das receitas arrecadadas pelo governo do estado de São Paulo. 
Figura 19 - esquema lógico de receitas orçamentárias - Governo do Estado de São Paulo

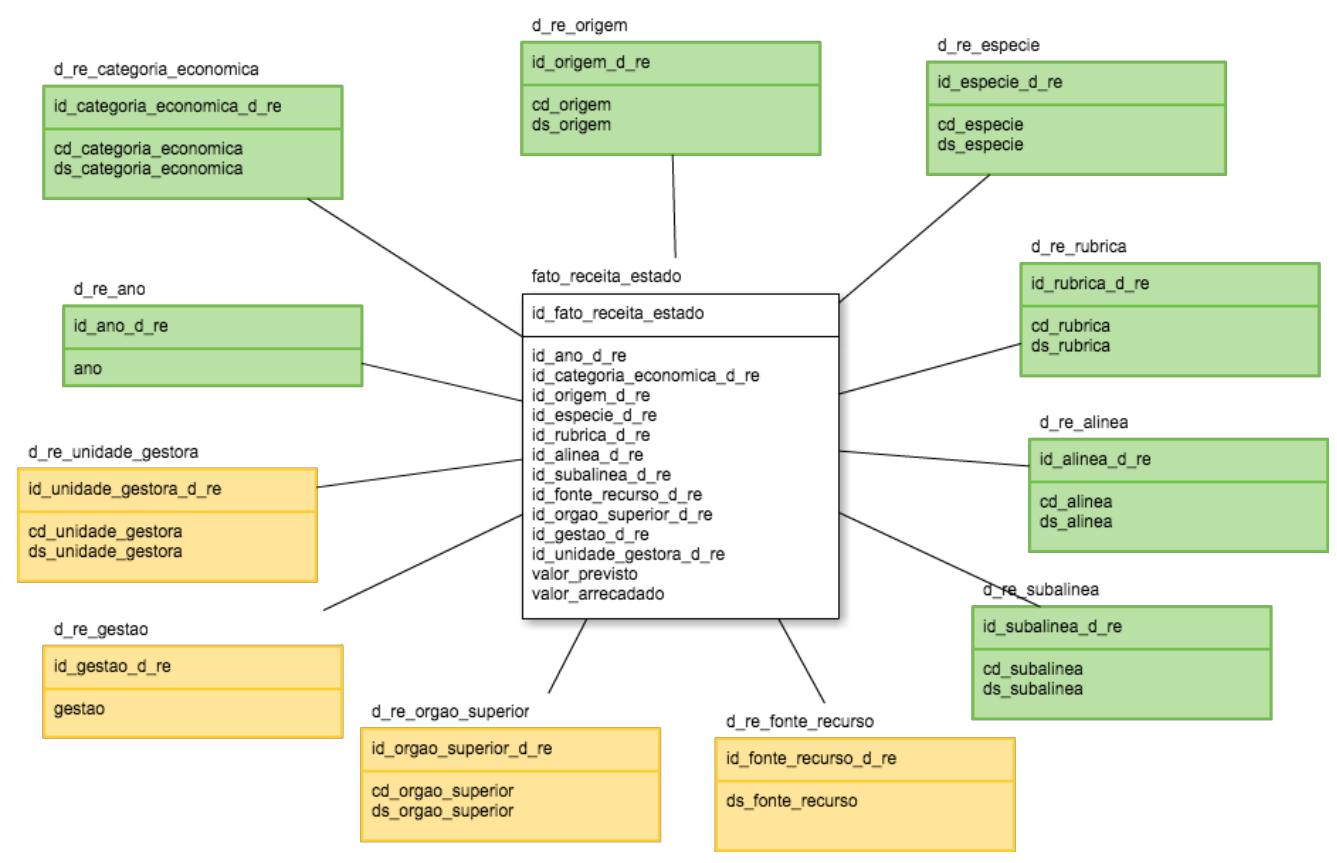

Fonte: José Rodolfo Beluzo, 2015.

A figura 20 ilustra o esquema lógico definido para os dados dos municípios do estado de São Paulo baseado nas intersecções observadas na figura 17. Este esquema representa outro data mart no sistema principal. A partir dele é possível obter informações multidimensionais a respeito dos valores das receitas arrecadadas de cada município do estado de São Paulo, exceto da capital, que não faz parte do dataset utilizado (TCE). 
Figura 20 - esquema lógico de receitas orçamentárias - Municípios do Estado de São Paulo (exceto a Capital São Paulo)

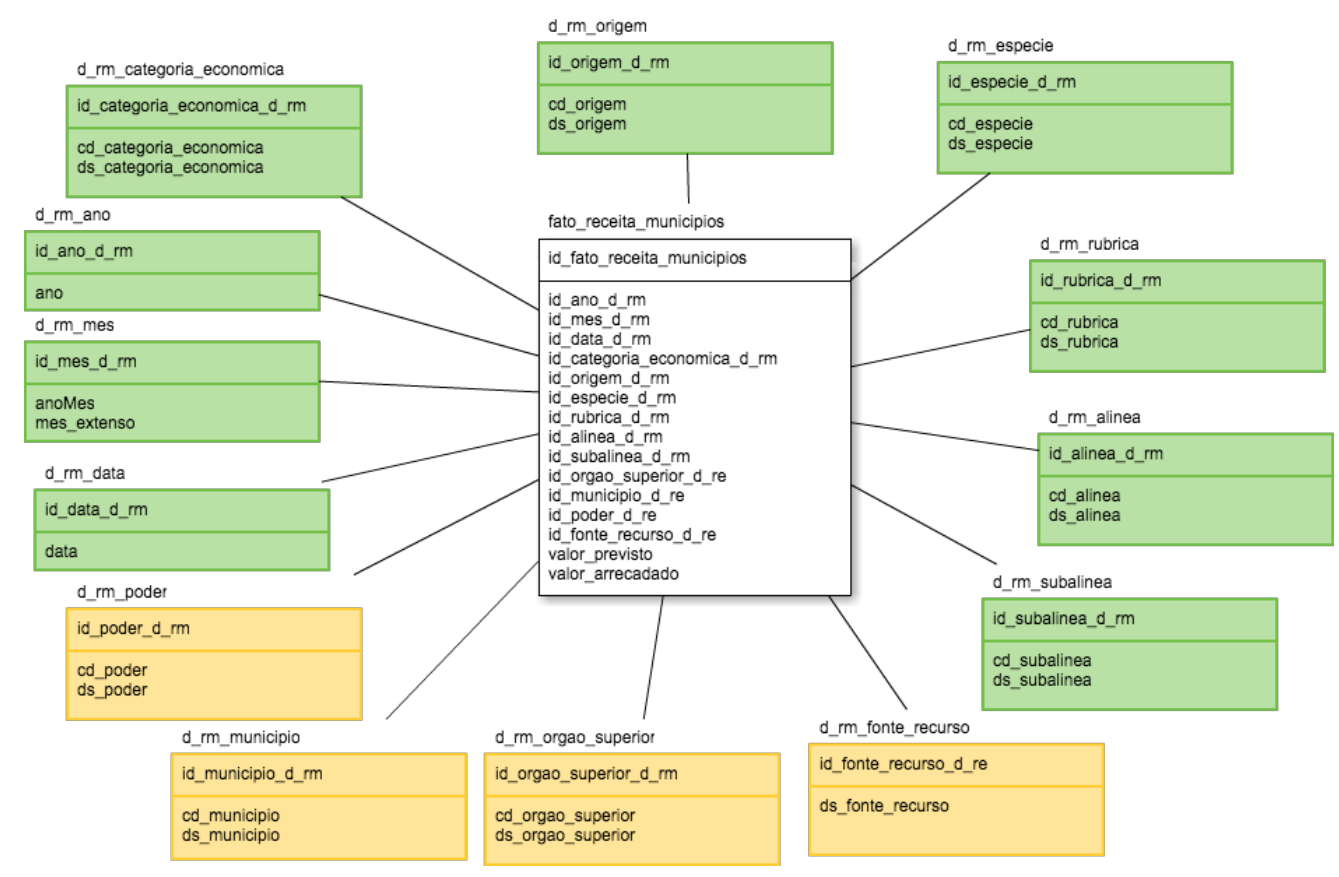

Fonte: José Rodolfo Beluzo, 2015.

Para o município de São Paulo não foi definido nem o modelo conceitual, nem o esquema lógico, pois não foram encontrados no portal do município os dados referentes à receita orçamentária (de acordo com os critérios adotados) durante a execução deste trabalho. Foi realizado um contato com o portal da Secretária de Planejamento, Orçamento e Gestão do município solicitando alguma localização na internet ou API para extração automatizada, porém os mesmos retornaram que possuem uma ferramenta ${ }^{10}$ no portal de transparência do município para visualização e extração de dados da receita. A ferramenta em questão não foi utilizada neste trabalho devido a mesma não estar dentro das três leis de dados abertos governamentais (Eaves, 2009) pois o dado "não pode ser encontrado ou indexado na WEB", visto que para qualquer extração é necessário a interação humana no processo de extração de cada base.

Baseado nos esquemas conceituais e lógicos demonstrados nas figuras anteriores de cada ente federativo (exceto município de São Paulo), foram criados o modelo conceitual e o esquema lógico de integração de receitas orçamentárias nas três esferas, realizando a intersecção das informações comuns que são encontradas em todas elas.

\footnotetext{
${ }^{10} \mathrm{http} / /$ transparencia.prefeitura.sp.gov.br/contas/receitas/Paginas/default.aspx
} 
A figura 21 se refere ao modelo conceitual da intersecção dos modelos da figura 14, figura 15 e figura 16 ilustrando o que há em comum entre os três entes, demonstrando quais informações podem ser obtidas diretamente para os três entes e em qual granularidade isto será possível. Observa-se que a granularidade é apenas anual.

Figura 21 - modelo conceitual de receitas orçamentárias - intersecção dos três entes federativos - governo Federal, Estado de São Paulo e dos municípios do estado de São Paulo (exceto a Capital São Paulo) - com o modelo conceitual baseado nas descrições do MCASP 2014

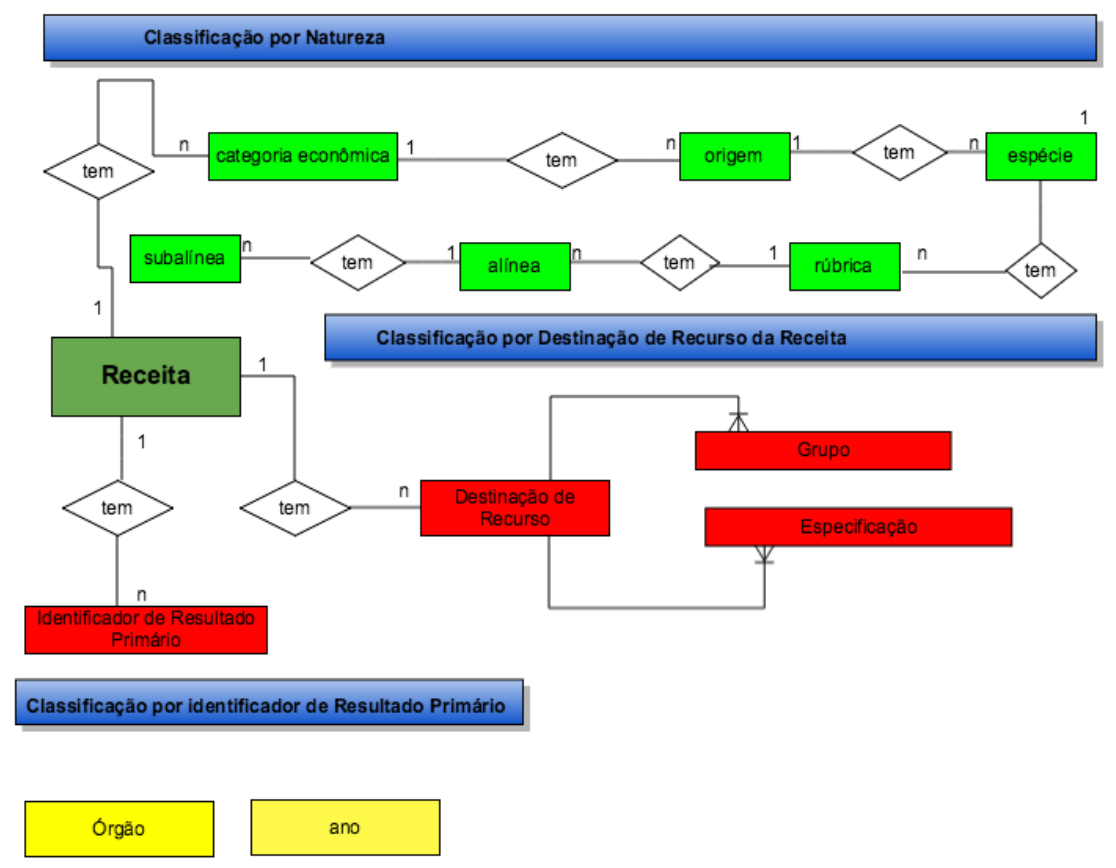

Fonte: José Rodolfo Beluzo, 2015.

A figura 22 se refere ao esquema lógico da intersecção dos esquemas da figura 18, figura 19 e figura 20. Este esquema representa o sistema principal de dados das receitas, construído a partir dos data marts de cada ente federativo. 
Figura 22 - esquema lógico de receitas orçamentárias - Intersecção dos três entes federativos - Governo Federal, Governo do Estado de São Paulo e municípios de São Paulo

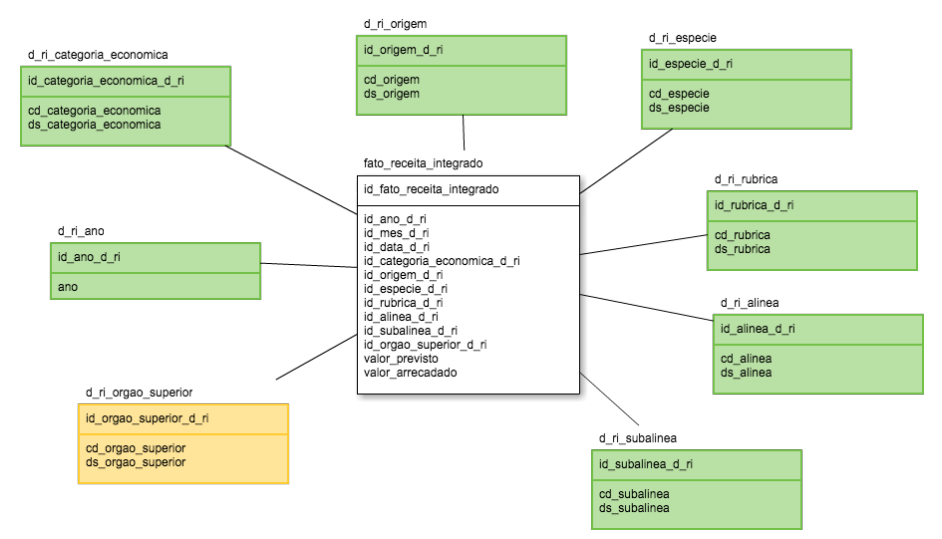

Fonte: José Rodolfo Beluzo, 2015.

\subsubsection{Esquemas conceituais e esquemas lógicos - Despesas}

Com relação às despesas orçamentárias, estas possuem muito mais classificações para definir um fato de despesa do que as classificações de receitas. Como citado na Seção 2.2.1, nas despesas elas se dão na seguinte forma:

- Por Esfera: identifica se a despesa pertence ao orçamento fiscal, da seguridade social ou se é de investimento de empresas estatais (MCASP, 2014);

- Institucional: Identifica as estruturas administrativas e organizacionais que realizam a despesa (MCASP, 2014);

- Por Função: Define em qual área a ação governamental será realizada (MCASP, 2014);

- Por Programas: As ações governamentais são estruturadas em programas os quais serão realizados com objetivos estratégicos definidos no Planejamento Plurianual a cada quatro anos (MCASP, 2014);

- Por Natureza da Despesa: Informa a categoria econômica, o grupo, a modalidade de aplicação e o elemento de uma despesa (MCASP, 2014);

- Por Fonte de Recursos: Informa de onde virão os recursos para realizar determinada despesa. Informa um grupo e a especificação da fonte (MCASP, 2014);

- Por Identificador de resultado primário: Auxilia a apuração do resultado primário previsto na Lei de Diretrizes Orçamentárias (LDO) (MCASP, 2014); 
- Por Identificador de uso: Indicam se os recursos compõem contrapartida nacional de empréstimos ou de doações ou destinam-se a outras aplicações (MCASP, 2014);

- Por Identificador de doação e operação de crédito: Identifica doações de entidades internacionais ou operações de crédito contratuais alocadas nas ações orçamentárias, com ou sem contrapartida da União (MCASP, 2014).

Assim como nas receitas, foi definido inicialmente um modelo conceitual que define um relacionamento entre as despesas e seus classificadores, ilustrado na figura 23:

Figura 23 - modelo conceitual de despesas orçamentárias baseado nas descrições do MCASP 2014

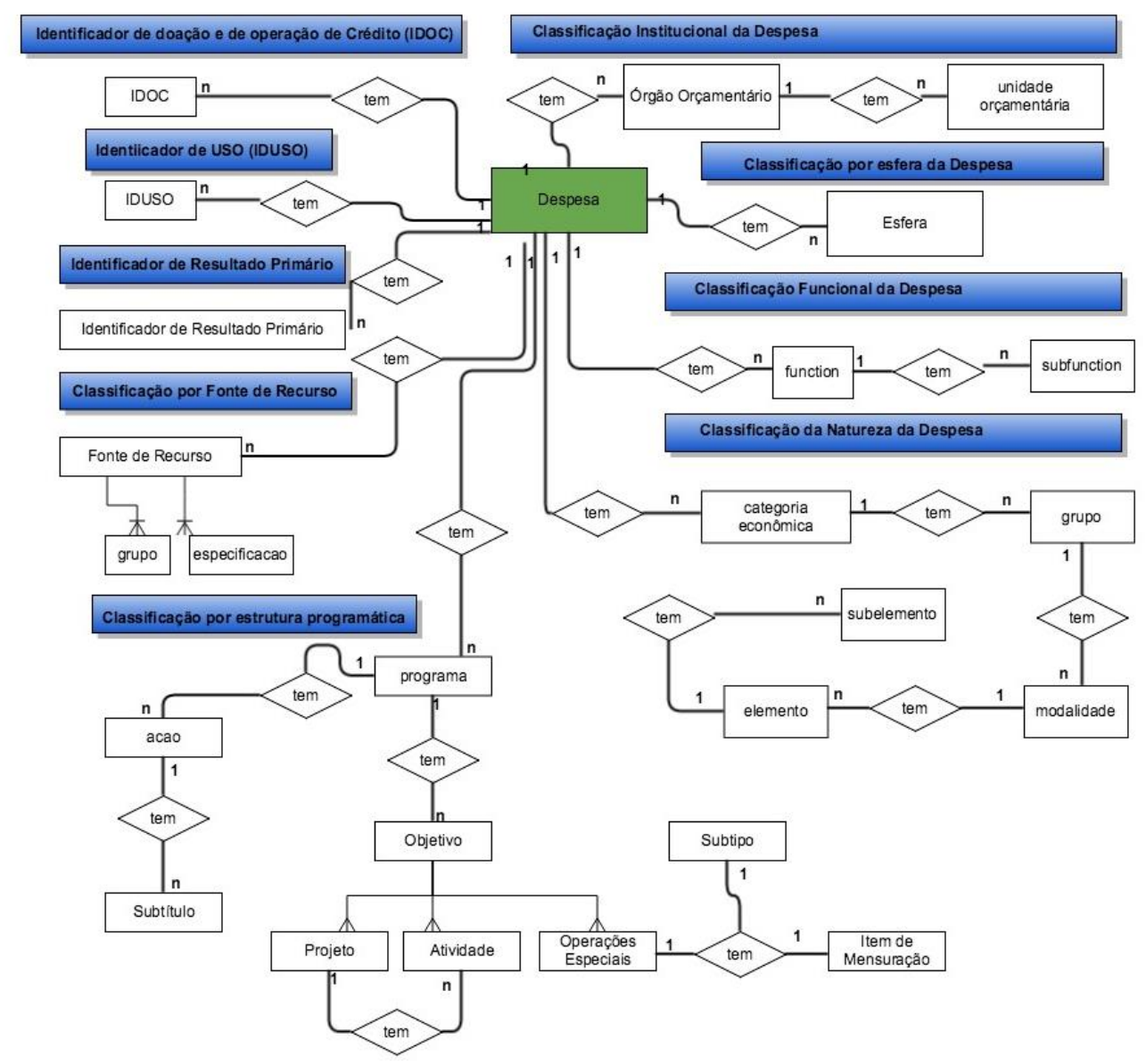

Fonte: José Rodolfo Beluzo, 2015.

Para a criação dos esquemas lógicos de despesas que serão utilizados no sistema final também foi utilizado a mesma metodologia de marcação de cores definida para as receitas. 
Para os gastos de despesas do governo federal em especial, os dados disponibilizados estão classificados em três subgrupos de datasets: "Gastos Diretos", "Transferências", e "Programas Sociais". Os gastos diretos definem recursos financeiros gastos diretamente pelo governo federal; as transferências são os recursos repassados a estados, municípios e entidades privadas; os programas sociais referem-se aos recursos repassados diretamente aos cidadãos por meio dos programas sociais criados pelo governo. Dentro de cada subgrupo, os datasets também estão divididos pelo contexto em que estes se aplicam no subgrupo. No subgrupo "Gastos diretos" os dados estão subdivididos em datasets de "pagamentos", "diárias e passagens" e "cartão de pagamento do Governo Federal (CPGF)".

A figura 24 ilustra a intersecção do modelo conceitual de despesas com os datasets de "pagamentos - Gastos diretos". Para este grupo, as informações mínimas exigidas pelo Decreto 7.158 (Brasil, 2010) estão disponibilizadas parcialmente, pois a categoria econômica e modalidade (elementos da classificação por natureza) não estão informados. Contudo, estes elementos podem ser obtidos por derivação do código do elemento da despesa. Esta tarefa será descrita na seção 5.2.2, no processo de transformação dos dados. Também não foi disponibilizado a fonte de recursos da despesa. 
Figura 24 - modelo conceitual: Intersecção de Gastos Diretos - Pagamentos - Governo Federal com modelo conceitual de despesas de acordo com o MCASP

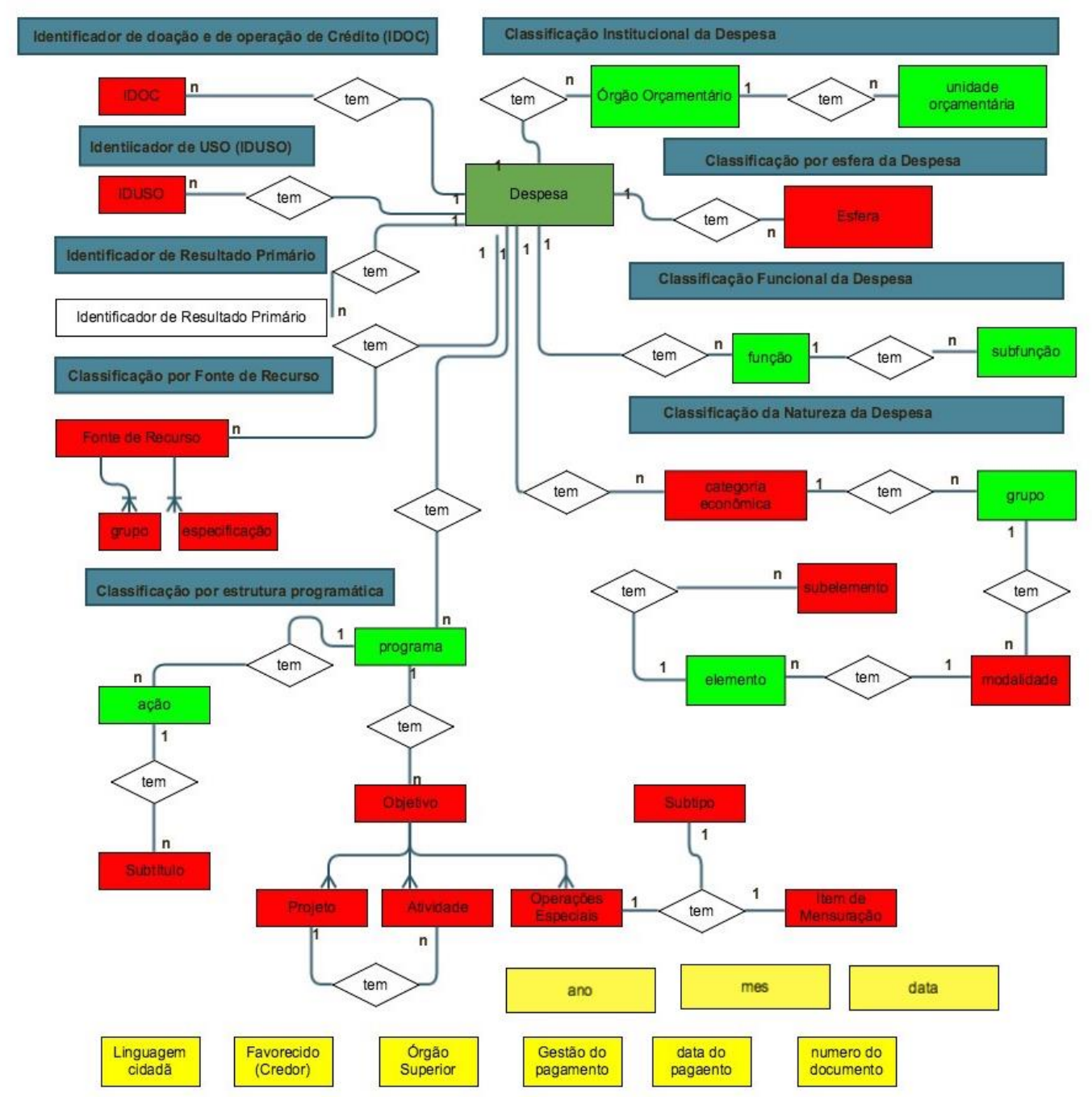

Fonte: José Rodolfo Beluzo, 2015.

A figura 25 ilustra a intersecção do modelo conceitual de despesas da figura 23 com os datasets de “diárias e passagens". Para este grupo, não há como obter a classificação da natureza da despesa (elemento obrigatório de acordo com o Decreto 7.158). Também não foi informado a fonte de recurso da despesa. A classificação funcional, programática e institucional está de acordo com o decreto. 
Figura 25 - modelo conceitual: Intersecção de Gastos Diretos - Diárias - Governo Federal com modelo conceitual de despesas de acordo com o MCASP 2014

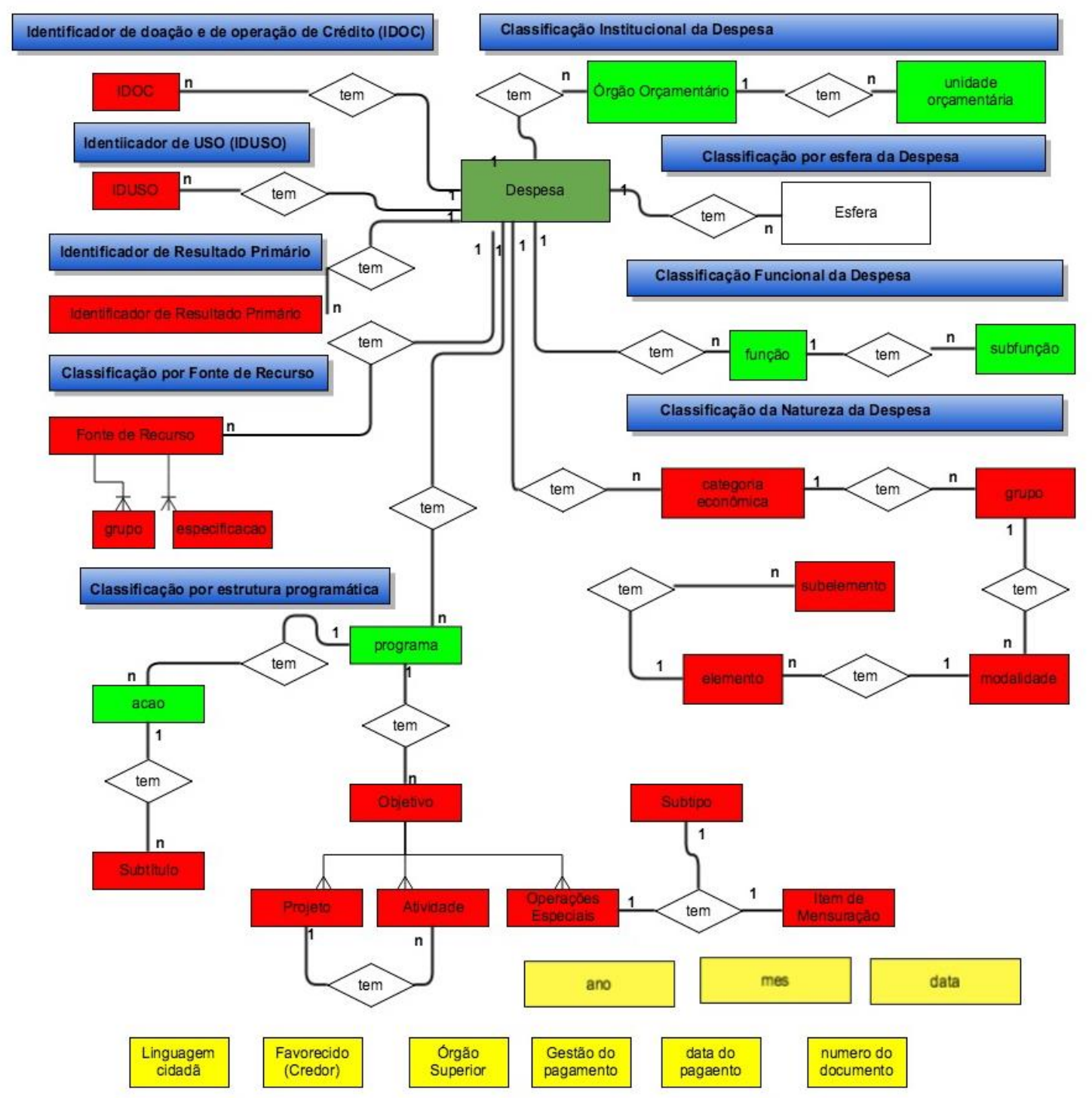

Fonte: José Rodolfo Beluzo, 2015.

A figura 26 ilustra a intersecção com os datasets de "CPGF”. Para este grupo, as únicas informações disponíveis que são condizentes com o Decreto 7.158 se referem à classificação institucional. O restante não está disponível. 
Figura 26 - modelo conceitual: Intersecção de Gastos Diretos - CPGF - Governo Federal com modelo conceitual de despesas de acordo com o MCASP 2014

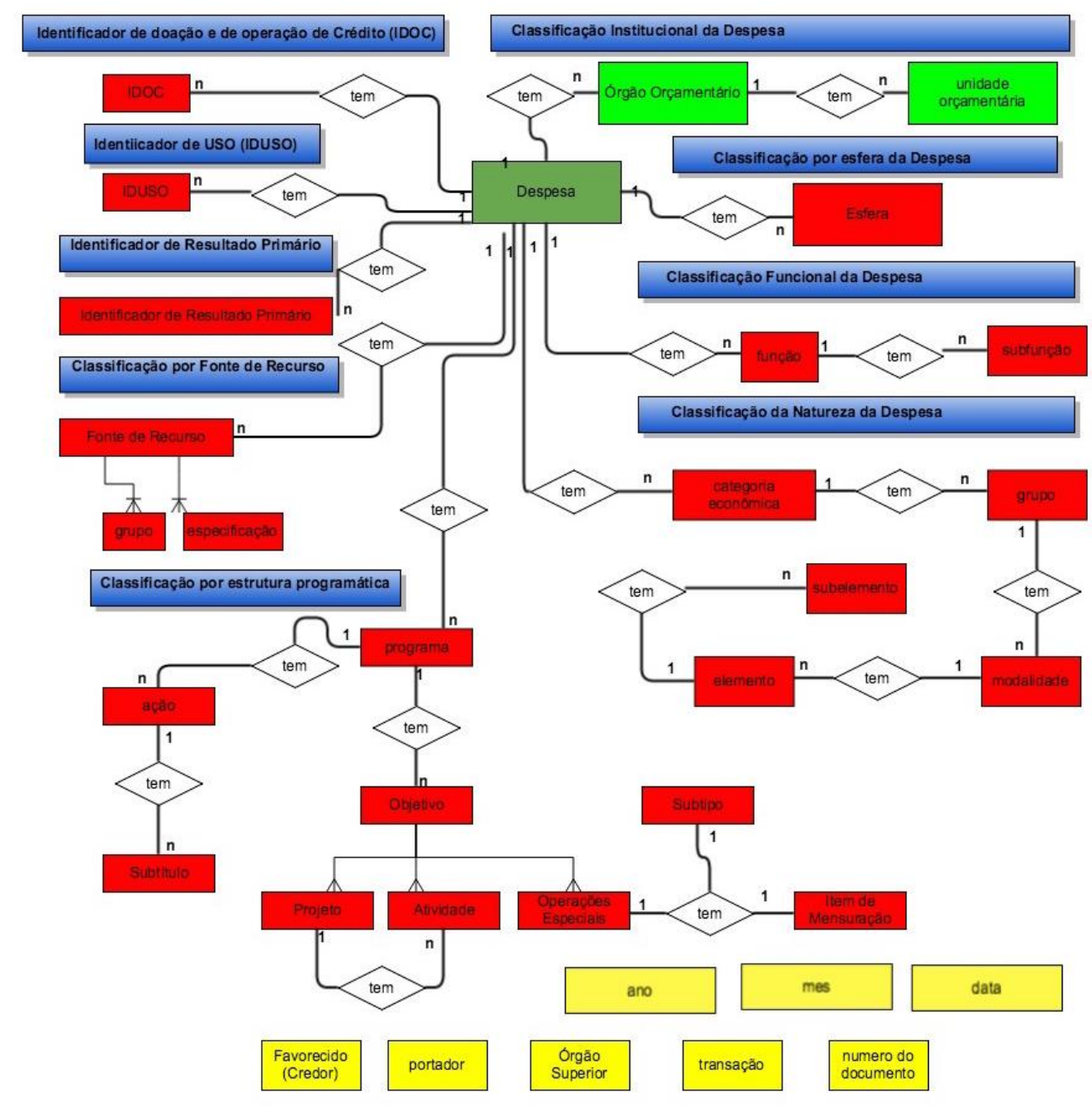

Fonte: José Rodolfo Beluzo, 2015.

No subgrupo "Transferência" os dados estão subdivididos em datasets de "pagamentos" e "cartão de pagamento da defesa civil - CPDC".

A Figura 27 ilustra a intersecção do modelo conceitual de despesas com os datasets de “pagamentos de transferências a estados e municípios". Para este grupo apenas as classificações funcionais e programáticas estão de acordo com o Decreto 7.158 (Brasil, 2010), assim como o favorecido (credor) da despesa. 
Figura 27 - modelo conceitual: Intersecção de Transferências - Pagamentos - Governo Federal com modelo conceitual de despesas de acordo com o MCASP 2014

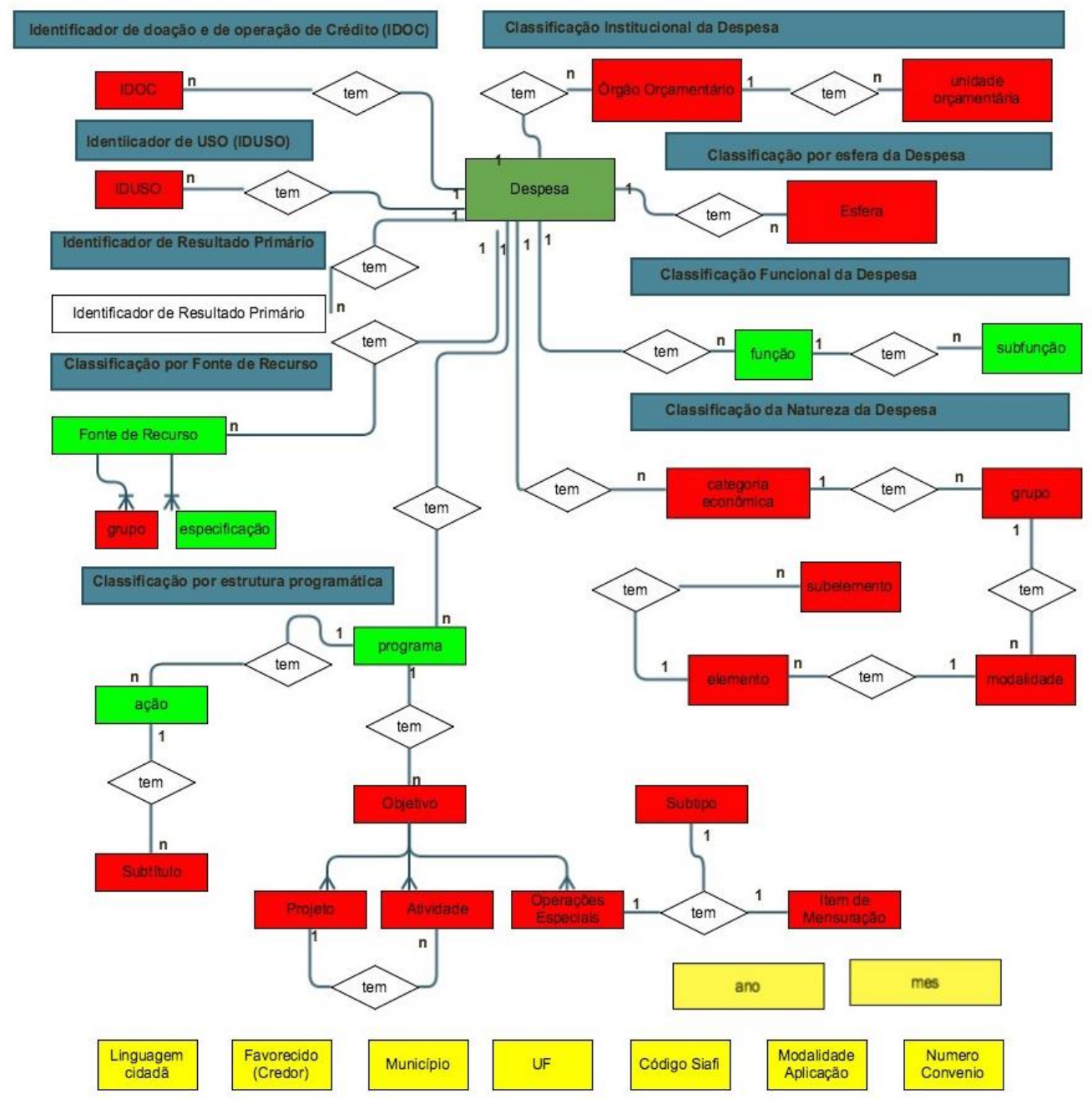

Fonte: José Rodolfo Beluzo, 2015.

A a Figura 28 ilustra a intersecção do modelo conceitual de despesas com os datasets de "CPDC". Para este grupo nenhuma das classificações do Decreto 7.158 (Brasil, 2010) foram atendidas. Apenas o credor da despesa está em consonância com o decreto. 
Figura 28 - modelo conceitual: Intersecção de Transferências - CPDC - Governo Federal com modelo conceitual de despesas de acordo com o MCASP 2014

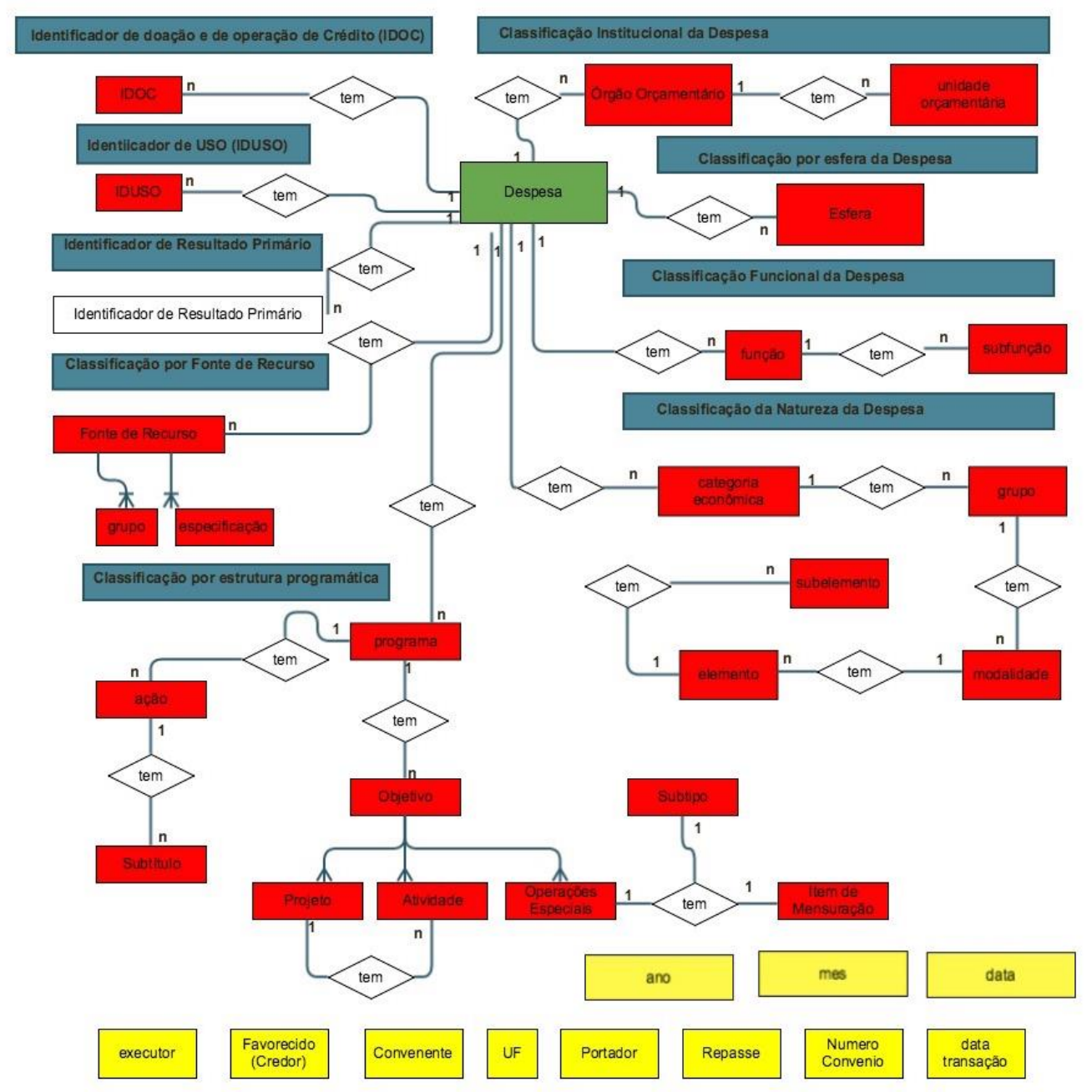

Fonte: José Rodolfo Beluzo, 2015.

No subgrupo "Programas Sociais" os dados estão subdivididos em datasets de "bolsa família - pagamentos", "pescador artesanal” e "outros programas sociais".

Os datasets de "bolsa família - pagamentos" e "outros programas sociais" são idênticos na estrutura, logo construiu-se uma única intersecção dos dois com o modelo conceitual, ilustrado na Figura 29. Para este grupo, as classificações por fonte de recurso, programática e funcional estão de acordo com o Decreto 7.158 (Brasil, 2010). Porém não há a classificação institucional. 
Figura 29 - modelo conceitual: Intersecção de Programas Sociais - Bolsa Família e Outros programas sociais - Governo Federal com modelo conceitual de despesas de acordo com o

MCASP 2014

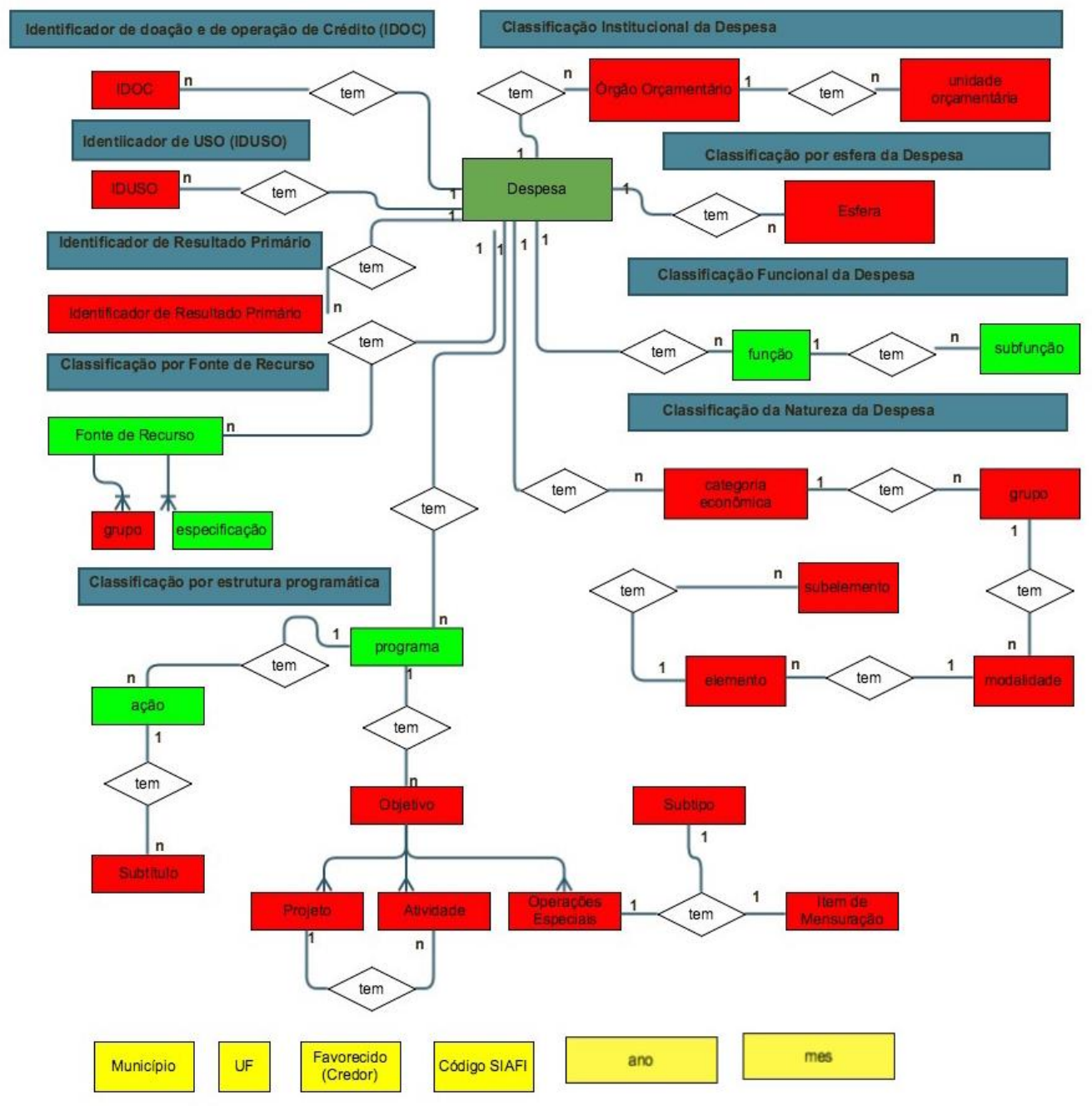

Fonte: José Rodolfo Beluzo, 2015.

Para os datasets de "pescador artesanal" foi realizado a intersecção do modelo conceitual representado na Figura 30. Apenas a classificação funcional e programática está em consonância com o Decreto 7.158 (Brasil, 2010). 
Figura 30 - modelo conceitual: Intersecção de Programas Sociais - Pescador Artesanal Governo Federal com modelo conceitual de despesas de acordo com o MCASP 2014

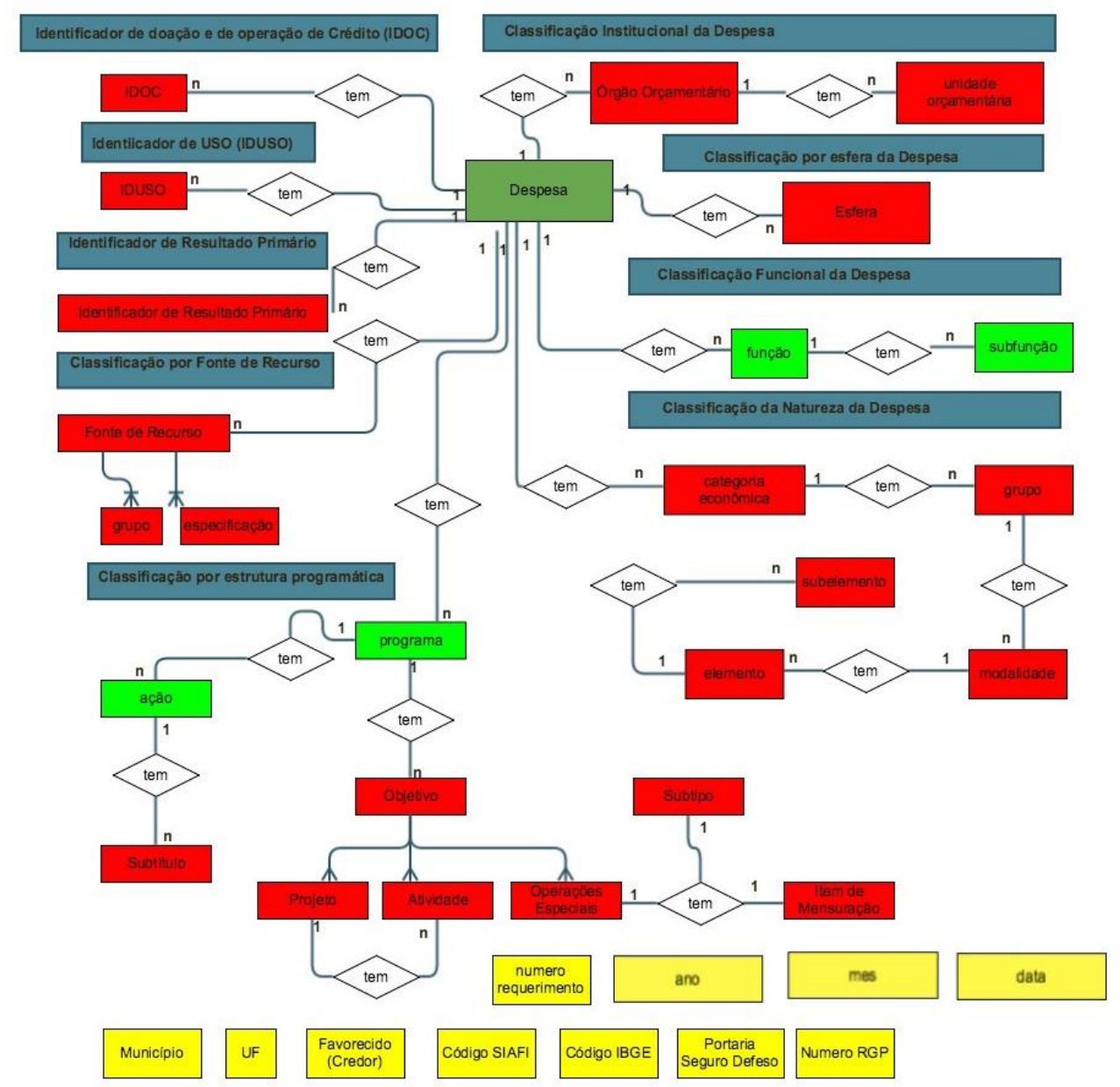

Fonte: José Rodolfo Beluzo, 2015.

Para criar o esquema lógico das despesas do governo federal adotou-se a estratégia de unir todos os campos encontrados em todos os datasets deste grupo. A figura 31 define a união de todos os elementos disponibilizados, interseccionando-se com o esquema conceitual das despesas. Para os tipos de classificação que são utilizados em um dataset e não são utilizados em outro, neste segundo será utilizado o domínio de valor "informação não disponibilizada". Este esquema representa o data mart dos dados do governo federal no sistema principal. A partir dele é possível obter informações multidimensionais a respeito dos valores das despesas do governo federal. 
Figura 31 - esquema lógico: união das intersecções dos datasets do governo Federal - Star Schema

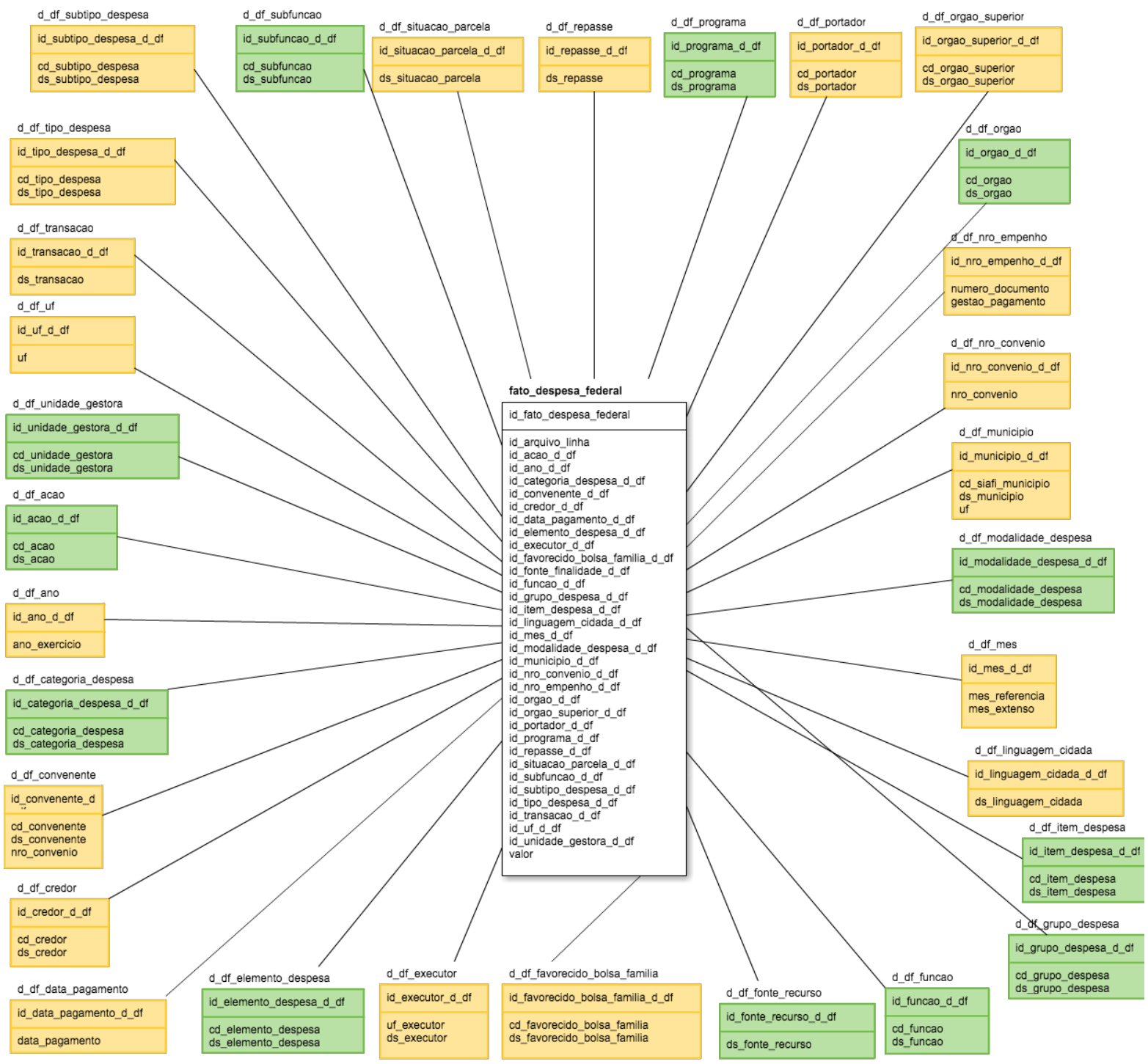

Fonte: José Rodolfo Beluzo, 2015.

Para criar os esquemas de dados do Governo do Estado de São Paulo e dos municípios do Estado de São Paulo foi adotado a mesma metodologia, porém nestes as informações constaram em apenas um modelo de dataset, tornando o processo de padronização e integração destes entes mais simples.

A figura 32 representa a intersecção do modelo conceitual da classificação das despesas baseado no MCASP com os datasets do governo do Estado de São Paulo. Todas as classificações mínimas exigidas pelo Decreto 7.158 (Brasil, 2010) foram atendidas. 
Figura 32 - Modelo conceitual: Intersecção Governo Estado de São Paulo com modelo conceitual de despesas de acordo com o MCASP 2014

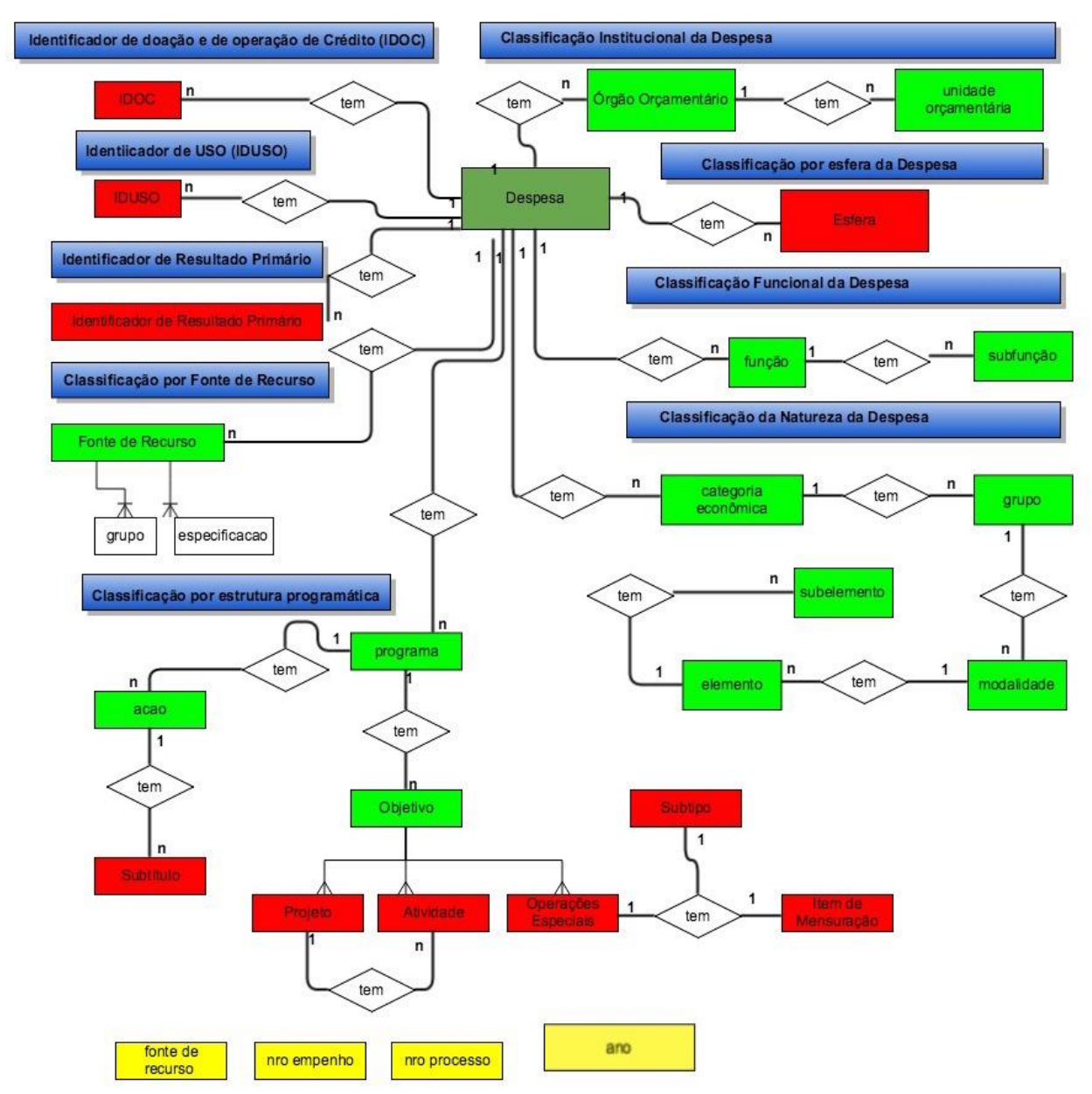

Fonte: José Rodolfo Beluzo, 2015.

A figura 33 representa a intersecção do modelo conceitual da classificação das despesas baseado no MCASP das com os datasets dos municípios do governo do Estado de São Paulo, exceto a capital. Todas as classificações mínimas exigidas pelo Decreto 7.158 (Brasil, 2010) foram atendidas. 
Figura 33 - modelo conceitual: Intersecção municípios do Estado de São Paulo (exceto a capital São Paulo) com modelo conceitual de despesas de acordo com o MCASP 2014

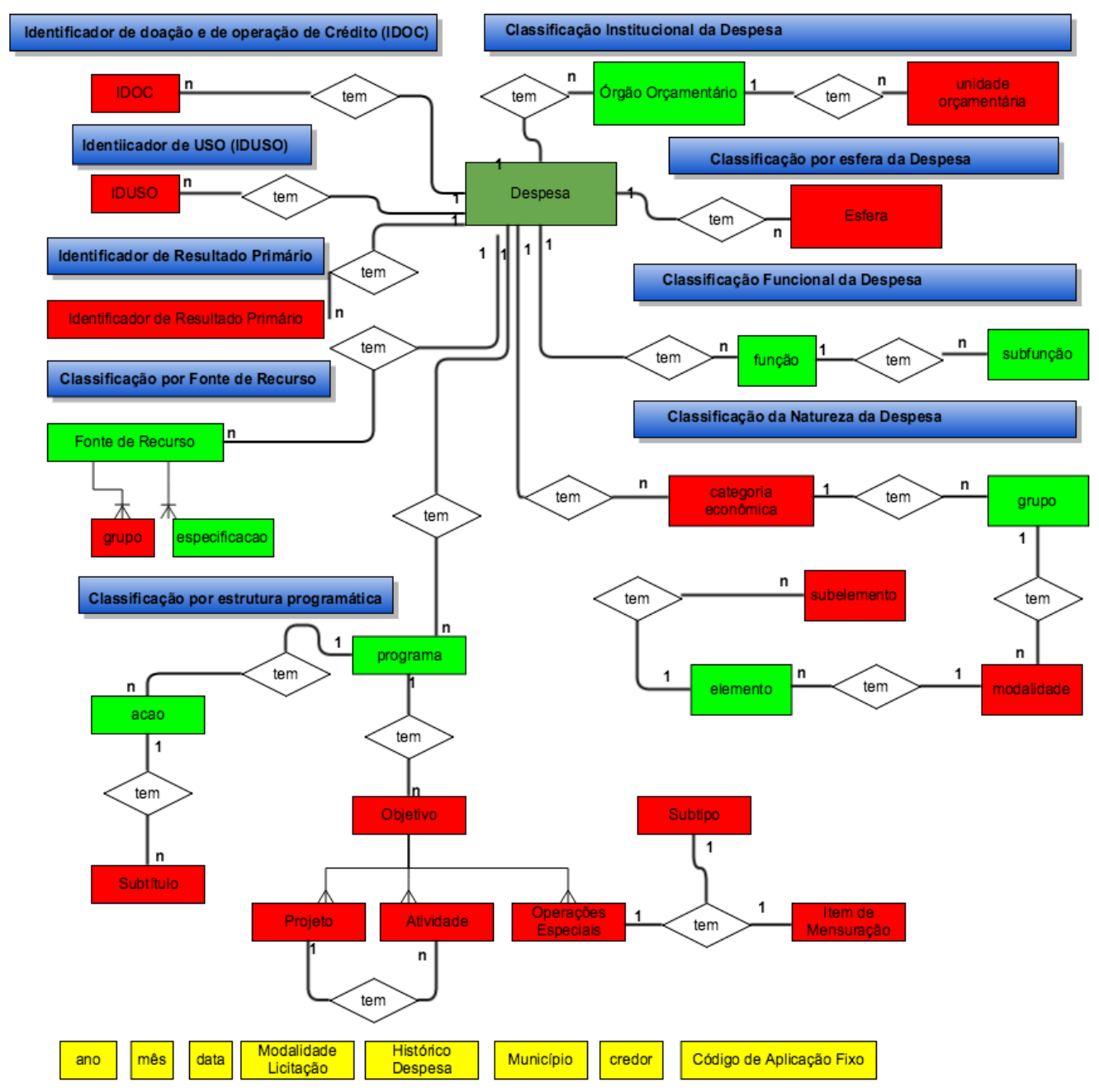

Fonte: José Rodolfo Beluzo, 2015.

A figura 34 representa a intersecção do modelo conceitual da classificação das despesas baseado no MCASP com os datasets do município de São Paulo. O município de São Paulo possui seu próprio tribunal de contas. Por isso o fato deste não estar representado no modelo da figura 32. Todas as classificações mínimas exigidas pelo Decreto 7.158 (Brasil, 2010) foram atendidas. 
Figura 34 - Modelo conceitual: Intersecção município de São Paulo com modelo conceitual de despesas de acordo com o MCASP 2014

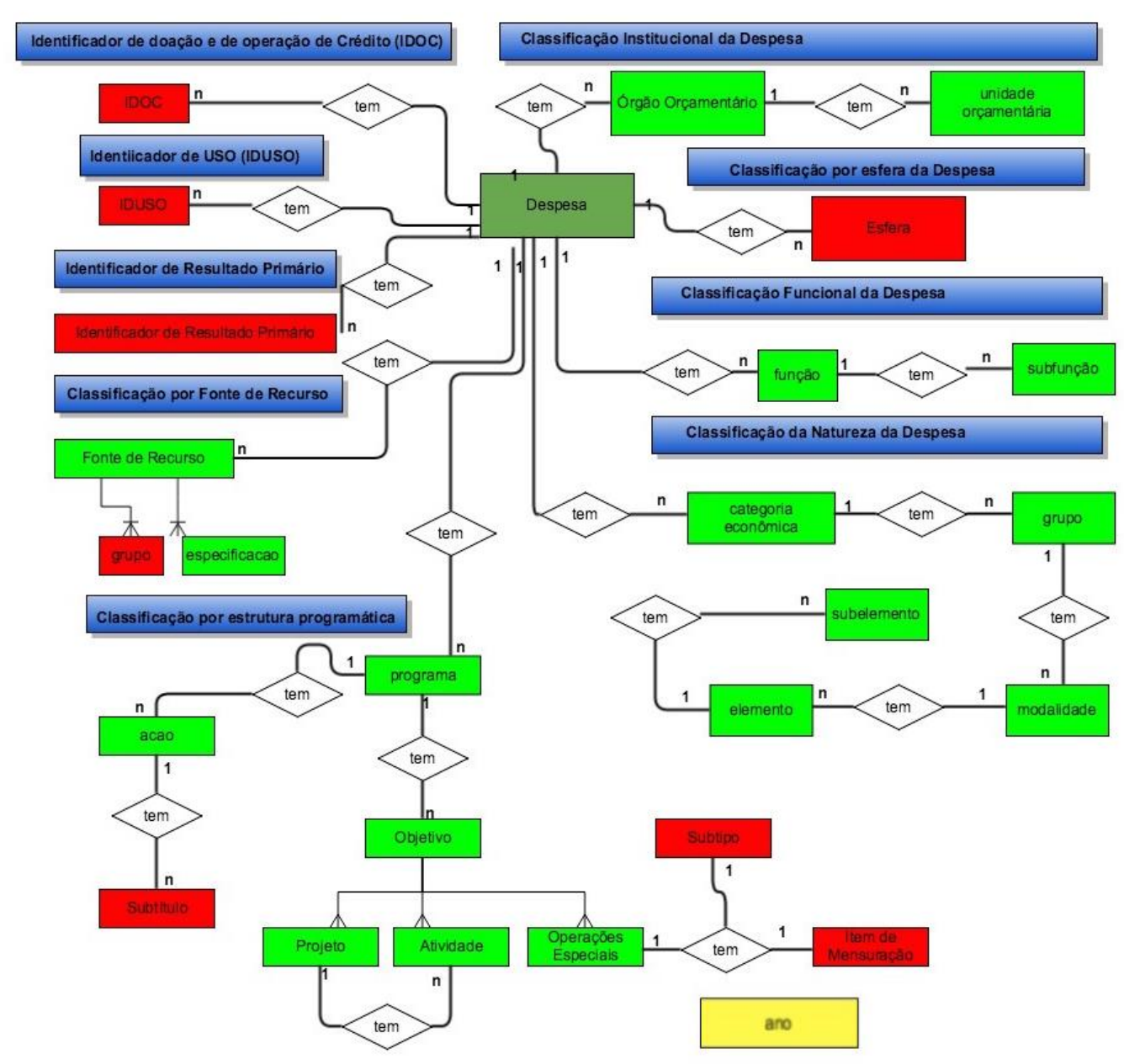

Fonte: José Rodolfo Beluzo, 2015.

A figura 35 ilustra o esquema lógico definido para os dados das despesas do governo do estado de São Paulo baseado nas intersecções observadas na figura 32. Este esquema representa um data mart no sistema principal. A partir dele é possível obter informações multidimensionais a respeito dos valores das despesas realizadas pelo governo do estado de São Paulo. 
Figura 35 - Esquema lógico: Governo do Estado de São Paulo - Star Schema

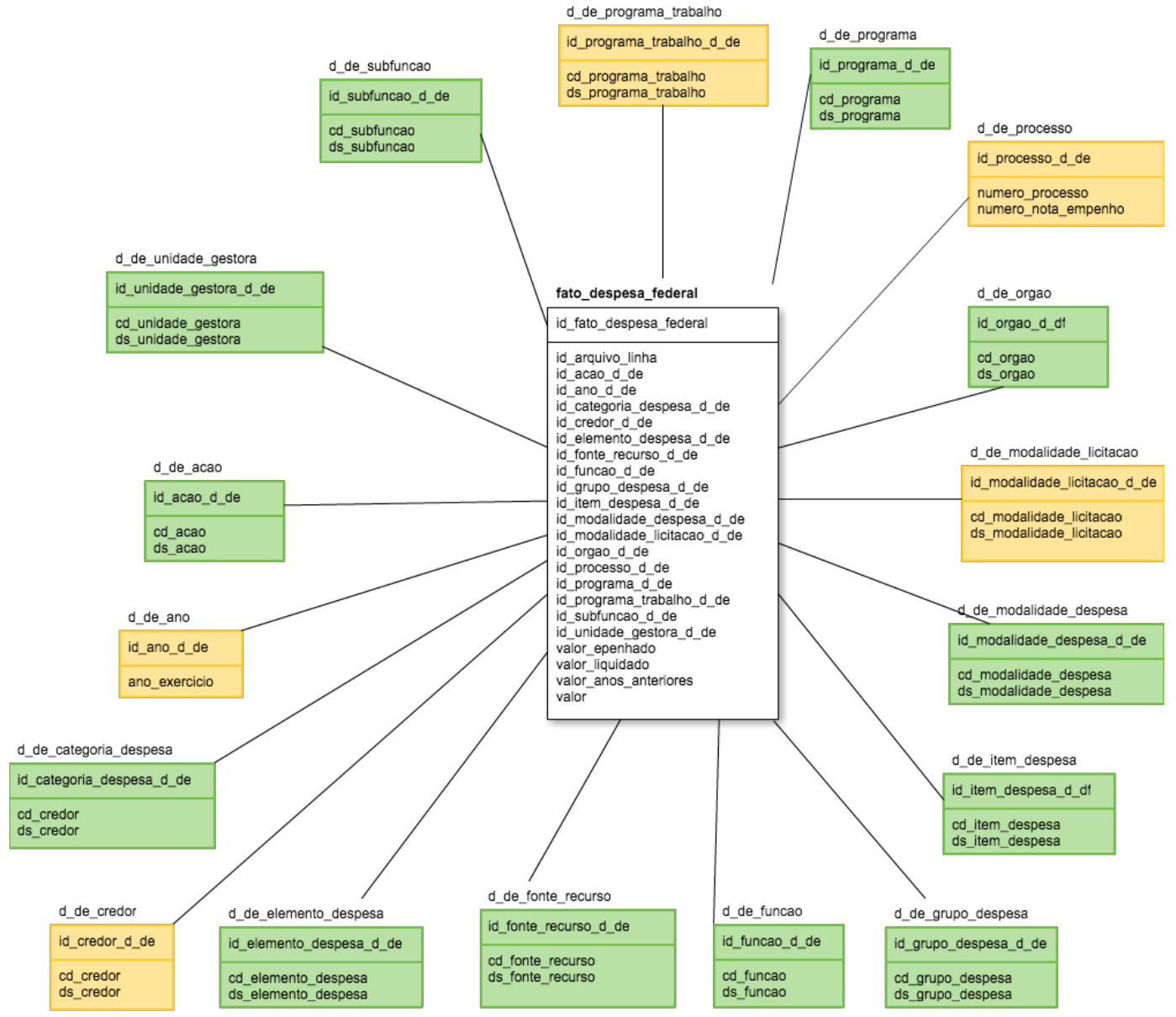

Fonte: José Rodolfo Beluzo, 2015.

A figura 36 ilustra o esquema lógico definido para os dados das despesas dos municípios do estado de São Paulo (exceto a capital) baseado nas intersecções observadas na figura 33. Este esquema representa um data mart no sistema principal. A partir dele é possível obter informações multidimensionais a respeito dos valores das despesas realizadas por cada município do estado de São Paulo (exceto a capital). 
Figura 36 - Esquema lógico: municípios do Estado de São Paulo (exceto a capital São Paulo) - Star Schema

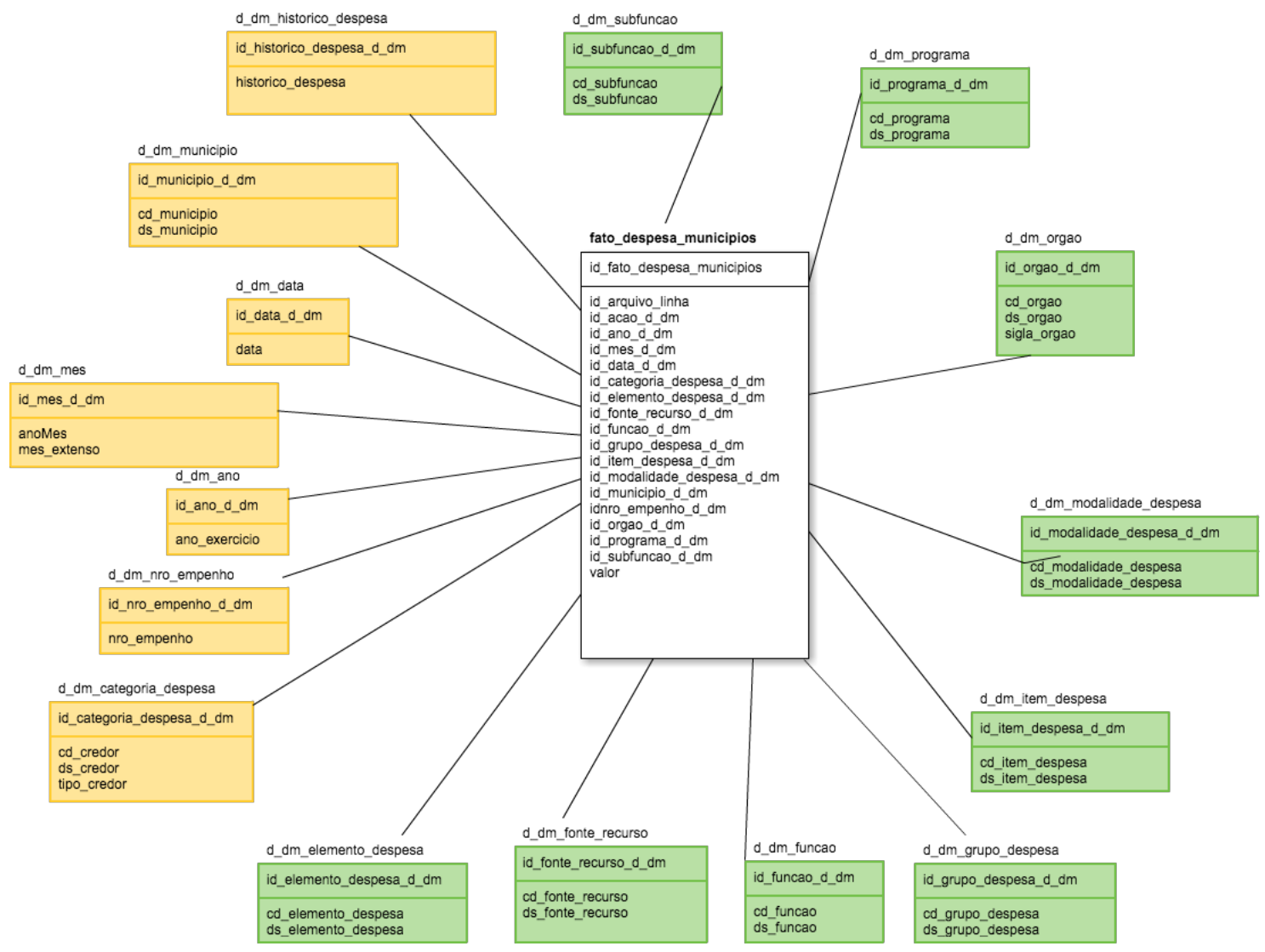

Fonte: José Rodolfo Beluzo, 2015.

A figura 37 ilustra o esquema lógico definido para os dados das despesas do município de São Paulo (capital) baseado nas intersecções observadas na figura 34figura 33. Este esquema representa um data mart no sistema principal. A partir dele é possível obter informações multidimensionais a respeito dos valores das despesas realizadas pelo município de São Paulo (capital). 
Figura 37 - Esquema Lógico: Município de São Paulo (Capital) - Star Schema

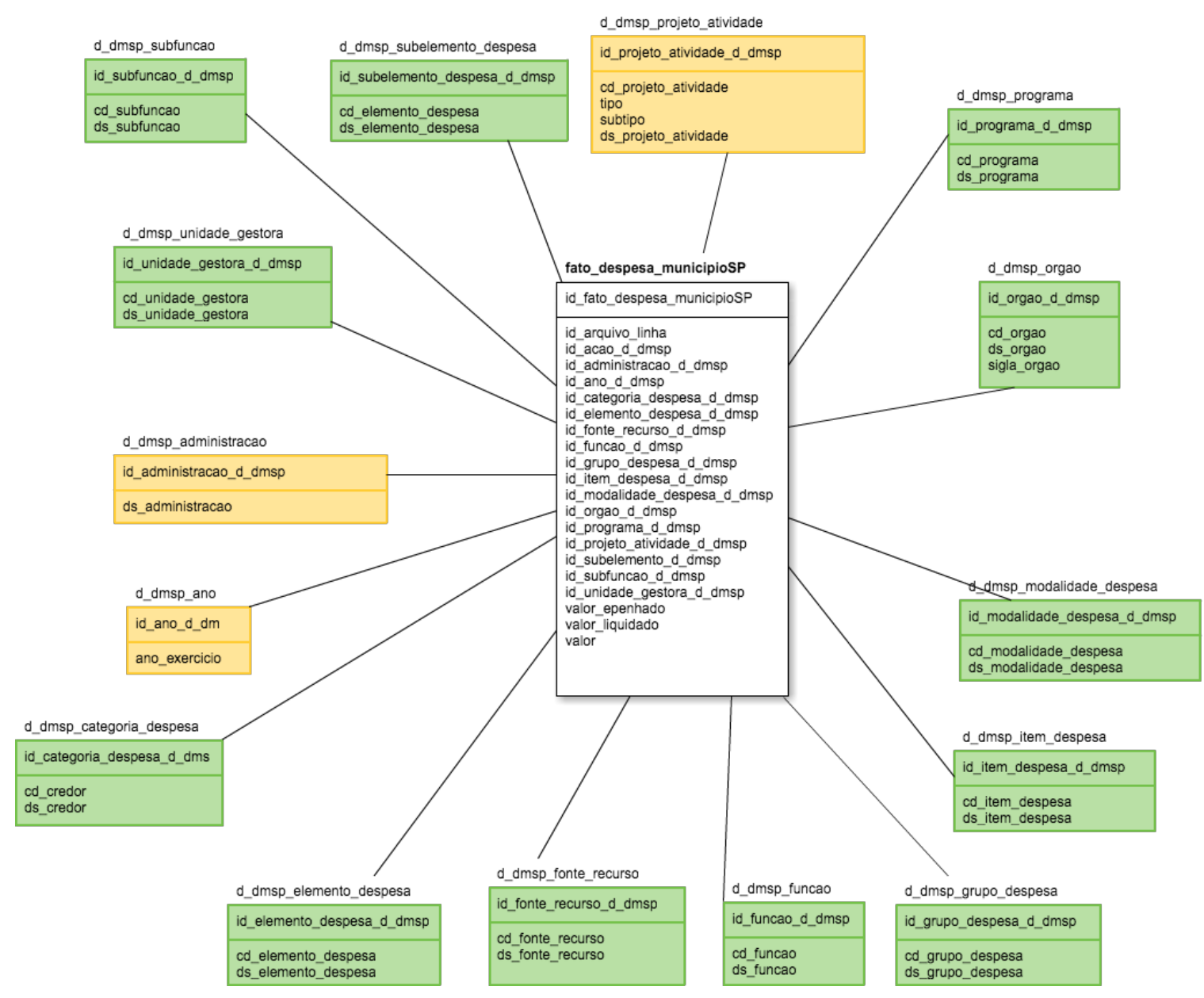

Fonte: José Rodolfo Beluzo, 2015.

Perceba que alguns conjuntos de dados não possuem informações descritas explicitamente, porém é possível extrair as informações por decomposição de outras. Um exemplo é a figura 33 que demonstra que o conjunto de dados disponibiliza pela classificação por "Natureza da Despesa" apenas as informações "grupo de despesa" e "elemento de despesa". Porém, a partir destas duas informações, é possível restaurar as informações "categoria econômica" e "modalidade de aplicação" (já acrescentados no seu respectivo esquema lógico na figura 36), visto que esta classificação é criada baseada em uma estrutura de dados em árvore, onde é possível se obter a informação anterior pela hierarquia. Assim, sabendo-se qual o "elemento da despesa", é possível descobrir qual a "modalidade", o "grupo de natureza" e a "categoria econômica".

Baseado nos esquemas lógicos demonstrados nas figuras acima referentes as despesas, foram criados o modelo conceitual e o esquema lógico de integração de despesas orçamentárias 
nas três esferas governamentais, realizando a intersecção das informações comuns que são encontradas em todos os conjuntos.

A figura 38 se refere ao modelo conceitual da intersecção dos modelos da figura 31, figura 32, figura 33 e figura 34 ilustrando o que há em comum entre os três entes, demonstrando quais informações podem ser obtidas diretamente para os três entes e em qual granularidade isto será possível. Observa-se que a granularidade da dimensão temporal da classificação é apenas anual.

Figura 38 - Modelo conceitual: Intersecção das três esferas governamentais (Governo Federal, do Estado de São Paulo e municípios do Estado de São Paulo, incluindo a capital) com o MCASP 2014

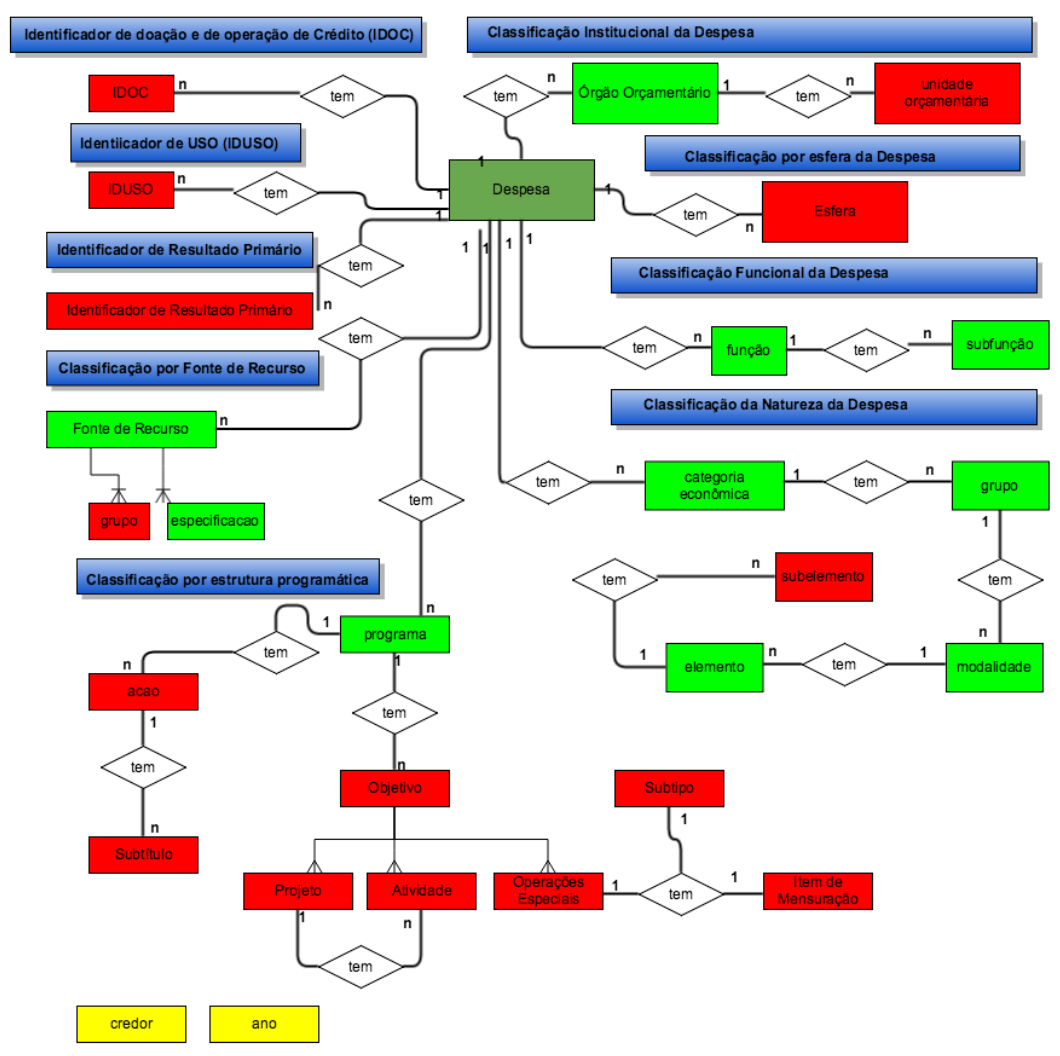

Fonte: José Rodolfo Beluzo, 2015.

A figura 39 se refere ao esquema lógico da intersecção dos esquemas da figura 31, figura 35, figura 36 e figura 37. Este esquema representa o sistema principal de dados das despesas, construído a partir dos data marts de cada ente federativo. 
Figura 39 - Esquema lógico: Intersecção das três esferas governamentais (Governo Federal, do Estado de São Paulo e municípios do Estado de São Paulo, incluindo a capital) com o

MCASP 2014 - Star Schema

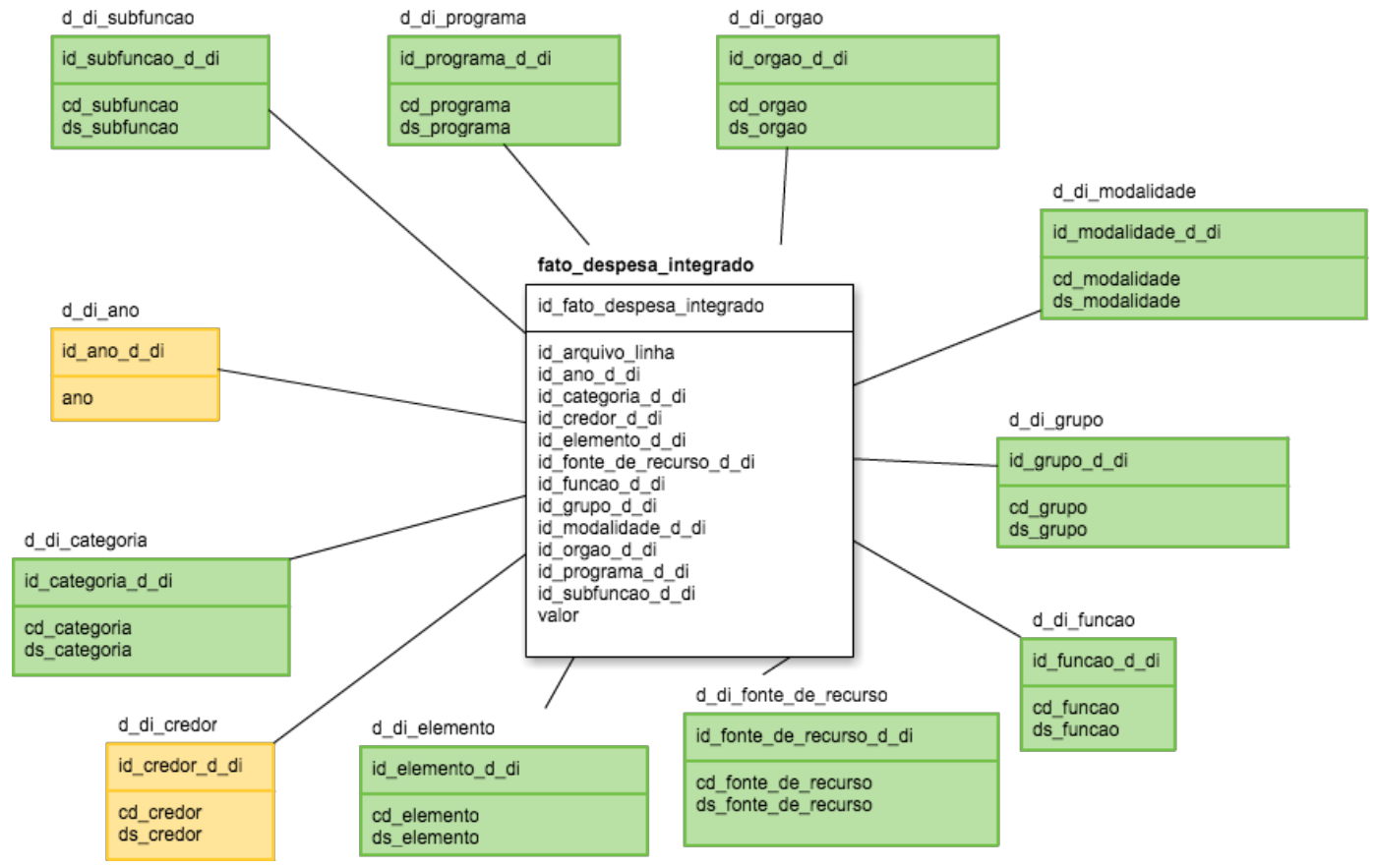

Fonte: José Rodolfo Beluzo, 2015.

Esta fase irá servir de base para o processo ETL - próxima etapa do desenvolvimento que será discutido na Subseção 5.2.

\subsection{Processo ETL}

Como foi visto anteriormente na Seção 4.4, esta etapa irá demonstrar o processo de extração dos dados dos portais (Seção 5.2.1); as transformações necessárias e úteis para o novo sistema (Seção 5.2.2); e o carregamento (Seção 5.2.3) dos dados nos esquemas lógicos definidos anteriormente, assim como nos esquemas integrados.

\subsubsection{Extração}

A $1^{\mathrm{a}}$ etapa do processo ETL consiste em extrair os dados dos portais de transparência. Para tal foi confeccionado um artefato de software denominado "Extrator" desenvolvido na linguagem de programação de scripts PHP. Como não há uma padronização no serviço de disponibilização dos dados (nem no caminho de publicação dos dados, nem no formato do 
arquivo) foi criado uma sub ferramenta extratora para cada ente federativo (todas acionadas pelo script "extrator.php").

Os arquivos extraídos nesta etapa estão disponíveis no formato CSV compactados no padrão de compactação ZIP para os dados do governo federal, estado de São Paulo e Municípios de São Paulo. Os arquivos do município de São Paulo estão disponíveis no formato "XLS". Este processo realiza o download automático dos arquivos (.ZIP e .XLS) em um diretório do sistema IDEO separados pelos respectivos nomes dos entes federativos ("Federal", "Estado", "Municipios" e "MunicipioSP") em subpastas do respectivo elemento da execução orçamentária (“despesas" e "receitas"). Durante o processo de extração os arquivos são descompactados para o formato original (CSV) ou são transformados do formato XLS para CSV (no caso dos arquivos do município de São Paulo). Cópias dos arquivos originais serão mantidas no sistema para futura auditoria e/ou verificação e detecção de correção de dados que já foram carregados no sistema.

Ao término de todos os processos, o script gera um arquivo “arquivosNaoDisponiveisParaDownloadNoPortal.txt" localizado em cada subpasta (“despesas" e "receitas") de cada ente federativo, que relata os arquivos em que os links existem no portal, porém não existe o arquivo para download (link quebrado), ou que por algum motivo de conexão tenha ocorrido falha na transferência do arquivo.

\subsubsection{Transformação}

A $2^{\mathrm{a}}$ etapa consiste em realizar uma transformação nos arquivos extraídos, de tal forma que estes sejam carregados de forma correta na $3^{\mathrm{a}}$ etapa. As transformações podem estar relacionadas à padronização do dado inserido; acréscimo de codificação específica para dados previamente codificados pelo MCASP 2014 e que o dataset não disponibiliza; acréscimo de elementos de classificação que não estão disponibilizados no dataset, porém podem ser obtidos através de outros elementos (vide exemplo do "elemento de despesa", que a partir de sua codificação é possível determinar a modalidade, categoria e grupo de despesa); e "datadeduplication" - processo de definição de um único dado que representará os vários dados com mesmo significado em uma dimensão.

A etapa de transformação foi dividida em duas subpartes: totalmente automatizada (Seção 5.2.2.1) e parcialmente automatizada (Seção 5.2.2.2). A etapa totalmente automatizada realiza as transformações sem necessidade de um usuário no sistema. A segunda etapa parcialmente automatizada - necessita da intervenção de um usuário humano com 
conhecimentos prévios sobre orçamento público e/ou sobre a estrutura do arquivo carregado. $\mathrm{O}$ sistema irá apontar a possível necessidade de transformação e o usuário irá confirmar se a correção a ser realizada é ou não correta.

\subsubsection{Transformação totalmente automatizada}

Para cada grupo de datasets referentes a cada ente federativo (federal, estadual e municipais) foi aplicado um processo de transformação específico. Existem transformações que foram padronizadas para todos os grupos. A seguir são descritas as transformações comuns e as transformações realizadas em cada ente federativo:

\subsection{Transformações comuns a todos os entes federativos}

Houve transformação nos cabeçalhos de dados para facilitar o processo de carregamento dos dados, padronizando as nomenclaturas de cada campo em letras minúsculas; campos de código com o prefixo "cd_" e campos descritivos com o prefixo "ds_" e troca de espaços em branco pelo caractere “_”.

Outra transformação realizada foi com relação a acentuação. A fim de simplificar o armazenamento dos dados (com relação a codificação dos mesmos) e padronizar aqueles dados que não disponibilizavam dados acentuados, foi adotado a alteração no domínio dos dados para dados não acentuados. Todos os dados que possuem algum tipo de acentuação da língua portuguesa foram transformados para o equivalente sem acentuação. Este processo foi aplicado para todos os grupos de dados utilizados no sistema.

Alguns datasets utilizaram o caractere "TAB" como separador de dados. Foi realizado a conversão deste caractere para o caractere específico para arquivos do tipo "CSV" - o caractere “;" - facilitando a leitura dos dados por funções pré-definidas da linguagem de programação utilizada para dados no formato "CSV".

\subsection{Transformações específicas para o governo federal - receitas}

Para os dados de receitas do governo federal foi realizado o acréscimo de codificação de campos não codificados nos datasets, porém possíveis de serem reaplicados através de tabelas de codificação disponibilizada no MCASP 2014. Os campos que sofreram a aplicação de código foram: categoria econômica, origem e espécie. 


\subsection{Governo Federal - Despesas}

Para os dados de despesas do governo federal foi aplicado a correção citada no processo de definição do esquema lógico na figura 31, pois como realizou-se a união dos campos de despesas de diferentes tipos (gastos diretos, transferências e programas sociais) em um esquema único, alguns campos de dados das classificações não precisam ou não devem ser publicados para determinados gastos. Assim, adotou-se o domínio de valor "informação não disponibilizada" para as dimensões que não possuem influencia em um determinado fato. Esta etapa de transformação é uma exceção, pois ela ocorre após a carga de dados. Os dados da tabela de fatos de despesas do governo federal que estão com valor NULL é alterado para a codificação de identificação "-1" - código do identificador do elemento "informação não disponibilizada" para todas as dimensões da tabela de fato de despesas do governo federal.

\subsection{Governo do Estado de São Paulo - receitas e despesas}

Não foi aplicado transformações específicas para estes datasets, pois os mesmos estão dentro dos critérios aceitos de dados abertos governamentais com relação ao esquema definido no projeto.

\subsection{Municípios do Estado de São Paulo - receitas}

Os dados das receitas dos municípios do estado de São Paulo estão aglutinados, onde o código e a descrição dos campos se encontram no mesmo campo. Foi realizado o desmembramento destes elementos para os campos categoria, subcategoria, fonte, rubrica, alínea, subalínea, código de aplicação fixo, código de aplicação variável. Para o campo “município" foi aplicado a identificação de código do município junto ao rais ${ }^{11}$.

\subsection{Municípios do Estado de São Paulo - despesas}

Os dados das despesas dos municípios do estado de São Paulo estão com códigos faltantes para vários campos. Foi aplicado a colocação das codificações para estes campos

\footnotetext{
${ }^{11} \mathrm{http}: / /$ www.rais.gov.br/municipio.asp
} 
(funções e subfunções) baseadas no MCASP 2014 e na RAIS (municípios). Também houve o desmembramento de campos aglutinados (código de aplicação fixo e credor) e a reconstrução dos dados categoria econômica e modalidade a partir de grupo de despesa e elemento de despesas, visto que um grupo de despesa é um subgrupo de categoria econômica e elemento de despesa é subgrupo de modalidade da despesa.

\subsection{Município de São Paulo - despesas}

Os dados referentes ao município de São Paulo estão incompletos nos anos anteriores a 2013. Para estes casos, os campos que foram encontrados a partir de 2013 são reconstruídos nos datasets como “informação não disponível”.

\subsubsection{Transformação parcialmente automatizada}

A transformação parcialmente automatizada acontece para a correção de valores errados, falta de valores ou falha de formatação dos dados no arquivo original. Esta etapa necessita da intervenção de um usuário que entenda o significado de cada campo de dado a ser analisado pela ferramenta, pois este irá tomar a decisão de modificar ou não o dado encontrado com possível erro (ou falta de valor) ou identificar o ponto de correção de um determinado dataset com erro de formatação nos dados.

A primeira transformação parcialmente automatizada diz respeito a falha de formatação dos dados no arquivo original. Em alguns arquivos dos datasets, existem linhas de dados que estão com campos de dados faltantes, o que ocasiona um deslocamento de todos os elementos posteriores ao dado faltante para as colunas da esquerda, gerando inconsistência na informação para este fato. Este tipo de erro foi encontrado nos datasets do governo federal para as despesas em "gastos diretos - pagamentos", "transferências - pagamentos" e "gastos diretos - diárias". Para realizar esta transformação foi elaborado o seguinte algoritmo: 
Algoritmo 1 - Transformação parcialmente automatizada - correção de deslocamento de dados no dataset

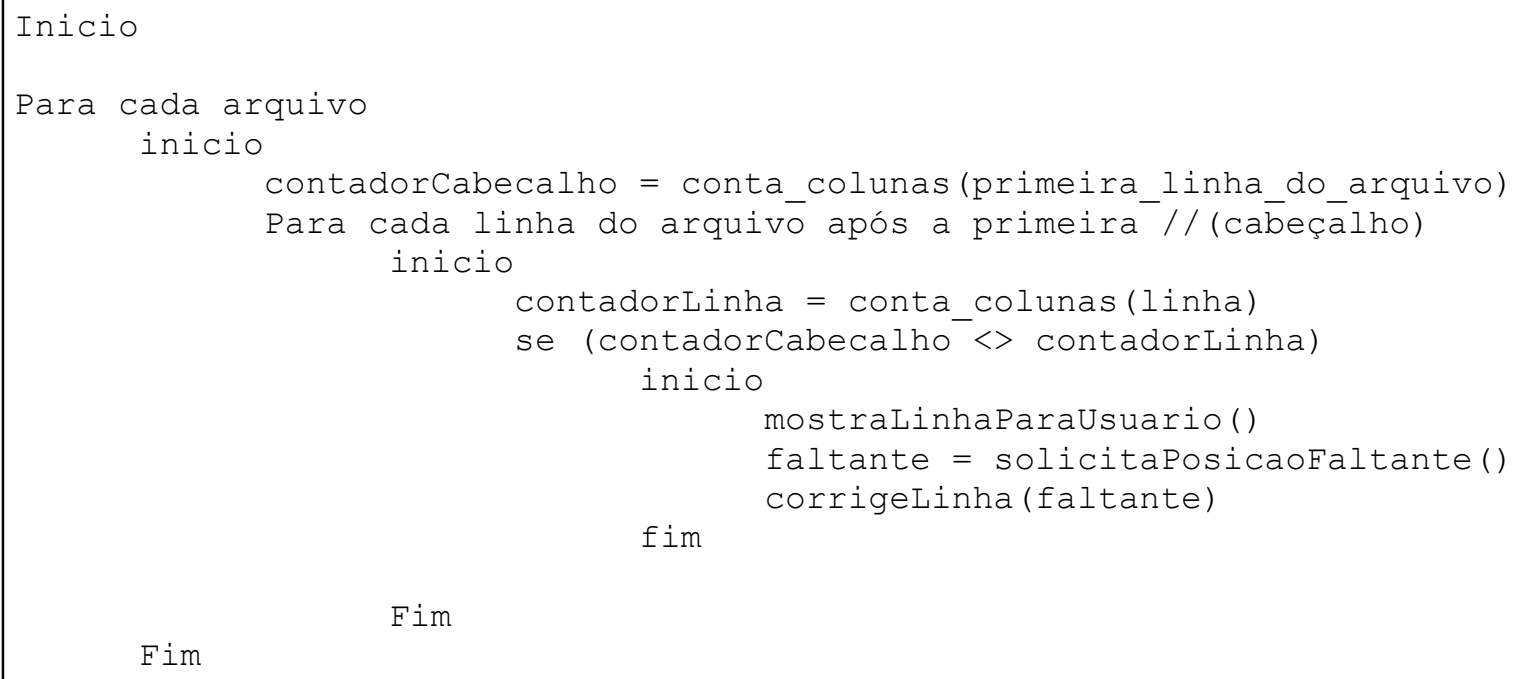

Fonte: José Rodolfo Beluzo, 2015

A segunda transformação foi criada para o correto carregamento do esquema integrado. As tabelas de dimensões de cada esfera governamental em algumas situações possuem o mesmo domínio de valor, ou subdomínios iguais. Para estas situações foi criado uma ferramenta que disponibiliza os possíveis valores iguais, e o usuário especialista identifica em um formulário quais são os elementos que se combinam e a partir desta seleção o sistema cria uma única instância para este elemento na tabela de dimensão integrada.

Outra transformação parcialmente automatizada é com relação a elementos duplicados. Um processo verifica se elementos semelhantes existem, e a partir desta seleção o usuário especialista informa se o elemento é uma duplicação ou se realmente são elementos distintos. Por exemplo: uma instância da dimensão "credor" pode ter um identificador de CNPJ com nome "João Domingues M.E” e outra instância sem o campo de identificação de CNPJ com o nome “João Dom. M.E”. Neste caso o usuário especialista pode determinar que ambas as instâncias de elementos se referem à mesma instância, removendo a duplicação. 


\subsubsection{Carregamento}

A etapa de carregamento dos dados no sistema é composta pela fase de construção dos esquemas físicos dos dados e carregamento destes esquemas a partir dos dados transformados na etapa anterior.

Os esquemas físicos foram construídos utilizando-se da ferramenta de integração de dados PDI (Pentaho Data Integration) do Sistema Pentaho. A ferramenta identifica a partir dos conjuntos de dados (exemplo - "despesasMunicipiosCSV" na figura 40) utilizados qual o tipo de dado de cada item das dimensões a partir de um desenho de fluxo de dados, assim como também já define a tabela de fato com os valores de medidas (no caso específico deste trabalho os valores de receitas e despesas da execução orçamentária) e os respectivos identificadores de dimensões que geram cada fato. A Figura 40 demonstra o desenho do fluxo de dados para o caso dos municípios de São Paulo na execução orçamentária das despesas. Para todos os datasets utilizados no Data Warehouse foi seguido a mesma metodologia.

Figura 40 - exemplo de criação de fluxo de dados para criação dos esquemas físicos das tabelas dimensões e tabela fato para as despesas dos municípios do estado de São Paulo através da ferramenta Pentaho Data Integration

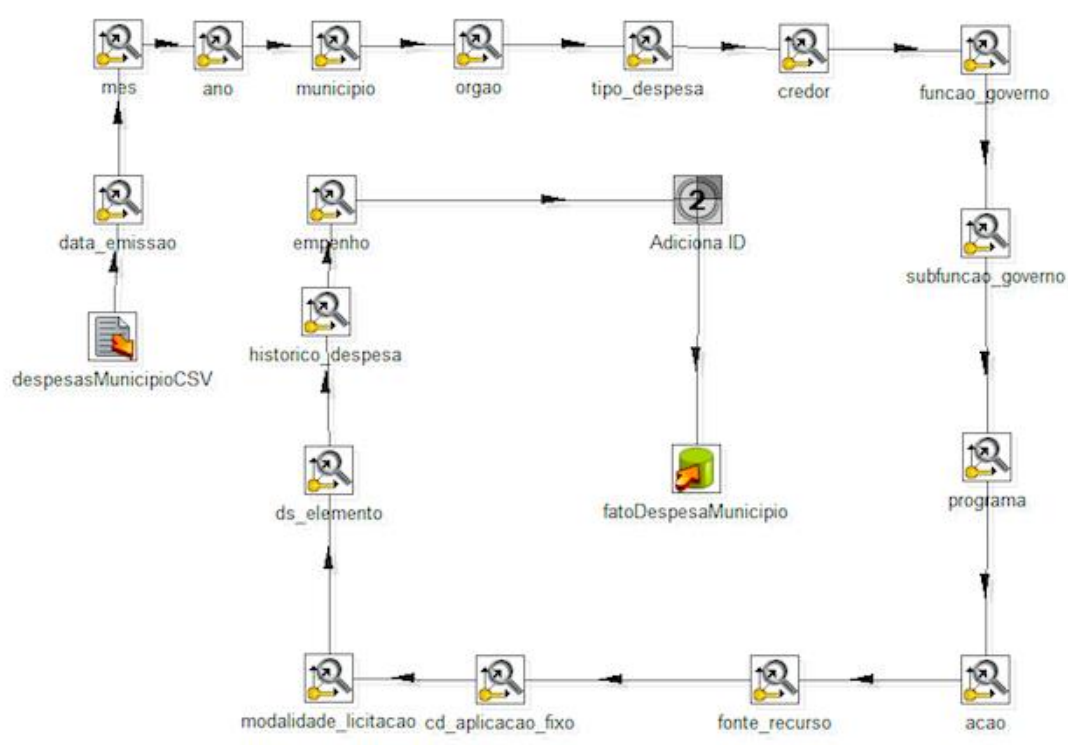

Fonte: José Rodolfo Beluzo, 2015.

Para o processo de carregamento optou-se por criar um algoritmo específico pois os testes realizados com a ferramenta de carregamento de dados do PDI, ao perder a conexão com 
o servidor, dificultava o processo de restauração a partir do ponto em que o carregamento havia sido interrompido. Desta forma, optou-se por criar um algoritmo próprio para o processo de carregamento dos dados para melhorar o controle sobre a carga de dados. $\mathrm{O}$ algoritmo 2 define os passos realizados para o processo de carregamento.

Algoritmo 2 - carregamento dos dados nos esquemas lógicos do Data Warehouse

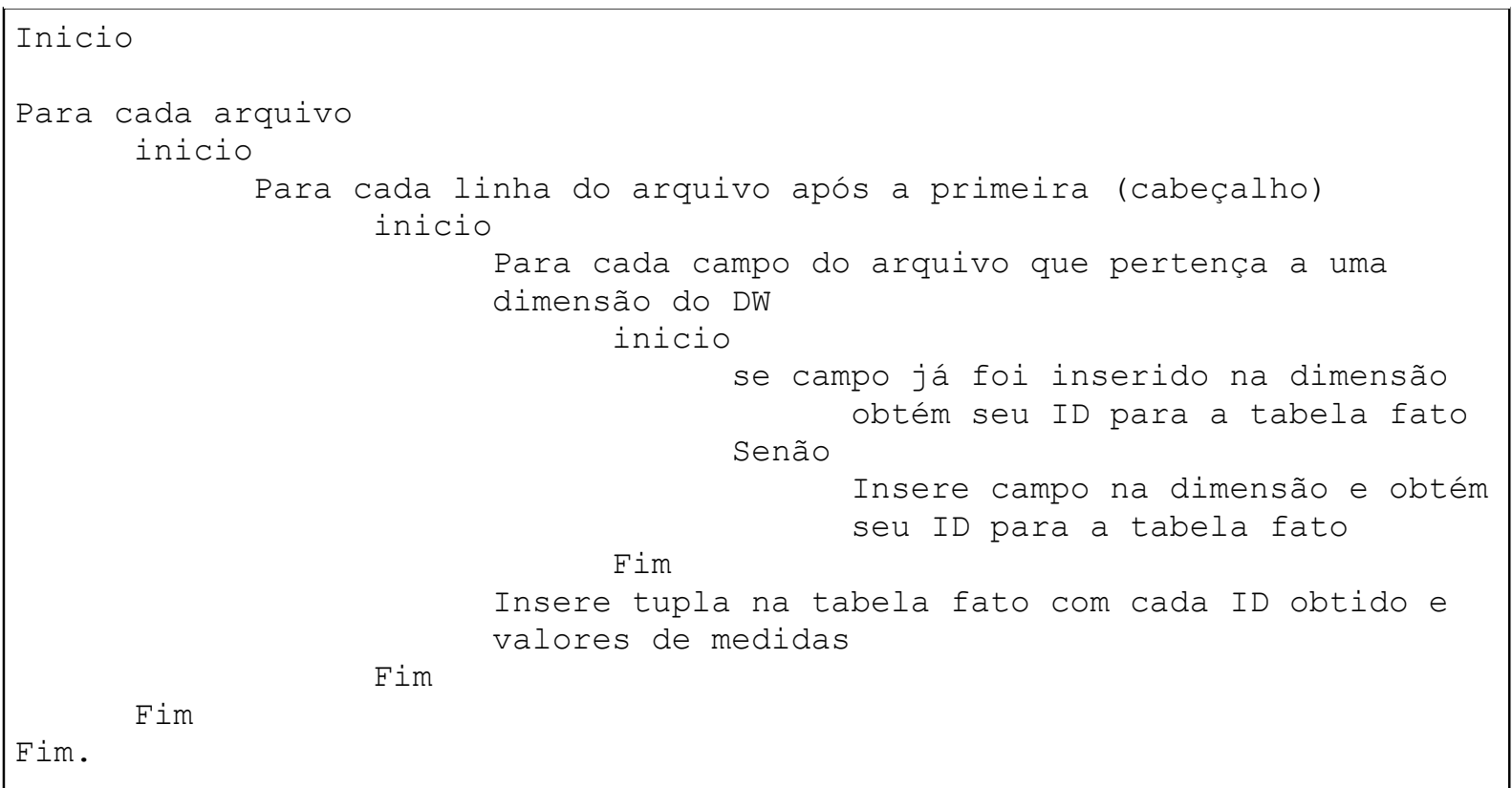

Fonte: José Rodolfo Beluzo, 2015

Após realizado o carregamento dos dados o objetivo principal do projeto foi atingido. A próxima etapa (Seção 5.3) consiste em visualizar os dados de forma analítica para conseguir realizar a validação (Seção 5.4) dos processos realizados até esta etapa.

\subsection{Visualização de dados}

A etapa de visualização de dados do Data Warehouse consiste em uma ferramenta que possibilite gerar os relatórios de acordo com a necessidade do usuário do sistema. O "Pentaho Business Analytics" é uma ferramenta (software) que possui diversos plugins aos quais realizam este processo de visualização de dados em Data Warehouse conhecido como OLAP. Para a realização das operações OLAP foi utilizado o plugin "Saiku Analytics", fornecido de forma gratuita pelos desenvolvedores da comunidade Pentaho. A primeira etapa da visualização é a 
definição dos cubos de dados Data Warehouse. A figura 41 mostra as três etapas de criação do cubo Data Warehouse no software "Pentaho Business Analytics".

Figura 41 - assistente de criação de fonte de dados do "Pentaho Business Analytics" exemplo de criação do cubo dos dados das receitas dos municípios do estado de São Paulo
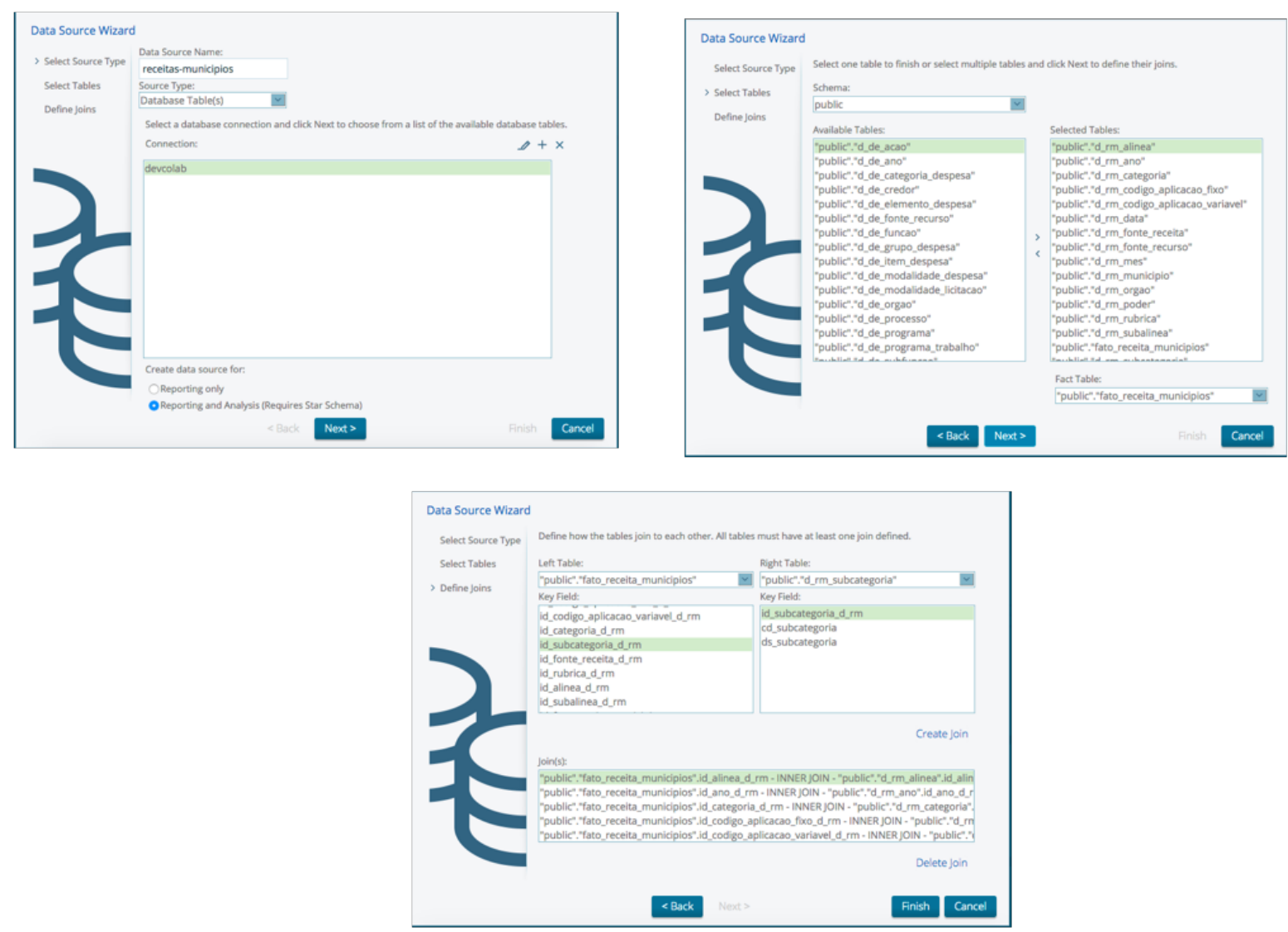

Fonte: José Rodolfo Beluzo, 2015.

A segunda etapa é a utilização da ferramenta OLAP propriamente dita para as consultas desejadas nos cubos de dados. A figura 42 mostra a tela inicial do plugin "Saiku Analytics" utilizado sobre o sistema "Pentaho Business Analytics". No quadrante esquerdo existe três opções: "Cubos", "Medidas" e "Dimensões". O elemento "Cubos" permite que o usuário selecione um cubo Data Warehouse para realizar operações OLAP. O elemento "Medidas" permite que o usuário escolha qual a medida será utilizada para o cálculo analítico. O elemento "Dimensões" permite que o usuário escolha quais as combinações de dimensões serão utilizadas. 
Figura 42 - Tela inicial da ferramenta Saiku Analytics

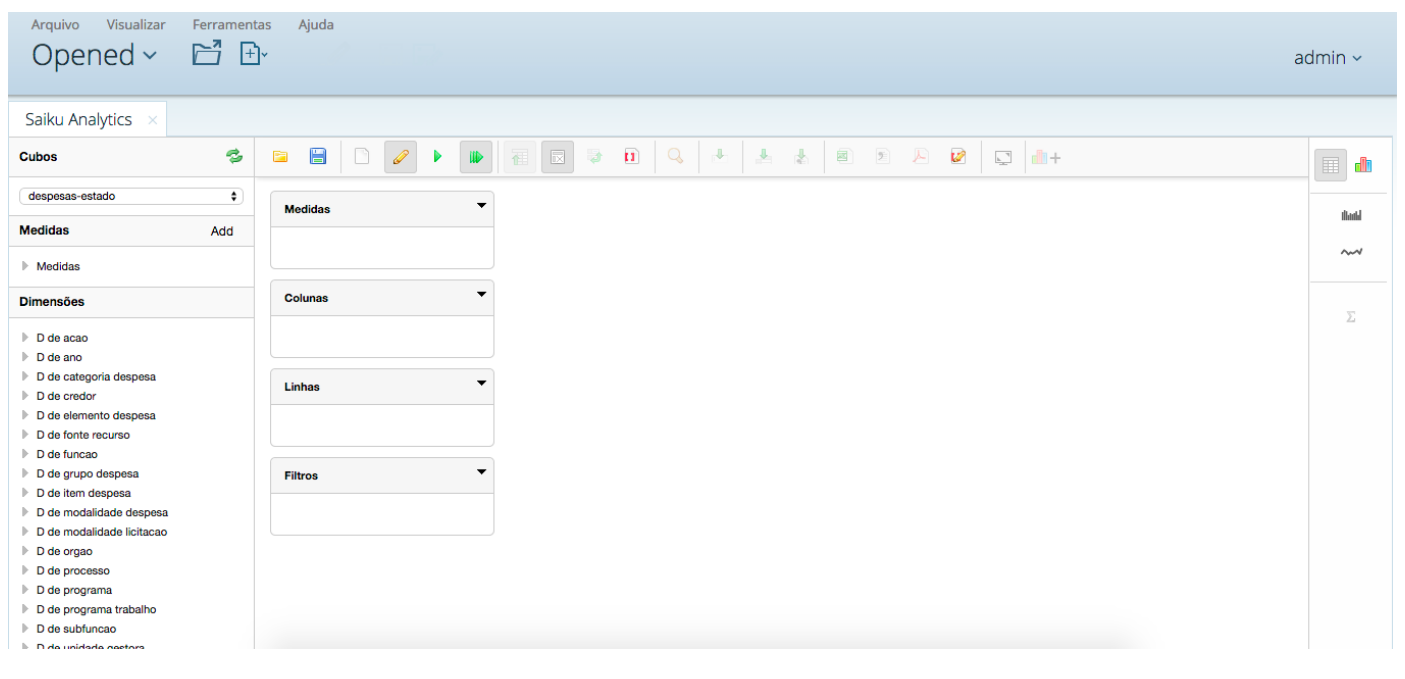

Fonte: José Rodolfo Beluzo, 2015.

A ferramenta possui o recurso "Drag-and-drop" que permite que o usuário clique para selecionar a dimensão desejada, arraste e solte sobre a posição que deseja que a dimensão apareça (linha ou coluna - caixas internas ao elemento central visualizador da ferramenta). No exemplo da figura 43 foi consultado o valor gasto na função educação pelo governo do estado de São Paulo para os anos de 2011 a 2014. Do lado esquerdo (a) encontra-se o resultado obtido por uma tabela de dados e do lado direito (b) o resultado obtido pela ferramenta de visualização dos dados em forma gráfica.

Figura 43 - Exemplo de consulta OLAP (a) Tabela; (b) Gráfico.

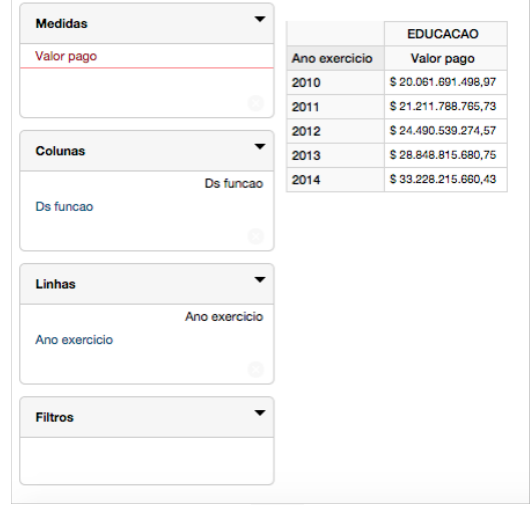

(a)

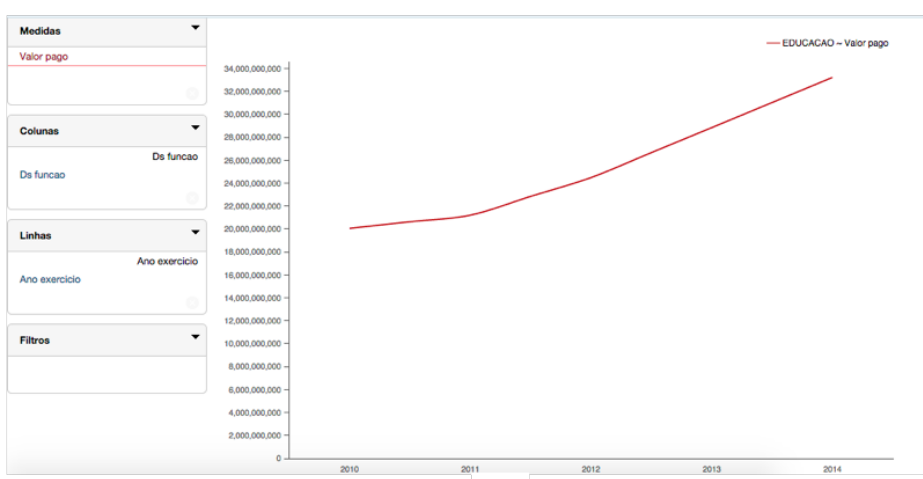

(b)

Fonte: José Rodolfo Beluzo, 2015. 
A ferramenta escolhida nesta etapa será utilizada na Seção 5.4 para o processo de validação dos dados do sistema integrador IDEO.

\subsection{Validação do sistema}

A validação do sistema se dá em três etapas. A primeira etapa (Seção 5.4.1) tem como objetivo validar se os dados carregados no sistema condizem com a realidade dos dados da fonte extraída.

A segunda etapa (Seção 5.4.2) tem como objetivo validar os dados através de fontes externas que que realizam o balanço orçamentário dos entes federativos estudados neste trabalho, através de informações consolidadas e compiladas do balanço orçamentário em um total de receitas e despesas.

A terceira etapa (Seção 5.4.3) tem como objetivo analisar se a ferramenta disponibilizada para as consultas OLAP está produzindo os resultados que condizem com a realidade orçamentária estudada por especialistas. Desta forma, um especialista em gestão de políticas públicas foi convidado a analisar alguns resultados previamente solicitados pelo mesmo.

\subsubsection{Validação de dados}

Para validar os dados foram utilizadas as ferramentas de consulta dos próprios portais de onde os dados foram extraídos ou utilizou-se os próprios datasets. Alguns portais possuem ferramentas de consulta livre e outros possuem relatórios gerais sobre gastos e receitas anuais. No caso de não haver uma ferramenta no próprio portal para avaliar a corretude do carregamento, o mesmo foi realizado de forma "manual", abrindo-se o dataset original em um software apropriado para o mesmo (neste caso como os datasets estão em formato ".csv" foi utilizado a ferramenta Microsoft Excel 2011) e solicitando o somatório da coluna específica do campo de dados "valor". Para os casos em que a quantidade de datasets totais foi inferior a 10 arquivos, foi realizado o processo de teste para todos os arquivos verificando-se a totalidade encontrada nos arquivos, com a totalidade encontrada no sistema IDEO; para os casos de mais de 10 arquivos foi adotado o método por amostragem, selecionando-se ao acaso amostras de arquivos dentro de um mesmo período e analisando-se a totalidade apenas para este determinado período. 
Nesta etapa atentou-se apenas a mostrar os fatos de validação ou não validação com fontes externas. As discussões referentes às falhas de validação serão discutidas no Capítulo 6 . Para todos os casos o período de validação é o período do escopo do trabalho - de 2010 a 2014. A seção 5.4.1.1 se refere ao processo de validação dos dados de despesas e receitas do governo federal; a seção 5.4.1.3 se refere ao processo de validação dos dados de despesas e receitas do governo do estado de São Paulo; a seção 5.4.1.3 se refere ao processo de validação dos dados de despesas e receitas dos municípios do estado de São Paulo exceto a capital e a Seção 5.4.1.4 se refere a validação da despesa do município de São Paulo.

\subsubsection{Validação de dados - Governo Federal}

Para o processo de validação dos dados do governo federal foi realizado um comparativo a partir de consultas disponíveis no Portal da Transparência da Controladoria Geral da União (PTCGU). Para a validação das despesas foram selecionadas as seguintes consultas:

1. gastos diretos - pagamentos;

2. diárias pagas;

3. CPGF;

4. Transferências de recursos para Estados e Municípios.

Para a consulta (1) foram encontradas falta de dados nos datasets utilizados de acordo com os totais encontrados para esta consulta. Desta forma, o problema foi analisado baseado na classificação da natureza da despesa no item "Grupo de Despesa". Foi identificado que havia falta de dados para os grupos "Amortização e Juros da Dívida" e "Pessoal e Encargos Sociais". Para os grupos "Inversões Financeiras", "Investimentos" e "Outras despesas Correntes" há diferença nos totais por grupo (exceto para "Inversões Financeiras” nos anos de 2012 e 2013).

A tabela 1 indica o resultado gerado por "Grupo de Despesa" no sistema IDEO no período de 2010 a 2014. Para realizar esta consulta, foi selecionado o fato "Valor Pago" da despesa do governo federal para este data mart e as dimensões "ano", "subtipo da despesa" e “categoria da despesa". Na dimensão "subtipo da despesa" selecionou-se apenas "Pagamentos - Gastos Diretos”. Para estes anos e este dominínio de valor para o subtipo da despesa, os dominínios de valores disponíveis no sistema para a dimensão "categoria da despesa" foram “Inversões Financeiras", "Investimentos" e "Outras Despesas Correntes”. 
Tabela 1 - Totais gerados pelo sistema IDEO - despesas do governo federal - "Gastos Diretos: Pagamentos"

\begin{tabular}{l|l|c|c}
\hline \multirow{2}{*}{$\begin{array}{c}\text { Ano } \\
\text { exercício }\end{array}$} & \multicolumn{3}{|c}{ Valor pago $(\mathrm{R} \$)$} \\
\cline { 2 - 4 } & Inversões Financeiras & Investimentos & $\begin{array}{c}\text { Outras Despesas } \\
\text { Correntes }\end{array}$ \\
\hline 2010 & $26.605 .911 .849,67$ & $23.162 .235 .483,50$ & $74.270 .656 .488,53$ \\
\hline 2011 & $29.357 .817 .022,80$ & $20.739 .023 .246,59$ & $91.821 .685 .220,29$ \\
\hline 2012 & $37.229 .871 .430,00$ & $21.553 .835 .770,04$ & $100.899 .043 .352,03$ \\
\hline 2013 & $52.773 .879 .701,31$ & $28.084 .220 .592,67$ & $136.066 .478 .200,17$ \\
\hline 2014 & $58.010 .373 .451,10$ & $31.731 .921 .585,89$ & $180.105 .437 .762,46$ \\
\hline
\end{tabular}

Fonte: José Rodolfo Beluzo, 2015

A tabela 2 indica o resultado gerado pela ferramenta no PTCGU no mesmo período (2010 a 2014). Para gerá-la, selecionou-se no gupo "Gastos Diretos” a consulta por "Tipo de Despesa". A partir do resultado, foram somados manualmente os totais de cada grupo de despesa, pois a ferramenta não permite realizar esta função de forma automática. Foram encontrados cinco grupos de despesa: "Inversões Financeiras", "Investimentos”, “Outras Despesas Correntes", “Amortização e Juros da Dívida" e "Pessoal e Encargos Sociais". Este processo foi necessário ser realizado para cada ano das despesas.

Tabela 2 - Totais gerados pelo sistema do PTCGU - despesas do governo federal - "Gastos Diretos: Pagamentos"

\begin{tabular}{c|c|c|c|c|c}
\hline \multirow{2}{*}{$\begin{array}{c}\text { Ano } \\
\text { exe. }\end{array}$} & Inversões Fin. & Investimentos & $\begin{array}{c}\text { Outras Despesas } \\
\text { Correntes }\end{array}$ & $\begin{array}{c}\text { Amort. e Juros da } \\
\text { dívida }\end{array}$ & $\begin{array}{c}\text { Pessoal e enc. } \\
\text { Sociais }\end{array}$ \\
\hline 2010 & $26.605 .911 .849,67$ & $23.162 .235 .483,50$ & $279.825 .656 .452,70$ & $598.968 .638 .860,04$ & $116.391 .741 .279,83$ \\
\hline 2011 & $28.523 .058 .277,75$ & $22.889 .775 .204,74$ & $367.305 .670 .126,10$ & $708.142 .636 .125,93$ & $160.126 .841 .119,04$ \\
\hline 2012 & $37.229 .871 .430,00$ & $21.674 .923 .718,15$ & $415.567 .418 .586,07$ & $753.246 .932 .087,21$ & $167.546 .919 .342,19$ \\
\hline 2013 & $52.773 .879 .701,31$ & $28.091 .014 .095,04$ & $486.896 .676 .787,01$ & $718.822 .143 .294,27$ & $181.478 .817 .981,83$ \\
\hline 2014 & $63.626 .257 .676,39$ & $34.833 .597 .494,59$ & $585.293 .401 .295,47$ & $978.673 .195 .583,85$ & $198.238 .344 .383,79$ \\
\hline
\end{tabular}

Fonte: Portal da Transparência da Controladoria Geral da União, 2015

A tabela 3 aponta a diferença existente entre a tabela 1 do sistema IDEO e a tabela 2 do sistema do PTCGU. Para facilitar a visualização da diferença, no local em que a diferença de valores encontrado entre os sistemas é nula foi informado "Não há diferença"; no caso dos grupos de despesa "Amortização e Juros da Dívida" e "Pessoal e encargos Sociais" foi apresentado o valor "ausente" acima da diferença, para informar que este campo está ausente no sistema IDEO. Note que há diferença de valores para a maior parte da análise, não aprovando na primeira análise a validação. 
Tabela 3 - Diferença de valores / Ausência de dados em PTCGU e IDEO - despesas do governo federal - "Gastos Diretos: Pagamentos". (Observação: valor - "ausente" definido para quando não foi encontrado o dado nos datasets utilizados no sistema IDEO acrescido do valor original disponibilizado apenas na ferramenta de consulta do PTCGU)

\begin{tabular}{l|c|c|c|r|r}
\hline \multirow{2}{*}{ Ano } & \multicolumn{6}{|c}{ Diferença (R\$) } \\
\cline { 2 - 7 } & Inversões Fin. & Investimentos & $\begin{array}{c}\text { Outras Despesas } \\
\text { Correntes }\end{array}$ & $\begin{array}{c}\text { Amort. e Juros da } \\
\text { dívida }\end{array}$ & $\begin{array}{c}\text { Pessoal e enc. } \\
\text { sociais }\end{array}$ \\
\hline 2010 & Não há diferença & Não há diferença & $205.554 .999 .964,17$ & $598.968 .638 .860,04$ & $\begin{array}{r}\text { ausente } \\
\text { ausente }\end{array}$ \\
\hline 2011 & $-834.758 .745,05$ & $2.150 .751 .958,15$ & $275.483 .984 .905,81$ & $708.142 .636 .125,93$ & $160.126 .841 .119,04$ \\
\hline 2012 & Não há diferença & $121.087 .948,11$ & $314.668 .375 .234,04$ & $753.246 .932 .087,21$ & $167.546 .919 .342,19$ \\
\hline 2013 & Não há diferença & $6.793 .502,37$ & $350.830 .198 .586,84$ & $718.822 .143 .294,27$ & $181.478 .817 .981,83$ \\
\hline 2014 & $5.615 .884 .225,29$ & $3.101 .675 .908,70$ & $405.187 .963 .533,01$ & $978.673 .195 .583,85$ & $198.238 .344 .383,79$ \\
\hline
\end{tabular}

Fonte: José Rodolfo Beluzo, 2015

Para garantir que os dados da consulta (1) foram carregados de forma correta e há erro nos datasets publicados foi utilizado o método de conferência direta por amostragem nos datasets utilizados. Para a consulta (1) selecionou-se os doze datasets referentes ao ano de 2013 e realizou seu somatório geral. Os totais foram condizentes com o total gerado pelo sistema IDEO no mesmo referido período, validando o método de carregamento do sistema IDEO, e apontando falta e erro de dados para este grupo de dataset.

Para as consultas (2) e (3) a validação foi realizada com sucesso. Não foi encontrado diferença entre os valores de dados entre os sistemas avaliados.

A tabela 4 apresenta os totais encontrados pelo sistema IDEO selecionando o fato "Valor Pago" e as dimensões "Subtipo da despesa" para o domínio de valor "Diárias - Gastos Diretos" e a dimensão "ano" para o período de 2010 a 2014.

Tabela 4 - Totais gerados pelo sistema IDEO - despesas do governo federal - "Diárias"

\begin{tabular}{c|r}
\hline Ano exercício & \multicolumn{1}{|c}{ Valor Pago (R\$) } \\
\hline 2010 & $1.081 .292 .449,53$ \\
\hline 2011 & $702.562 .761,70$ \\
\hline 2012 & $857.694 .336,48$ \\
\hline 2013 & $916.501 .864,85$ \\
\hline 2014 & $1.032 .673 .018,13$ \\
\hline
\end{tabular}

Fonte: José Rodolfo Beluzo, 2015 
A tabela 5 apresenta os totais encontrados pelo PTCGU para a mesma consulta. Para tal foi selecionado na área "Consultas temáticas" o item "Diárias Pagas" e em seguida foi selecionado o ano da pesquisa. O processo foi realizado para os anos de 2010 a 2014.

Tabela 5 - Totais gerados pelo sistema do PTCGU - despesas do governo federal - "Diárias"

\begin{tabular}{c|r}
\hline Ano exercício & \multicolumn{1}{|c}{ Valor $(\mathrm{R} \$)$} \\
\hline 2010 & $1.081 .292 .449,53$ \\
\hline 2011 & $702.562 .761,70$ \\
\hline 2012 & $857.694 .336,48$ \\
\hline 2013 & $916.501 .864,85$ \\
\hline 2014 & $1.032 .673 .018,13$ \\
\hline
\end{tabular}

Fonte: Portal da Transparência da Controladoria Geral da União, 2015

A tabela 6 apresenta a diferença entre os sistemas IDEO e PTCGU dos resultados da tabela 4 e tabela 5 para os gastos com "diárias" do tipo "Gastos Diretos". Para este grupo de datasets a validação foi realizada com sucesso. Todos os valores do período foram iguais para ambos os sistemas.

Tabela 6 - Diferença de valores: PTCGU e IDEO - despesas do governo federal - "Diárias"

\begin{tabular}{c|c}
\hline Ano & Diferença $(\mathrm{R} \$)$ \\
\hline 2010 & Não há diferença \\
\hline 2011 & Não há diferença \\
\hline 2012 & Não há diferença \\
\hline 2013 & Não há diferença \\
\hline 2014 & Não há diferença \\
\hline
\end{tabular}

Fonte: José Rodolfo Beluzo, 2015

A tabela 7 apresenta os totais encontrados pelo sistema IDEO selecionando o fato "Valor Pago" e as dimensões "Subtipo da despesa" para o dominío de valor "CPGF - Gastos Diretos" e a dimensão "ano" para o período de 2010 a 2014.

Tabela 7 - Totais gerados pelo sistema IDEO - despesas do governo federal - "CPGF"

\begin{tabular}{c|c}
\hline Ano exercício & Valor \\
\hline 2010 & $80.079 .782,60$ \\
\hline 2011 & $58.743 .558,95$ \\
\hline 2012 & $59.645 .468,15$ \\
\hline 2013 & $61.792 .021,67$ \\
\hline 2014 & $65.274 .622,26$ \\
\hline
\end{tabular}

Fonte: José Rodolfo Beluzo, 2015 
A tabela 8 apresenta os totais encontrados pelo PTCGU para a mesma consulta. Para tal foi selecionado na área "Consultas temáticas" o item "CPGF" e em seguida foi selecionado o ano da pesquisa. O processo foi realizado para os anos de 2010 a 2014.

Tabela 8 - Totais gerados pelo sistema do PTCGU - despesas do governo federal - "CPGF"

\begin{tabular}{c|r}
\hline Ano exercício & \multicolumn{1}{|c}{ Valor $(\mathrm{R} \$)$} \\
\hline 2010 & $80.079 .782,60$ \\
\hline 2011 & $58.743 .558,95$ \\
\hline 2012 & $59.645 .468,15$ \\
\hline 2013 & $61.792 .021,67$ \\
\hline 2014 & $65.274 .622,26$ \\
\hline
\end{tabular}

Fonte: Portal da Transparência da Controladoria Geral da União, 2015

A tabela 9 apresenta a diferença entre os sistemas IDEO e PTCGU dos resultados da tabela 4 e tabela 5 para os gastos de "CPGF" do tipo "Gastos Diretos". Para este grupo de datasets a validação foi realizada com sucesso. Todos os valores do período foram iguais para ambos os sistemas.

Tabela 9 - Diferença de valores nos dados em PTCGU e IDEO - despesas do governo federal - "CPGF"

\begin{tabular}{c|c}
\hline Ano & Diferença $(\mathrm{R} \$)$ \\
\hline 2010 & Não há diferença \\
\hline 2011 & Não há diferença \\
\hline 2012 & Não há diferença \\
\hline 2013 & Não há diferença \\
\hline 2014 & Não há diferença \\
\hline
\end{tabular}

Fonte: José Rodolfo Beluzo, 2015

Para a consulta (4) foram encontradas diferença nos datasets utilizados de acordo com os totais encontrados para esta consulta. Os dados encontrados pelos totais do sistema IDEO não foram condizentes com os dados encontrados pela consulta no PTCGU.

A

tabela 10 indica o total encontrado geral pelo sistema IDEO. Para gerar este resultado, foi selecionado o fato "Valor Pago" e as dimensões "subtipo" com o domínio "Pagamento Transferências de recursos" e a dimensão "ano" para o período de 2010 a 2014. 
Tabela 10 - Totais gerados pelo sistema IDEO - despesas do governo federal "Transferências de recursos por Estado e Municípios"

\begin{tabular}{c|c}
\hline Ano exercício & Valor $(\mathrm{R} \$)$ \\
\hline 2010 & $137.959 .675 .177,53$ \\
\hline 2011 & $254.064 .121 .797,06$ \\
\hline 2012 & $278.981 .529 .776,83$ \\
\hline 2013 & $270.328 .649 .276,07$ \\
\hline 2014 & $304.672 .853 .362,93$ \\
\hline
\end{tabular}

Fonte: José Rodolfo Beluzo, 2015

A tabela 11 indica o total encontrado pela ferramenta do PTCGU para a mesma consulta. Para tal, foi selecionado na área "Transferência de Recursos" o item “por Estado/Município" e o ano desejado. O processo foi realizado para os anos de 2010 a 2014.

Tabela 11 - Totais gerados pelo sistema do PTCGU - despesas do governo federal "Transferências de recursos por Estado e Municípios"

\begin{tabular}{c|c}
\hline Ano exercício & Valor $(\mathrm{R} \$)$ \\
\hline 2010 & $232.587 .288 .530,76$ \\
\hline 2011 & $271.460 .729 .042,01$ \\
\hline 2012 & $299.878 .708 .104,98$ \\
\hline 2013 & $296.511 .342 .410,53$ \\
\hline 2014 & $332.417 .577 .922,45$ \\
\hline
\end{tabular}

Fonte: Portal da Transparência da Controladoria Geral da União, 2015

A tabela 12 indica as diferenças de valores para os datasets de "Transferências de recursos por Estados e Municípios" do subgrupo "Transferências entre os sistemas IDEO e PTCGU. Note que há diferença de valores para toda a análise, não aprovando na primeira análise a validação.

Tabela 12 - Diferença de valores nos dados em PTCGU e IDEO - despesas do governo federal - "Transferências de recursos por Estado e Municípios"

\begin{tabular}{l|c}
\hline Ano & Diferença $(\mathrm{R} \$)$ \\
\hline 2010 & $94.627 .613 .353,23$ \\
\hline 2011 & $17.396 .607 .244,95$ \\
\hline 2012 & $20.897 .178 .328,15$ \\
\hline 2013 & $26.182 .693 .134,46$ \\
\hline 2014 & $27.744 .724 .559,52$ \\
\hline
\end{tabular}

Fonte: José Rodolfo Beluzo, 2015 
Para garantir que os dados da consulta (4) foram carregados de forma correta foi utilizado o método de conferência direta por amostragem nos datasets utilizados. Selecionouse os doze datasets referentes ao ano de 2012 para o subtipo "Pagamentos - Transferências" do tipo de despesa "Transferências de Recursos". Os totais foram condizentes com o total gerado pelo sistema IDEO no mesmo referido período, validando o método de carregamento do sistema IDEO, e apontando falta de dados para este grupo de dataset, visto que a diferença foi um valor positivo para todos os anos.

A respeito dos dados das receitas do governo federal a partir dos totais gerados pelo sistema IDEO foi identificado que os anos de 2013 e 2014 estavam com grandes falhas de valores. Os outros anos $(2010,2011$ e 2012) também possuíam diferenças, mas não tão exorbitantes. Desta forma iniciou-se um trabalho exploratório sobre os dados.

Foi realizado uma análise minuciosa sobre os datasets dos cinco anos utilizados (2010 a 2014) e foi constatado que o modelo de publicação do valor arrecadado nos datasets das receitas dos anos de 2013 e 2014 não seguem o mesmo padrão de publicação dos anos de 2010 a 2013 (uma tupla de dados para cada receita). No referido período os dados estão disponibilizados de forma gradual. Existem várias tuplas de dados referentes a uma mesma receita, e apenas uma delas (a de maior valor) diz respeito ao valor total arrecadado para esta receita. Desta forma, podemos observar que a falta de padronização pode acarretar em erros de análises por usuários dos dados, visto que não há qualquer indicação da mudança de padronização de publicação dos dados no portal.

A correção para os anos posteriores a 2013 foi aplicada da seguinte forma: selecionouse apenas o maior valor de uma determinada receita específica do dataset, definindo-o como a final. Para determinar uma receita como específica foi determinado como combinação única de valor para os seguintes campos do dataset: “Órgão Superior”, “Órgão Subordinado”, "Unidade Gestora", "Categoria da Despesa", “Origem", "Espécie”, "Rubrica”, “Alínea” e "Subalinea". Para as tuplas que possuíam todos estes campos em comum, selecionou-se a tupla de maior valor e descartou-se as restantes. Desta forma obteve-se o total por cada tipo de receita por unidade gestora, de acordo com o estipulado no Decreto 7.158 (Brasil, 2010).

A tabela 13 indica os totais gerado pelo sistema IDEO após estas correções. Para a consulta selecionou-se o fato "Valor Arrecadado" do data mart referente às receitas do governo federal e a dimensão "ano" para o período de 2010 a 2014, gerando os totais gerais por ano, ilustrados abaixo: 
Tabela 13 - Totais gerados pelo sistema IDEO - receitas do governo federal

\begin{tabular}{c|r}
\hline Ano exercício & Valor Arrecadado (R\$) \\
\hline 2010 & $1.461 .355 .349 .256,69$ \\
\hline 2011 & $1.686 .752 .444 .068,82$ \\
\hline 2012 & $1.762 .337 .770 .078,30$ \\
\hline 2013 & $1.782 .824 .927 .813,20$ \\
\hline 2014 & $2.261 .119 .058 .640,00$ \\
\hline
\end{tabular}

Fonte: José Rodolfo Beluzo, 2015

A tabela 14 indica os totais gerados pelo sistema PTCGU. Para esta consulta foi selecionado a aba "Receitas" e escolheu-se o item "Por Órgão" e o período desejado. O processo foi realizado para os anos de 2010 a 2014.

Tabela 14 - Totais gerados pelo sistema do PTCGU - receitas do governo federal

\begin{tabular}{c|c}
\hline Ano exercício & Valor $(\mathrm{R} \$)$ \\
\hline 2010 & $1.487 .959 .746 .309,02$ \\
\hline 2011 & $1.708 .851 .976 .174,56$ \\
\hline 2012 & $1.957 .384 .033 .047,06$ \\
\hline 2013 & $1.893 .623 .959 .403,52$ \\
\hline 2014 & $2.238 .439 .698 .780,23$ \\
\hline
\end{tabular}

Fonte: Portal da Transparência da Controladoria Geral da União, 2015

A tabela 15 indica as diferenças de valores para os datasets de receitas do governo federall entre os sistemas IDEO e PTCGU. Note que há diferença de valores para toda a análise, não aprovando na primeira análise a validação. Para os anos de 2010 a 2013 a diferença foi positiva, indicando que há falta de dados; para o ano de 2014 a diferença foi negativa, indicando erro de dados.

Tabela 15 - Diferença de valores nos dados em PTCGU e IDEO - receitas do governo federal

\begin{tabular}{l|r}
\hline Ano & Diferença $(\mathrm{R} \$)$ \\
\hline 2010 & $26.604 .397 .052,33$ \\
\hline 2011 & $22.099 .532 .105,74$ \\
\hline 2012 & $195.046 .262 .968,76$ \\
\hline 2013 & $110.799 .031 .590,32$ \\
\hline 2014 & $-22.679 .359 .859,77$ \\
\hline
\end{tabular}

Fonte: José Rodolfo Beluzo, 2015 
5.4.1.2 Validação de dados - Governo do estado de São Paulo

Para os dados referentes ao governo do estado de São Paulo foi utilizado a ferramenta de consultas por ano do portal da Secretária da Fazenda "Prestando Contas" para se realizar a validação tanto para despesas quanto para as receitas. Os dados produzidos para todos os anos de pesquisas no sistema IDEO condizem com os dados consolidados no portal, exceto para o valor previsto das receitas no ano de 2011 que diferem no valor R \$ 2,00. Por ser uma margem de erro pequena referente ao montante, o processo foi considerado como validado.

A tabela 16 foi gerada pelo sistema IDEO para as despesas do governo do estado de São Paulo. Os dados foram obtidos selecionando-se os fatos "Valor empenhado", "Valor Liquidado" e "Valor Pago", disponíveis neste data mart a partir da dimensão "ano" da despesa.

Tabela 16 - Totais gerados pelo sistema IDEO - despesas do governo do estado de São Paulo

\begin{tabular}{l|l|l|l}
\hline Ano exercício & Valor empenhado (R\$) & Valor Liquidado (R\$) & Valor Pago (R\$) \\
\hline 2010 & $147.056 .059 .385,73$ & $147.056 .059 .385,73$ & $129.043 .743 .885,51$ \\
\hline 2011 & $159.949 .788 .187,88$ & $159.949 .788 .187,88$ & $135.840 .757 .372,28$ \\
\hline 2012 & $173.106 .698 .940,17$ & $173.106 .698 .940,17$ & $152.637 .967 .224,40$ \\
\hline 2013 & $197.870 .171 .922,07$ & $197.870 .171 .922,07$ & $171.163 .774 .380,58$ \\
\hline 2014 & $209.842 .014 .024,00$ & $209.842 .014 .024,00$ & $190.709 .044 .358,61$ \\
\hline
\end{tabular}

Fonte: José Rodolfo Beluzo, 2015

Na sequência a mesma consulta foi gerada no portal "Prestando Contas" do governo do estado de São Paulo. Para realizar esta consulta no portal foram necessários cinco acessos de pesquisa (um por ano desejado). A tabela 17 demonstra o resultado encontrado.

Tabela 17 - Totais gerados pelo sistema interno do portal "Prestando Contas" - despesas do governo do estado de São Paulo

\begin{tabular}{l|l|l|l}
\hline Ano exercício & Valor empenhado (R\$) & Valor Liquidado (R\$) & Valor Pago (R\$) \\
\hline 2010 & $147.056 .059 .385,73$ & $147.056 .059 .385,73$ & $129.043 .743 .885,51$ \\
\hline 2011 & $159.949 .788 .187,88$ & $159.949 .788 .187,88$ & $135.840 .757 .372,28$ \\
\hline 2012 & $173.106 .698 .940,17$ & $173.106 .698 .940,17$ & $152.637 .967 .224,40$ \\
\hline 2013 & $197.870 .171 .922,07$ & $197.870 .171 .922,07$ & $171.163 .774 .380,58$ \\
\hline 2014 & $209.842 .014 .024,00$ & $209.842 .014 .024,00$ & $190.709 .044 .358,61$ \\
\hline
\end{tabular}

Fonte: Portal da Secretária da Fazenda de São Paulo - item "Prestando Contas", 2015

A partir dos resultados encontrados na tabela 16 e tabela 17 realizou-se a diferença entre elas e obteve-se a tabela 18. Observa-se que não há diferença entre os valores dos dois sistemas, validando o resultado de carregamento do sistema IDEO para as despesas do governo do estado de São Paulo. 
Tabela 18 - Diferença / Ausência de dados em Portal "Prestando Contas" e IDEO - despesas do governo do Estado de São Paulo

\begin{tabular}{c|c}
\hline Ano & Diferença $(\mathrm{R} \$)$ \\
\hline 2010 & Não há diferença \\
\hline 2011 & Não há diferença \\
\hline 2012 & Não há diferença \\
\hline 2013 & Não há diferença \\
\hline 2014 & Não há diferença \\
\hline
\end{tabular}

Fonte: José Rodolfo Beluzo, 2015

A tabela 19 demonstra os montantes encontrados pelo sistema IDEO para receitas do governo do estado de São Paulo gerados pelo sistema IDEO. Os dados foram obtidos selecionando-se os fatos "Valor Previsto" e "Valor Arrecadado", disponíveis neste data mart a partir da dimensão "ano" da receita.

Tabela 19 - Totais gerados pelo sistema IDEO - receitas do governo do estado de São Paulo

\begin{tabular}{l|c|c}
\hline Ano exercício & Valor Previsto (R\$) & Valor Arrecadado (R\$) \\
\hline 2010 & $140.424 .395 .708,00$ & $149.373 .064 .469,30$ \\
\hline 2011 & $155.550 .876 .891,00$ & $159.225 .823 .532,20$ \\
\hline 2012 & $174.067 .877 .304,00$ & $172.866 .153 .793,43$ \\
\hline 2013 & $192.844 .281 .051,00$ & $196.875 .515 .667,48$ \\
\hline 2014 & $212.191 .448 .179,00$ & $209.486 .514 .330,74$ \\
\hline
\end{tabular}

Fonte: José Rodolfo Beluzo, 2015

Na sequência a mesma consulta foi gerada no portal "Prestando Contas" do governo do estado de São Paulo. Para realizar esta consulta no portal foram necessários cinco acessos de pesquisa (um por ano desejado). A

tabela 20 demonstra os montantes encontrados para os anos de 2010 a 2014.

Tabela 20 - Totais gerados pelo sistema interno do portal "Prestando Contas" - receitas do governo do estado de São Paulo

\begin{tabular}{l|c|c}
\hline Ano exercício & Valor Previsto (R\$) & Valor Arrecadado (R\$) \\
\hline 2010 & $140.424 .395 .708,00$ & $149.373 .064 .469,30$ \\
\hline 2011 & $155.550 .876 .889,00$ & $159.225 .823 .532,20$ \\
\hline
\end{tabular}




\begin{tabular}{l|l|l}
\hline 2012 & $174.067 .877 .304,00$ & $172.866 .153 .793,43$ \\
\hline 2013 & $192.844 .281 .051,00$ & $196.875 .515 .667,48$ \\
\hline 2014 & $212.191 .448 .179,00$ & $209.486 .514 .330,74$ \\
\hline
\end{tabular}

Fonte: Portal da Secretária da Fazenda de São Paulo - item "Prestando Contas", 2015

A tabela 21 demonstra que não existe diferenças (significativas) entre os valores encontrados nos portais e o sistema IDEO. A única diferença encontrada foi com relação ao valor previsto de 2011 - diferença de $\mathrm{R} \$ 2,00$. Como isso representa menos de $0,01 \%$ do total o erro foi desconsiderado, validando o resultado de carregamento do sistema IDEO para as receitas do governo do estado de São Paulo.

Tabela 21 - Diferença de valores nos dados em Portal "Prestando Contas" e IDEO - receitas do governo do Estado de São Paulo

\begin{tabular}{l|c|c}
\hline Ano exercício & Valor Previsto $(\mathrm{R} \$)$ & Valor Arrecadado (R\$) \\
\hline 2010 & Não há diferença. & Não há diferença. \\
\hline 2011 & $-2,00$ & Não há diferença. \\
\hline 2012 & Não há diferença. & Não há diferença. \\
\hline 2013 & Não há diferença. & Não há diferença. \\
\hline 2014 & Não há diferença. & Não há diferença. \\
\hline
\end{tabular}

Fonte: José Rodolfo Beluzo, 2015

Desta forma, conclui-se que o processo de validação dos dados do governo do estado de São Paulo foi validado por completo no sistema IDEO.

A seção 5.4.1.3 irá apontar o processo de validação dos dados de receitas e despesas referentes aos municípios do estado de São Paulo, exceto a capital.

\subsubsection{Validação de dados - Municípios do estado de São Paulo (Exceto a Capital)}

Para os dados dos municípios do estado de São Paulo foi criado um script para se extrair os totais disponibilizados pela ferramenta WEB no portal do TCE São Paulo. O script recupera do código HTML da página de cada órgão de cada cidade de cada ano o valor total; realiza o somatório dos órgãos de cada cidade para o respectivo ano e compara com o total encontrado no sistema IDEO. A validação foi realizada com sucesso tanto para as despesas quanto para as receitas de todas as cidades.

A tabela 22 indica o total gerado pelo sistema IDEO para todas as despesas de todos os municípios do estado de São Paulo, exceto a capital. Para realizar esta consulta foi selecionado 
o fato "Valor Pago" do data mart referente às despesas dos municípios e a dimensão "ano" para o período de 2010 a 2014.

Tabela 22 - Totais gerados pelo sistema IDEO - despesas dos municípios do estado de São Paulo (Exceto a Capital)

\begin{tabular}{l|l}
\hline Ano exercício & Valor Pago (R\$) \\
\hline 2010 & $55.777 .278 .486,49$ \\
\hline 2011 & $64.118 .930 .031,10$ \\
\hline 2012 & $72.321 .654 .997,16$ \\
\hline 2013 & $76.820 .908 .474,35$ \\
\hline 2014 & $85.439 .563 .934,08$ \\
\hline
\end{tabular}

Fonte: José Rodolfo Beluzo, 2015

A tabela 23 foi gerada pelo script que obtém as informações diretamente do HTML gerado pela consulta web no portal do TCE para as despesas dos municípios do governo do estado de São Paulo, exceto a capital. Os dados foram gerados para o período de 2010 a 2014.

Tabela 23 - Totais gerados pela ferramenta WEB do TCE SP - despesas dos municípios do estado de São Paulo (Exceto a Capital)

\begin{tabular}{l|l}
\hline Ano exercício & Valor Pago (R\$) \\
\hline 2010 & $55.777 .278 .486,49$ \\
\hline 2011 & $64.118 .930 .031,10$ \\
\hline 2012 & $72.321 .654 .997,16$ \\
\hline 2013 & $76.820 .908 .474,35$ \\
\hline 2014 & $85.439 .563 .934,08$ \\
\hline
\end{tabular}

Fonte: Portal da Secretária da Fazenda de São Paulo - item "Prestando Contas", 2015

A tabela 24 indica a diferença entre os resultados encontrados para as despesas entre o sistema IDEO e as consultas WEB no portal do TCE (geradas pelo script citado anteriormente). Para esta etapa não houve diferença encontrada, validando o carregamento dos dados das despesas dos municípios no sistema IDEO.

Tabela 24 - Diferença de valores nos dados em ferramenta WEB do TCE SP e IDEO despesas dos municípios do estado de São Paulo (Exceto a Capital)

\begin{tabular}{c|c}
\hline Ano & Diferença $(\mathrm{R} \$)$ \\
\hline 2010 & Não há diferença \\
\hline 2011 & Não há diferença \\
\hline 2012 & Não há diferença \\
\hline 2013 & Não há diferença \\
\hline 2014 & Não há diferença \\
\hline
\end{tabular}


A tabela 25 indica o total gerado pelo sistema IDEO para todas as receitas de todos os municípios do estado de São Paulo, exceto a capital. Para realizar esta consulta foi selecionado o fato "Valor Arrecadado" do data mart referente às receitas dos municípios do governo do estado de São Paulo (exceto a capital) e a dimensão “ano” para o período de 2010 a 2014.

Tabela 25 - Totais gerados pelo sistema IDEO - receitas dos municípios do estado de São Paulo (Exceto a Capital)

\begin{tabular}{l|l}
\hline Ano exercício & Valor Arrecadado $(\mathrm{R} \$)$ \\
\hline 2010 & $62.510 .508 .674,89$ \\
\hline 2011 & $71.946 .928 .427,91$ \\
\hline 2012 & $80.429 .241 .550,02$ \\
\hline 2013 & $86.531 .228 .075,74$ \\
\hline 2014 & $94.820 .229 .076,16$ \\
\hline
\end{tabular}

Fonte: José Rodolfo Beluzo, 2015

A tabela 26 foi gerada pelo script que obtém as informações diretamente do HTML gerado pela consulta web no portal do cidadão do TCE para as receitas dos municípios do governo do estado de São Paulo, exceto a capital. Os dados foram gerados para o período de 2010 a 2014.

Tabela 26 - Totais gerados pela ferramenta WEB do TCE SP - receitas dos municípios do estado de São Paulo (Exceto a Capital)

\begin{tabular}{l|l}
\hline Ano exercício & Valor Arrecadado (R\$) \\
\hline 2010 & $62.510 .508 .674,89$ \\
\hline 2011 & $71.946 .928 .427,91$ \\
\hline 2012 & $80.429 .241 .550,02$ \\
\hline 2013 & $86.531 .228 .075,74$ \\
\hline 2014 & $94.820 .229 .076,16$ \\
\hline
\end{tabular}

Fonte: Portal do Cidadão do Tribunal de Contas do Estado de São Paulo, 2015

A tabela 27 indica a diferença entre os resultados encontrados para as receitas entre o sistema IDEO e as consultas WEB no portal do cidadão do TCE (geradas pelo script citado anteriormente) para os municípios do governo do estado de São Paulo. Para esta etapa não houve diferença encontrada, validando o carregamento dos dados das despesas dos municípios no sistema IDEO. 
Tabela 27 - Diferença de valores nos dados em ferramenta WEB do TCE SP e IDEO receitas dos municípios do estado de São Paulo (Exceto a Capital)

\begin{tabular}{c|c}
\hline Ano & Diferença $(\mathrm{R} \$)$ \\
\hline 2010 & Não há diferença \\
\hline 2011 & Não há diferença \\
\hline 2012 & Não há diferença \\
\hline 2013 & Não há diferença \\
\hline 2014 & Não há diferença \\
\hline
\end{tabular}

Fonte: José Rodolfo Beluzo, 2015

Desta forma, conclui-se que o processo de validação dos dados dos municípios do governo do estado de São Paulo (exceto a capital) foi validado por completo no sistema IDEO.

A seção 5.4.1.4 irá apontar o processo de validação dos dados de receitas e despesas referentes ao município de São Paulo capital.

\subsubsection{Validação de dados - Município de São Paulo}

Para os dados referentes ao município de São Paulo foi realizado o processo de validação apenas para as despesas (receitas não disponíveis nos requisitos exigidos pelo sistema IDEO, como citado anteriormente). A primeira validação se deu através dos resultados consolidados em um relatório - Quadro Detalhado da Despesa, em cumprimento às Leis n ${ }^{\circ} 13.949$ de 21 de janeiro de 2011 e n 14.106 de 28 de junho de 2011 - disponível no mesmo endereço de extração do dataset.

A tabela 28 indica o total gerado pelo sistema IDEO para todas as despesas do município de São Paulo. Para realizar esta consulta foi selecionado os fatos "Valor empenhado", "Valor Liquidado" e "Valor Pago" do data mart referente às despesas do município de São Paulo e a dimensão "ano" para o período de 2010 a 2014. Para o ano de 2010 o "Valor Pago" não estava disponível.

Tabela 28 - Totais gerados pelo Sistema IDEO

\begin{tabular}{c|c|c|c}
\hline Ano & Valor empenhado $(\mathrm{R} \$)$ & Valor Liquidado $(\mathrm{R} \$)$ & Valor Pago (R\$) \\
\hline 2010 & $28.761 .555 .363,83$ & $27.079 .346 .334,65$ & - \\
\hline 2011 & $32.118 .255 .856,02$ & $30.369 .524 .152,64$ & $30.369 .524 .152,64$ \\
\hline 2012 & $35.873 .752 .829,91$ & $34.116 .141 .151,52$ & $34.116 .141 .151,52$ \\
\hline 2013 & $38.506 .141 .671,89$ & $36.163 .968 .805,64$ & $35.864 .037 .385,30$ \\
\hline 2014 & $42.762 .490 .238,64$ & $41.660 .125 .004,84$ & $41.449 .912 .427,83$ \\
\hline
\end{tabular}


A tabela 29 se refere aos valores encontrados referentes aos totais disponibilizados do relatório "Quadro Detalhado da Despesa", disponível em formato PDF (Acesso em 10 de abril de 2015), ao qual se refere a um relatório das despesas do município de São Paulo. Para cada ano entre 2010 e 2014 foi acessado um arquivo em PDF e verificado o valor total referente ao ano. Neste quadro não estava disponível a informação "Valor Pago" para nenhum dos anos pesquisados.

Tabela 29 - Totais extraídos dos relatórios - Quadro Detalhado da Despesa, em cumprimento às Leis $n^{\circ} 13.949$ de 21 de janeiro de 2011 e n 14.106 de 28 de junho de 2011

\begin{tabular}{c|c|c|c}
\hline \multicolumn{5}{c}{ Quadro Detalhado da Despesa } \\
\hline Ano exercício & Valor empenhado (R\$) & Valor Liquidado (R\$) & Valor Pago (R\$) \\
\hline 2010 & $28.761 .555 .364,00$ & $27.127 .222 .910,00$ & - \\
\hline 2011 & $32.118 .255 .856,00$ & $30.369 .524 .153,00$ & - \\
\hline 2012 & $35.873 .752 .830,00$ & $34.116 .141 .152,00$ & - \\
\hline 2013 & $39.096 .428 .632,00$ & $36.745 .747 .569,00$ & - \\
\hline 2014 & $43.413 .724 .121,00$ & $41.520 .661 .553,00$ & - \\
\hline
\end{tabular}

Fonte: Portal da Secretária de Planejamento, Orçamento e Gestão do Município de São Paulo , 2015

A tabela 30 informa quais são os as diferenças encontradas entre os valores empenhados e valores liquidados pelo sistema IDEO e o relatório - Quadro Detalhado da Despesa (QDD) disponibilizado no portal. Perceba que a comparação realizada foi apenas entre os valores empenhados e valores liquidados pois no QDD não possui a informação do valor pago. Para diferença menores de $0,01 \%$ do montante foi considerado que não há diferença.

Tabela 30 - Diferenças entre o sistema IDEO e o Quadro Detalhado da Despesa (QDD)

\begin{tabular}{c|c|c}
\hline \multicolumn{3}{c}{ Diferenças de valores maiores que R\$ 1,00 (R\$) } \\
\hline Ano & Valor empenhado & Valor Liquidado \\
\hline 2010 & Não há diferença & $47.876 .575,35$ \\
\hline 2011 & Não há diferença & Não há diferença \\
\hline 2012 & Não há diferença & Não há diferença \\
\hline 2013 & $590.286 .960,11$ & $581.778 .763,36$ \\
\hline 2014 & $651.233 .882,36$ & $139.463 .451,84$ \\
\hline
\end{tabular}

Fonte: José Rodolfo Beluzo, 2015

Desta forma, para garantir que os datasets utilizados estavam sendo carregados de forma correta, foi adotado uma conferência manual dos valores dos datasets do município de São 
Paulo a qual foi verificado que os somatórios da planilha da tabela 28 estão em conformidade, eliminando a possibilidade de erro no processo sistêmico de carregamento dos dados no sistema IDEO. Assim, descarta-se a possibilidade de erro do sistema IDEO e confirma-se um erro durante a publicação em formato aberto nos datasets ou durante a publicação do relatório "Quadro Detalhado da Despesa" do portal da SEMPLA de São Paulo e validou o processo de carregamento do sistema IDEO para os dados de despesa do município de São Paulo.

\subsubsection{Validação com fontes externas}

A validação por fontes externas seguiu a seguinte metodologia: utilizar fontes de dados que em tese deveriam representar os mesmos montantes encontrados nos portais utilizados, por se referirem ao mesmo contexto (balanço orçamentário) e período de dado.

Para os dados do governo federal foi utilizado o portal do senado federal através da ferramenta SIGA Brasil ${ }^{12}$. Para os dados do governo estadual e municípios do estado de São Paulo foi utilizado o portal da STN - Secretaria do Tesouro Nacional, através do FINBRAFinanças do Brasil - que possuem dados contábeis dos estados e municípios em todo o país. Nesta etapa atentou-se apenas a mostrar os fatos de validação ou não validação com fontes externas. As discussões referentes à não validação serão discutidas no Capítulo 6 .

A Seção 5.4.2.1 se refere ao processo de validação dos dados de despesas e receitas do governo federal; a Seção 5.4.2.2 se refere ao processo de validação dos dados de despesas e receitas do governo do estado de São Paulo; a Seção 5.4.2.3 se refere ao processo de validação dos dados de despesas e receitas dos municípios do estado de São Paulo exceto a capital e a Seção 5.4.2.4 se refere a validação da despesa do município de São Paulo.

\subsubsection{Validação de dados - Governo do Federal}

A validação de dados com fontes externas no governo federal não foi positiva nem para os dados de receitas, nem para despesas. Para ambos os casos houve diferença entre o sistema externo e o IDEO em todos os casos de teste.

A tabela 31 indica os totais gerados pelos três sistemas para as receitas do governo federal - PTCGU, IDEO e SIGA (validador externo). Os dados se diferem para os três sistemas

\footnotetext{
12 http://www12.senado.gov.br/orcamento/sigabrasil
} 
em todos os anos. Desta forma, a validação com dados de fontes externas não foi aprovada para as receitas.

Tabela 31 - Totais gerados pelo sistema PTCGU x IDEO x SIGA - receitas arrecadadas do governo federal

\begin{tabular}{c|c|c|c}
\hline Ano exercício & PTCGU (R\$) & IDEO (R\$) & SIGA (R\$) \\
\hline 2010 & $1.487 .959 .746 .309,02$ & $1.461 .355 .349 .256,69$ & $1.482 .728 .571 .543,00$ \\
\hline 2011 & $1.708 .851 .976 .174,56$ & $1.686 .752 .444 .068,82$ & $1.700 .996 .880 .045,00$ \\
\hline 2012 & $1.957 .384 .033 .047,06$ & $1.762 .337 .770 .078,30$ & $1.949 .296 .988 .672,00$ \\
\hline 2013 & $1.893 .623 .959 .403,52$ & $1.782 .824 .927 .813,20$ & $1.884 .566 .524 .614,00$ \\
\hline 2014 & $2.238 .439 .698 .780,23$ & $2.261 .119 .058 .640,00$ & $2.229 .721 .293 .132,00$ \\
\hline
\end{tabular}

Fonte: José Rodolfo Beluzo, 2015

O gráfico 1 aponta a diferença entre os três portais. Já havia sido demonstrado que os dados entre IDEO e PTCGU tinham uma diferença para os cinco anos analisados. Observa-se que existe também uma diferença entre o PTCGU e o SIGA Brasil, na mesma proporção. A partir deste ponto este trabalho não consegue identificar qual das bases estão erradas, porém é possível apontar que existe o erro.

Gráfico 1 - Comparativo dos valores (em Reais) de receitas entre 2010 e 2014 entre os sistemas IDEO, PTCGU e SIGA - Governo Federal

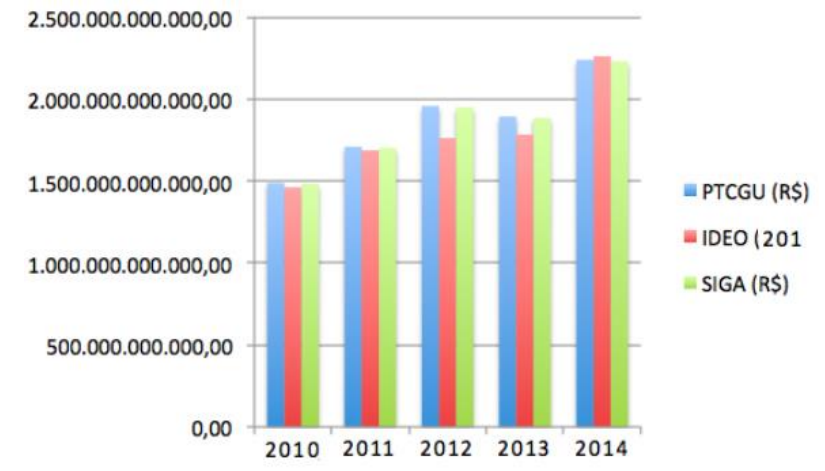

Fonte: José Rodolfo Beluzo, 2015

A tabela 32 indica os totais gerados pelos três sistemas para as despesas do governo federal - PTCGU, IDEO e SIGA (validador externo). Os dados se diferem para os três sistemas em todos os anos. Comparando-se os dados de despesas do SIGA com o PTCGU e do SIGA com o IDEO, para os dados da despesa percebe-se uma discrepância maior entre as diferenças SIGA e IDEO. Isto deve-se ao fato de as informações referentes a "Amortização e Juros da Dívida" e "Pessoal e encargos Sociais" não estarem disponíveis nos datasets, como foi 
analisado na tabela 2. Desta forma, a validação com dados de fontes externas não foi aprovada para as despesas.

Tabela 32 - Totais gerados pelo sistema PTCGU x IDEO x SIGA - despesas arrecadadas do governo federal - Gastos Diretos + Transferências

\begin{tabular}{c|c|c|c}
\hline $\begin{array}{c}\text { Ano } \\
\text { exercício }\end{array}$ & PTCGU (R\$) & IDEO (R\$) & SIGA (R\$) \\
\hline 2010 & $1.278 .702 .844 .688,63$ & $263.159 .851 .231,36$ & $1.414 .489 .603 .815,56$ \\
\hline 2011 & $1.559 .210 .016 .216,22$ & $396.743 .953 .607,39$ & $1.574 .070 .172 .440,65$ \\
\hline 2012 & $1.696 .062 .113 .073,23$ & $439.581 .620 .133,53$ & $1.712 .094 .779 .492,61$ \\
\hline 2013 & $1.765 .552 .168 .156,51$ & $488.231 .521 .656,74$ & $1.782 .716 .413 .457,11$ \\
\hline 2014 & $2.194 .180 .321 .996,93$ & $575.618 .533 .802,77$ & $2.167 .625 .473 .476,77$ \\
\hline
\end{tabular}

Fonte: José Rodolfo Beluzo, 2015

O gráfico 2 aponta a discrepância entre os três portais. Já havia sido demonstrado que os dados entre IDEO e PTCGU tinham uma diferença para os cinco anos analisados. Observase que existe também uma diferença entre o PTCGU e o SIGA Brasil, porém em proporções diferentes. Para os anos de 2011 a 2014 os valores são muito próximos. A partir deste ponto este trabalho não consegue identificar qual das bases estão erradas, porém é possível apontar que existe o erro.

Gráfico 2 - Comparativo dos valores de despesas entre 2010 e 2014 entre os sistemas IDEO, PTCGU e SIGA - Governo Federal

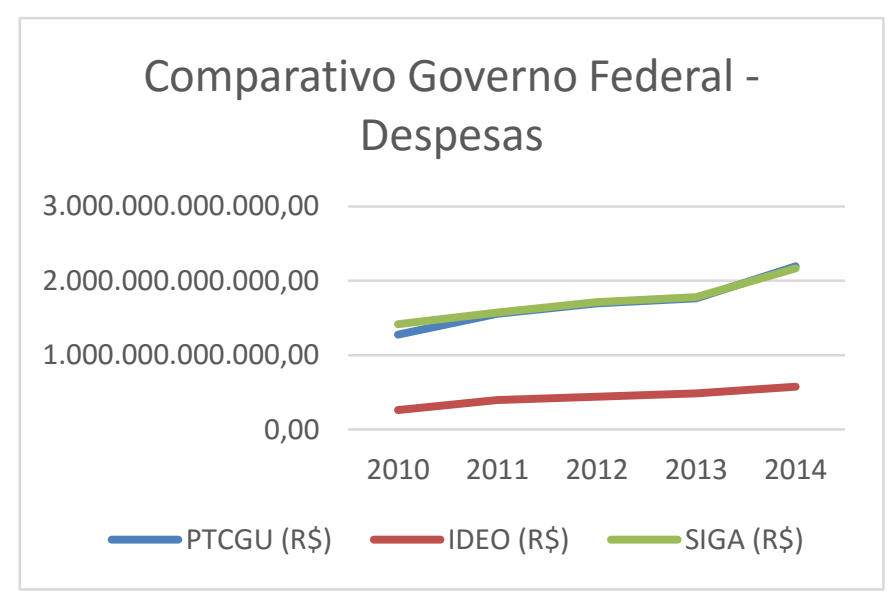

Fonte: José Rodolfo Beluzo, 2015 
5.4.2.2 Validação de dados - Governo do estado de São Paulo

Com relação aos dados do Governo do estado de São Paulo, os dados foram validados com sucesso tanto para receitas quanto despesas. Para todos os anos analisados pelo IDEO o total foi condizente com o que estava disponível no total exibido pelo FINBRA.

A tabela 33 demonstra os totais gerados pelo sistema IDEO e o encontrado no validador externo FINBRA para as receitas arrecadadas do governo do estado de São Paulo e a diferença (nula) entre eles. Desta forma, a validação externa dos dados do governo do estado de São Paulo para as receitas foi realizada com sucesso.

Tabela 33 - Totais gerados pelo sistema IDEO x FINBRA - receitas arrecadadas do governo do estado de São Paulo

\begin{tabular}{l|c|c|c}
\hline Ano exercício & IDEO (R\$) & FINBRA (R\$) & IDEO - FINBRA (R\$) \\
\hline 2010 & $149.373 .064 .469,30$ & $149.373 .064 .469,30$ & 0,00 \\
\hline 2011 & $159.225 .823 .532,20$ & $159.225 .823 .532,20$ & 0,00 \\
\hline 2012 & $172.866 .153 .793,43$ & $172.866 .153 .793,43$ & 0,00 \\
\hline 2013 & $196.875 .515 .667,48$ & $196.875 .515 .667,48$ & 0,00 \\
\hline 2014 & $209.486 .514 .330,74$ & $209.486 .514 .330,74$ & 0,00 \\
\hline
\end{tabular}

Fonte: José Rodolfo Beluzo, 2015

A tabela 34 demonstra os totais gerados pelo sistema IDEO e o encontrado no validador externo FINBRA para as despesas realizadas pelo governo do estado de São Paulo e a diferença (nula) entre eles. Desta forma, a validação externa dos dados do governo do estado de São Paulo para as despesas também foi realizada com sucesso

Tabela 34 - Totais gerados pelo sistema IDEO x FINBRA - despesas pagas pelo governo do estado de São Paulo

\begin{tabular}{c|c|c|c}
\hline Ano exercício & IDEO (R\$) & FINBRA (R\$) & IDEO - FINBRA (R\$) \\
\hline 2010 & $129.043 .743 .885,51$ & $129.043 .743 .885,51$ & 0,00 \\
\hline 2011 & $135.840 .757 .372,28$ & $135.840 .757 .372,28$ & 0,00 \\
\hline 2012 & $152.637 .967 .224,40$ & $152.637 .967 .224,40$ & 0,00 \\
\hline 2013 & $171.163 .774 .380,58$ & $171.163 .774 .380,58$ & 0,00 \\
\hline 2014 & $190.709 .044 .358,61$ & $190.709 .044 .358,61$ & 0,00 \\
\hline
\end{tabular}


Para o período de 2010 a 2013 os dados do FINBRA estão disponíveis em link direto ${ }^{13}$; para o ano de 2014 a consulta deve ser realizada através de ferramenta de pesquisa WEB no portal do Tesouro Nacional - SICONFI ${ }^{14}$ - Sistema de Informações Contábeis e Fiscais do Setor Público Brasileiro. Para todos os anos os arquivos disponíveis estão tabulados em arquivo de formato XLS.

5.4.2.3 Validação de dados - Municípios do estado de São Paulo (exceto a capital)

Com relação aos municípios do estado de São Paulo na validação foi verificado quantas cidades estão disponíveis na base do TCE SP; quantas estão disponíveis no relatório do FINBRA e quantas destas possuem valores iguais em ambos datasets, tanto para receitas quanto para despesas.

A tabela 35 ilustra estas diferenças para as receitas. O sistema FINBRA possui menos cidades do que o disponibilizado no TCE SP (origem dos dados de municípios no sistema IDEO). A validação foi parcial para os anos de 2010 a 2013. Em 2010 houve validação de 82,7\% das cidades; em 2011 houve validação de 86,2\% das cidades e em 2012 houve validação de $85,7 \%$ das cidades. No ano de 2013 houve apenas $0,7 \%$ das cidades e no ano de 2014 a validação foi nula.

Tabela 35 - Totais gerados pelo sistema IDEO x FINBRA - receitas dos municípios do estado de São Paulo

\begin{tabular}{c|c|c|c|c}
\hline Ano & $\begin{array}{c}\text { Quantidade de Cidades } \\
\text { auditadas no IDEO (Base } \\
\text { de dados - TCE SP) }\end{array}$ & $\begin{array}{c}\text { Quantidade de } \\
\text { Cidades Auditadas no } \\
\text { FINBRA }\end{array}$ & $\begin{array}{c}\text { Cidades com valores } \\
\text { iguais (FINBRA = } \\
\text { IDEO) }\end{array}$ & $\begin{array}{c}\text { Porcentagem de } \\
\text { validação (\%) }\end{array}$ \\
\hline 2010 & 644 & 642 & 531 & 82,7 \\
\hline 2011 & 644 & 638 & 550 & 86,2 \\
\hline 2012 & 644 & 625 & 536 & 85,7 \\
\hline 2013 & 644 & 631 & 5 & 0,7 \\
\hline 2014 & 644 & 567 & 0 & 0 \\
\hline
\end{tabular}

Fonte: José Rodolfo Beluzo, 2015

No caso das receitas, o gráfico 3 aponta que boa parte das cidades no FINBRA estão com os valores equivalentes até o ano de 2012; após o ano de 2013 não há igualdade. A hipótese

\footnotetext{
${ }^{13} \mathrm{http}$ ///www.tesouro.fazenda.gov.br/pt_PT/finbra-financas-municipais

${ }^{14} \mathrm{https} / / /$ siconfi.tesouro.gov.br/siconfi/index.jsf
} 
criada pelo autor é de que os valores de 2013 ou superior ainda não estão carregados por completo no sistema FINBRA e que futuramente estes valores serão corrigidos no dataset.

Gráfico 3 - Comparativo dos valores de receitas entre 2010 e 2014 entre os sistemas IDEO, PTCGU e SIGA - Municípios

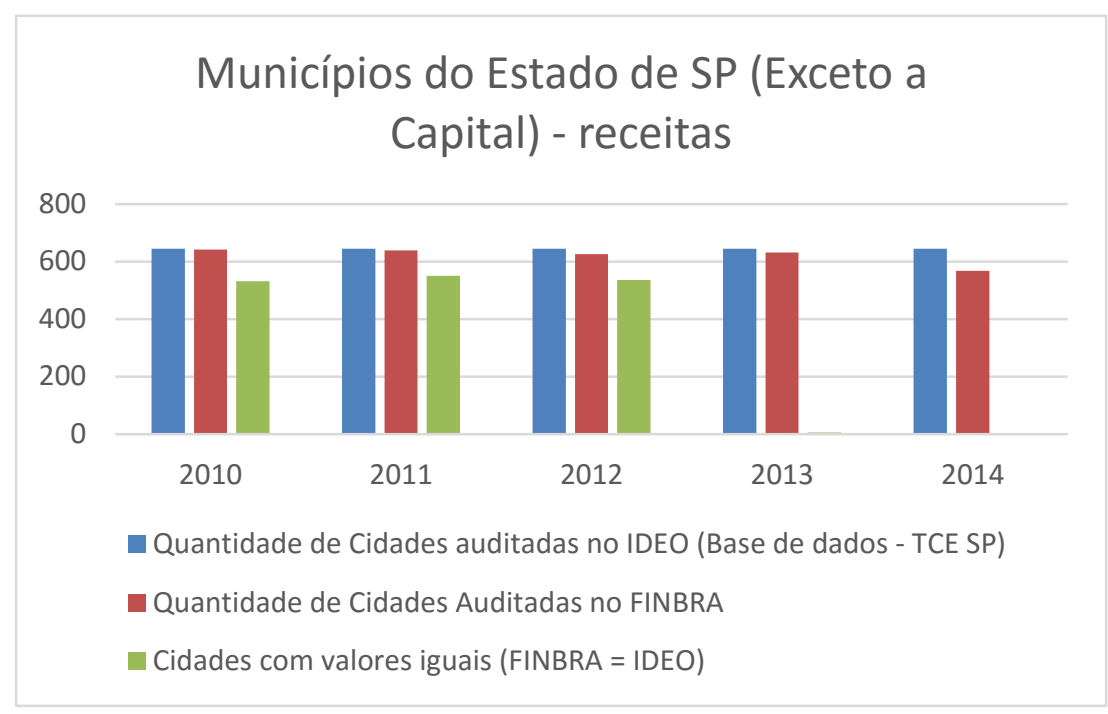

Fonte: José Rodolfo Beluzo, 2015.

A tabela 36 ilustra as diferenças na validação para as despesas. O sistema FINBRA possui menos cidades do que o disponibilizado no TCE SP (origem dos dados de municípios no sistema IDEO). A validação foi parcial para os anos de 2010 a 2014. Em 2010 houve validação de 45,5\% das cidades; em 2011 de 71,2\%; em 2012 de 69,1\%; em 2013 de 59,1\% e em 2014 houve validação de $68,3 \%$.

Tabela 36 - Totais gerados pelo sistema IDEO x FINBRA - despesas pagas pelos municípios do estado de São Paulo

\begin{tabular}{c|c|c|c|c}
\hline Ano & $\begin{array}{c}\text { Quantidade de } \\
\text { Cidades auditadas no } \\
\text { IDEO (Base de dados } \\
- \text { TCE SP) }\end{array}$ & $\begin{array}{c}\text { Quantidade de } \\
\text { Cidades } \\
\text { Auditadas no } \\
\text { FINBRA }\end{array}$ & $\begin{array}{c}\text { Cidades com } \\
\text { valores iguais } \\
\text { (FINBRA = IDEO) }\end{array}$ & $\begin{array}{c}\text { Porcentagem de } \\
\text { validação (\%) }\end{array}$ \\
\hline 2010 & 644 & 642 & 292 & 45,5 \\
\hline 2011 & 644 & 638 & 454 & 71,2 \\
\hline 2012 & 644 & 605 & 418 & 69,1 \\
\hline 2013 & 644 & 611 & 361 & 59,1 \\
\hline 2014 & 644 & 584 & 399 & 68,3 \\
\hline
\end{tabular}


No caso das despesas, o gráfico 4 aponta que mais da metade das cidades no FINBRA estão com os valores equivalentes. Sobre as cidades que não foram validadas a hipótese definida pelo autor é de que existe uma falha de comunicação entre os órgãos municipais e o órgão da Secretaria do Tesouro Nacional responsável por publicar os dados da contabilidade pública nacional dos entes estaduais e municipais.

Gráfico 4 - Comparativo dos valores de despesas entre 2010 e 2014 entre os sistemas IDEO, PTCGU e SIGA - Municípios

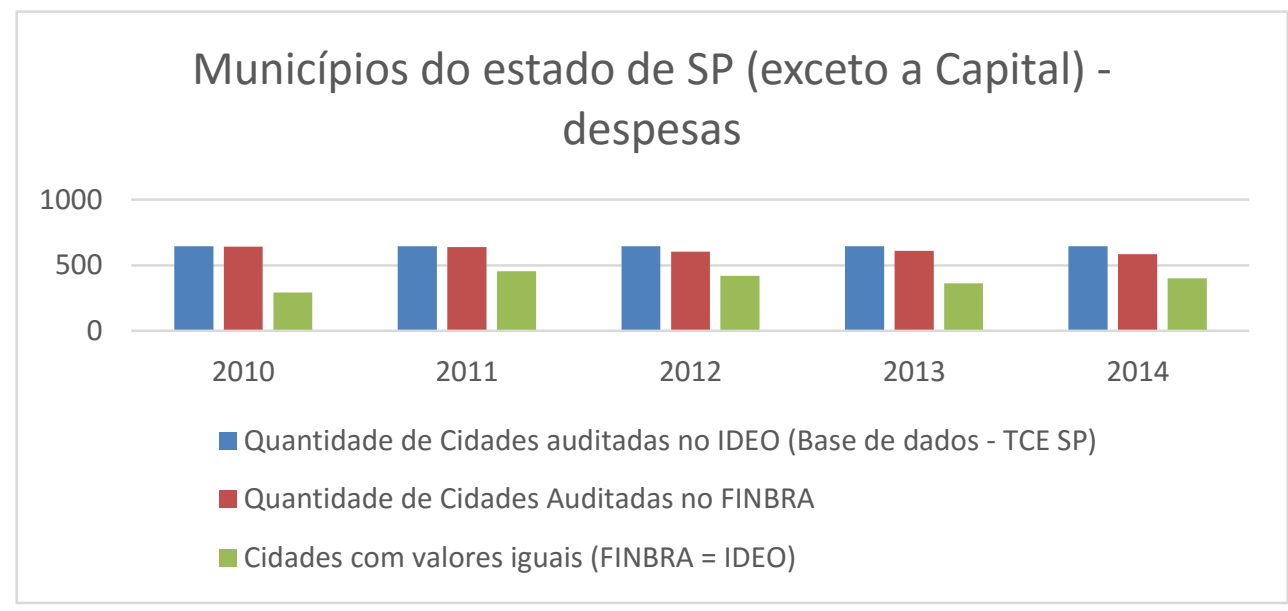

Fonte: José Rodolfo Beluzo, 2015.

Para o período de 2010 a 2012 os dados do FINBRA estão disponíveis em link direto ${ }^{15}$; para os anos de 2013 e 2014 a consulta deve ser realizada através da ferramenta de pesquisa WEB SICONFI no portal do Tesouro Nacional. A respeito do formato dos arquivos, para o período de 2013 a 2014 os dados estão tabulados em arquivos de formato XLS; para o período de 2010 a 2012 os dados estão formatados em arquivo de formato MDB. A validação foi parcial tanto para receitas quanto despesas.

\subsubsection{Validação de dados - Município de São Paulo (Capital)}

Com relação ao município de São Paulo as fontes de dados foram as mesmas utilizadas para os outros municípios anteriores. Os dados disponibilizados pelo FINBRA não são iguais para nenhum dos períodos estudados no trabalho. Para o munícipio de São Paulo só foi

\footnotetext{
${ }^{15} \mathrm{http}: / /$ www.tesouro.fazenda.gov.br/pt_PT/finbra-financas-municipais
} 
analisado a validação no FINBRA com relação às despesas, pois os dados de receitas não foram incluídos no IDEO, como citado anteriormente.

A tabela 37 ilustra a diferença entre os valores encontrados no sistema IDEO e no dataset do FINBRATabela 37. Para o ano de 2013 o FINBRA não possui informação referente às despesas do município de São Paulo. Para os outros anos o processo de validação foi concluído.

Tabela 37 - Totais gerados pelo sistema IDEO x FINBRA - despesas pagas pelo município de São Paulo

\begin{tabular}{l|c|c|c}
\hline Ano exercício & IDEO (R\$) & FINBRA (R\$) & IDEO - FINBRA (R\$) \\
\hline 2010 & $27.127 .222 .909,53$ & $26.844 .602 .315,48$ & $282.620 .594,05$ \\
\hline 2011 & $30.369 .524 .152,64$ & $29.967 .045 .888,40$ & $402.478 .264,24$ \\
\hline 2012 & $34.116 .141 .151,52$ & $34.436 .260 .091,22$ & $-320.118 .939,70$ \\
\hline 2013 & $35.864 .037 .385,30$ & Não disponível & Não aplicável \\
\hline 2014 & $41.449 .912 .427,83$ & $36.485 .494 .842,87$ & $4.964 .417 .584,96$ \\
\hline
\end{tabular}

Fonte: José Rodolfo Beluzo, 2015

O gráfico 5 mostra que as diferenças existentes entre o sistema IDEO e o dataset do FINBRA são pequenas, porém existentes para o período de 2010 a 2012; e um pouco mais elevada para o ano de 2014. Sobre o ano de 2013 não foi possível realizar a análise. A hipótese aqui é a mesma da seção anterior: existe uma falha na comunicação dos dados da execução orçamentária e a Secretaria do Tesouro Nacional.

Gráfico 5 - Comparativo dos valores de despesas entre 2010 e 2014 entre os sistemas IDEO, PTCGU e SIGA - Municípios

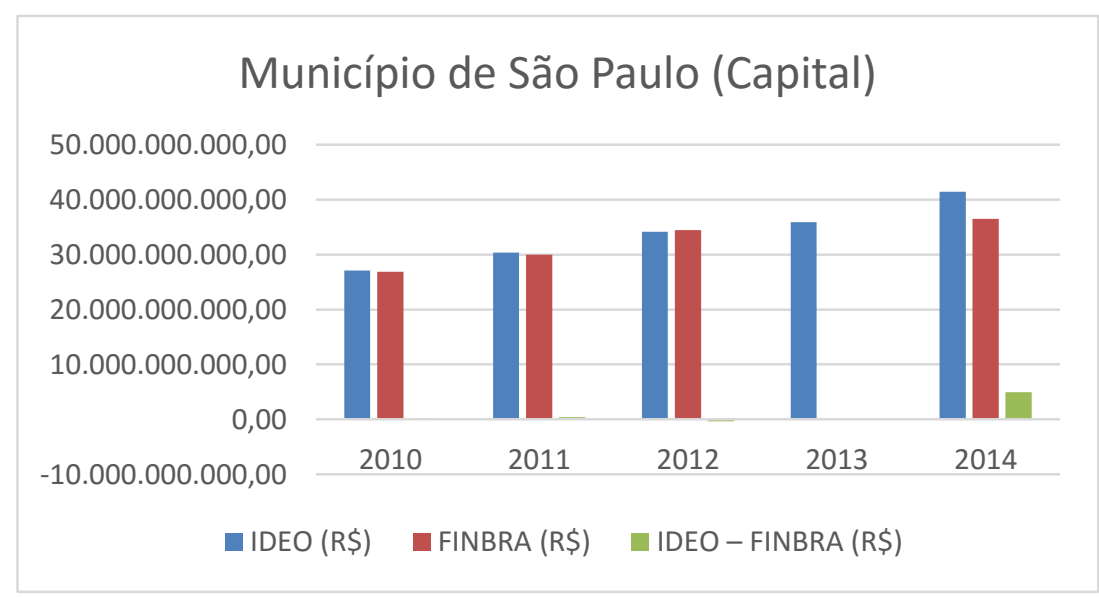

Fonte: José Rodolfo Beluzo, 2015. 
Os dados aqui utilizados do FINBRA são os mesmos da seção anterior (mesmas fontes e mesmos tipos de arquivos para os mesmos períodos).

\subsubsection{Validação com especialista de dados}

Para a validação com o especialista de dados, foi convidado para analisar a viabilidade do trabalho o pesquisador Gustavo Andrey de Almeida Lopes Fernandes ${ }^{16}$, Professor do Departamento de Gestão Pública da EAESP-FGV, e também Assessor Econômico do Tribunal de Contas do Estado de São Paulo. O processo de validação desta etapa consiste em verificar o trabalho do usuário com relação a consultar os dados através dos portais comparando-se com a ferramenta IDEO. Para tal, o mesmo selecionou consultas a serem realizadas no sistema que não seriam possíveis através das ferramentas nos portais governamentais de forma direta. As consultas selecionadas foram:

- Gastos em educação pelo governo federal, estado, capital e municípios (I);

- Somatório dos gastos de municípios pela função educação (II);

- Despesas com pessoal (ativos e inativos) para governo federal, estadual, capital e municípios (III);

- Custo total da função educação no universo de dados estudado (IV);

- Custo total de despesas com pessoal (ativo e inativo) no universo de dados estudado (V).

A consulta I é possível de se obter parcialmente através dos portais de transparência utilizados. Os portais PTCGU do Governo Federal e o portal "Prestando Contas" do Governo do Estado de São Paulo possuem ferramentas para consulta detalhada da função (conseguindo o valor compilado para cada função diretamente); para o município de São Paulo, a informação é possível de se obter através do QDD, que está em formato PDF; para os municípios de São Paulo não há uma ferramenta de consulta específica para se obter esta informação; seria necessário o usuário realizar o download dos datasets de todos os municípios e realizar uma soma condicional para cada dataset, tornando a tarefa inviável, visto que existem 644 munícipios (e respectivamente 644 datasets para cada ano).

A consulta II possui o mesmo problema da consulta I: há a necessidade de se realizar o download dos datasets para se obter a informação compilada.

\footnotetext{
${ }^{16} \mathrm{http}: / /$ gvpesquisa.fgv.br/professor/gustavo-andrey-de-almeida-lopes-fernandes
} 
A consulta III possui problemas semelhantes à consulta I, com o agravante de que no governo federal o usuário não conseguirá um relatório direto, como foi possível na consulta I: este deverá selecionar a consulta por tipos de despesas em gastos diretos e realizar o somatório manualmente dos elementos "Pessoal e encargos sociais" visíveis no resultado, sem opção de filtro.

A consulta IV é um somatório do resultado encontrado na consulta I; logo não será viabilizada também. $\mathrm{O}$ mesmo acontece com a consulta $\mathrm{V}$, que é um somatório do resultado encontrado na consulta III; logo também não é viável.

As cinco perguntas solicitadas pelo especialista foram possíveis de serem realizadas através da ferramenta de visualização deste projeto (plugin de visualização Sayku, integrado ao Pentaho Business Inteligence, citado anteriormente). O procedimento para gerar estas informações é básico: Para todas as perguntas basta selecionar o fato que deseja analisar (por exemplo "despesas federais", “despesa estadual”, "despesa municípios" ou “despesa integrada" - no caso de a análise ser comparativa entre todos os entes federativos); a medida "valor", incluir a dimensão que deseja analisar em linha ou coluna (por exemplo "função" nas perguntas (I), (II) e (IV) ou "categoria da despesa" nas perguntas (III) e (V)); selecionar a dimensão temporal "ano" em linha ou coluna. Ao clicar em executar, o sistema irá retornar o somatório de cada ano para cada item das dimensões escolhidas. Caso queira apenas um domínio de valor específico, clique na dimensão e selecione apenas os itens que deseja retornar (por exemplo, “educação" na dimensão "função"). No capítulo anterior a figura 43 exemplifica esta consulta.

Desta forma, validou-se a viabilidade do projeto de acordo com o objetivo inicial: proporcionar melhores formas de consultas sobre os datamarts e também consultas integradas entre os diferentes níveis de esferas governamentais. Para gerar as seguintes consultas e verificar o resultado das mesmas acesse http://www.beluzo.com.br/ideo/ com o usuário e senha de teste respectivamente "teste" e "teste". Caso tenha dúvidas na utilização, acesse http://www.beluzo.com.br/tutorial_ideo/. 


\section{Discussão dos Resultados}

Esta seção irá elencar os resultados positivos gerados por cada etapa deste trabalho detalhada no capítulo 5, assim como os problemas enfrentados e que não foram possíveis solucionar por estarem fora da alçada do projeto de pesquisa. Na seção 6.1 serão discutidos os resultados e dificuldades encontradas na definição dos esquemas conceituais e modelos lógicos e na seção 6.2 serão discutidos os resultados e dificuldades encontradas nas etapas do processo ETL.

\subsection{Esquemas conceituais e modelos lógicos}

A etapa de desenvolvimento dos esquemas conceituais e modelos lógicos foi fundamental para se realizar uma análise comparativa com relação ao formato de publicação dos dados abertos de execução orçamentária até o atual período. Foi observado que cada ente federativo disponibiliza seus dados de forma autônoma, não seguindo de forma completa a publicação dos dados da execução orçamentária de acordo com o que está descrito no MCASP. Desta forma, este trabalho levanta uma hipótese referente à esta seção: há uma irregularidade no formato de publicação, visto que as classificações orçamentárias são previstas em um manual técnico desenvolvido anualmente, e que ao menos as classificações que estão citadas e descritas no manual poderiam ser aplicadas, visto que a lei de Acesso a Informação no Art. $4^{\circ}$, Inciso $\mathrm{IX}^{17}$ diz que a informação deve estar em sua forma primária, com o máximo de detalhamento possível, sem modificações.

Destaca-se também nesta seção uma análise breve, porém indicadora de que a hipótese levantada no parágrafo anterior é impactante: o modelo integrado tanto de receita quanto despesa perde recursos de informações. Por exemplo: caso queira-se realizar consultas analíticas com relação a classificação por ações governamentais da despesa nos três entes federativos, esta não será possível pois durante a intersecção, este campo foi perdido por não ser campo comum a todas as bases. Outro exemplo é com relação à tentativa de se obter uma ligação entre receitas e despesas através dos campos destinação de recursos (pertencente ao modelo conceitual de receitas no MCASP 2014) e fonte de recursos (pertencente no modelo

\footnotetext{
${ }^{17} \mathrm{http} / /$ www.planalto.gov.br/ccivil_03/_ato2011-2014/2011/lei/112527.htm
} 
conceitual de despesas no MCASP 2014), pois não há publicação do elemento destinação em nenhum dos datasets.

Esta etapa do projeto também foi discutida por outros pesquisadores em 2014 durante o II Workshop de Transparência em Sistemas (WTrans), evento que ocorreu no X Simpósio Brasileiro de Sistemas de Informação (SBSI 2014) na cidade de Londrina / PR. O artigo aceito para apresentação no workshop intitulado "Criação de um repositório integrado de dados da execução orçamentária brasileira proveniente de diferentes fontes de dados em um modelo dimensional Data Warehouse" apresentou os resultados iniciais encontrados e a definição de metodologia que pretendia seguir para atingir os objetivos desta definição de esquemas.

Estes pontos levantados com relação a não publicação dos dados também foram enviados por email em Agosto de 2015 para a contatos diretos da CGU e STN para comentários e até a presente data deste trabalho aguarda retorno. Os Órgãos foram escolhidos por terem como missão a gestão das contas públicas de forma transparente e serem responsáveis pelo combate à corrupção e o mal uso de dinheiro público.

\subsection{ETL}

A fase ETL permitiu analisar as dificuldades que um cidadão comum encontraria ao tentar descobrir informações um pouco mais elaboradas do que as oferecidas nos portais de transparência.

Esta fase trata na seção 6.2.1 sobre os resultados obtidos no processo de extração dos dados no sistema IDEO: a seção 6.2.2 refere-se aos resultados e dificuldades encontrados na etapa de transformação dos dados; a seção 6.2.3 refere-se aos resultados e dificuldades encontrados na etapa de carregamento dos dados; a seção 6.2.4 refere-se a ferramenta de visualização utilizada e os benefícios que esta trouxe ao sistema e a seção 6.2 .5 se refere aos resultados encontrados no processo de validação do sistema IDEO.

\subsubsection{Extração}

Com relação à etapa de extração a sugestão é de que os portais de transparência publiquem os dados em um diretório de dados padronizados, com nomenclaturas padronizadas e granularidades padronizadas. Este processo facilitaria a criação de uma ferramenta de extração automática, não sendo necessário a criação de uma ferramenta específica para cada 
portal. O quadro 2 mostra as diferenças encontradas para o problema específico da granularidade:

Quadro 2 - Diferença na granularidade das publicações de dados

\begin{tabular}{|c|c|c|}
\hline \multirow[t]{2}{*}{ Ente Federativo } & \multicolumn{2}{|c|}{ Granularidade } \\
\hline & Receitas & Despesas \\
\hline Federal & Diário & Diário \\
\hline Estadual-SP & Anual (não define a data exata) & Anual (não define a data exata) \\
\hline Municípios SP & Mensal (não define a data exata) & Diário \\
\hline São Paulo/SP & (Base não disponível) & Anual (Não define a data exata) \\
\hline
\end{tabular}

Fonte: José Rodolfo Beluzo, 2015

\subsubsection{Transformação}

A etapa de transformação dos dados aponta críticas com relação ao processo sistêmico de disponibilização dos dados e de domínio dos dados.

O problema com relação ao processo sistêmico de disponibilização dos dados diz respeito ao fato de alguns datasets estarem com informações incompletas. Se um determinado tipo de dado possui descrição e um código padrão, este código deve vir detalhado e de forma granulada (alguns datasets publicam as duas informações, porém em um único campo separados por hífen). A correção destes elementos favoreceu o processo de carregamento dos dados em um sistema integrado, pois um código único garante que uma mesma informação não será representada por dois elementos no sistema.

Outro problema sistêmico diz respeito a má formatação das tabulações dos dados. Em alguns datasets foi identificado que a linha de dados possuía menos (ou mais) elementos do que a quantidade de cabeçalhos de informações. Desta forma, informações produzidas com estes datasets antes da prévia correção seriam inconsistentes.

\subsubsection{Carregamento}

A fase de carregamento possibilitou definir um algoritmo para se carregar os dados no sistema a partir dos datasets. $\mathrm{O}$ algoritmo permite o carregamento dos dados de forma paralela, aumentando a performance de carregamento. 


\subsubsection{Visualização}

A etapa de visualização possibilitou demonstrar que as consultas possíveis de se realizar em um cubo Data Warehouse vão além do que era possível nas consultas pré-definidas as quais alguns portais utilizados disponibilizavam.

A possibilidade de gerar novas informações, realizar processos de mineração de dados e aproximar a sociedade de informações mais concretas e relevantes é maior do que o estado atual dos portais de transparência. $\mathrm{O}$ fato de possibilitar consultas integradas também demonstra o poder computacional que a integração proporciona.

Esta etapa do projeto também foi visualizada e discutida por outros pesquisadores em Agosto de 2015 durante o Fórum de Pesquisas Emergentes (Emergent Research Forum - ERF) na Americas Conference on Information Systems (AMCIS) em Porto Rico. O artigo aceito para apresentação no fórum intitulado "The integration of multi-source heterogeneous data: an open data case study for budgetary execution in Brazil" apresentou os resultados iniciais possíveis de consultas integradas a partir da ferramenta de visualização utilizada no processo de integração dos dados.

\subsubsection{Validação}

A etapa da validação foi importante para verificar a situação dos dados abertos referentes à execução orçamentária. O quadro 3 demonstra a corretude dos dados no escopo estudado deste trabalho de acordo com os próprios portais.

Quadro 3 - Corretude dos dados dos entes federativos de acordo com os próprios portais

\begin{tabular}{|c|l|l|}
\hline Ente federativo & Tipo orçamento & Datasets disponíveis X Relatórios do Portal \\
\hline \multirow{2}{*}{ Federal } & Receita & Não confere \\
\cline { 2 - 3 } & Despesa & Possuí divergência em parte dos datasets \\
\hline \multirow{2}{*}{ Governo SP } & Receita & OK \\
\cline { 2 - 3 } & Despesa & OK \\
\hline \multirow{2}{*}{ Municípios SP } & Receita & OK \\
\cline { 2 - 3 } & Despesa & OK \\
\hline \multirow{2}{*}{ São Paulo Capital } & Receita & Não aplicável (informações não disponíveis no portal) \\
\cline { 2 - 3 } & Despesa & Possuí divergência em parte dos datasets \\
\hline
\end{tabular}

Fonte: José Rodolfo Beluzo, 2015 
O quadro 4 demonstra a corretude dos dados no escopo estudado deste trabalho de acordo com os dados utilizados e outras fontes de dados compiladas que se referenciam ao mesmo elemento de dado (SIGA e FINBRA, citados anteriormente).

Quadro 4 - Corretude dos dados dos entes federativos de acordo com outras fontes

\begin{tabular}{|l|l|l|}
\hline Ente federativo & Tipo orçamento & \multicolumn{1}{|c|}{ Datasets disponíveis X Outras Fontes } \\
\hline \multirow{2}{*}{ Federal } & Receita & Não confere \\
\cline { 2 - 3 } & Despesa & Não confere \\
\hline \multirow{2}{*}{ Governo SP } & Receita & OK \\
\cline { 2 - 3 } & Despesa & OK \\
\hline \multirow{2}{*}{ Municípios SP } & Receita & Confere parcialmente \\
\cline { 2 - 3 } & Despesa & Confere parcialmente \\
\hline \multirow{2}{*}{ São Paulo Capital } & Receita & Não aplicável (informações não disponíveis no portal) \\
\cline { 2 - 3 } & Despesa & Possú divergência em parte dos datasets \\
\hline
\end{tabular}

Fonte: José Rodolfo Beluzo, 2015

Desta forma a partir destas análises podemos gerar as seguintes questões aos órgãos publicadores: “Qual está publicando seus dados de forma correta? Qual informação está faltante em seu portal? Qual informação está incorreta? Qual a fonte de dados que um sistema integrador pode confiar em utilizar?". 


\section{Conclusão e trabalhos futuros}

Esse trabalho teve como objetivo mostrar a construção de um repositório integrado de dados de orçamento público provenientes de diferentes fontes em todas as esferas governamentais, algo ainda não realizado neste contexto tanto no Brasil quanto a nível mundial, de acordo com as buscas durante a revisão sistemática deste trabalho. Consideramos o Brasil, cujo o Estado é organizado por um poder federal, 26 estados e 5570 municípios. Para a prova de conceito, foram coletados dados provenientes do governo federal, de um governo estadual e dos 645 municípios do estado de São Paulo relativos as receitas e despesas realizadas em 5 anos. Assim, inicialmente foram estudados os conceitos orçamentários específicos do Brasil, assim como as leis que favorecem a transparência de dados governamentais no país e também os princípios básicos de dados abertos governamentais. Desta forma foi possível proporcionar durante a definição dos esquemas de dados um estudo relevante sobre os esquemas dos dados já publicados nos portais, facilitando o trabalho de novos projetos que iniciem na mesma linha de estudo, assim como demonstrando soluções para os problemas mapeados de heterogeneidade e falhas corrigíveis. Foi visto também que, apesar de existir o conceito e uma lei de transparência, ainda existem lacunas de dados não disponibilizados nos portais que impossibilita a produção de algumas informações, tornando esta transparência incompleta para determinados contextos. O produto final - uma base de dados carregada em um sistema de banco de dados Postgres no modelo Star Schema possibilita a integração dos dados com qualquer sistema OLAP compatível com Postgres, baseado no modelo Star Schema. Para validar esta integração utilizamos a ferramenta "Saiku" da comunidade Pentaho para visualização de informações e exportação de dados. $\mathrm{O}$ produto final gerado pela ferramenta foi avaliado baseado em dados consolidados disponíveis em portais de auditoria contábil, possibilitando aferir a confiabilidade dos dados integrados. Também foi consultado um especialista da área de políticas públicas ao qual analisou e também validou os resultados gerados pela ferramenta.

Os resultados produzidos até o momento foram satisfatórios (nem todas as perguntas iniciais da pesquisa foram respondidas, porém foi possível demonstrar como a publicação dos dados abertos governamentais do orçamento público brasileiro ainda está deficiente). Existe um longo caminho para a um portal de transparência único nos três entes federativos para todos os estados e municípios brasileiros, porém este trabalho teve como objetivo dar o primeiro passo. Para que isso aconteça ainda serão necessárias diversas mudanças políticas, legislativas e tecnológicas no país. 
Este trabalho também abre portas para outros trabalhos em diversas áreas computacionais: mineração de dados, visualização de dados, republicação de dados, linked data, big data, dentre outras. Além disso, os dados padronizados facilitam a comunidade desenvolvedora de aplicativos civis, que podem gerar desde aplicações de fiscalização assim como aplicações utilitárias para aqueles que desejam participar ativamente na política, aproximando o cidadão nos atos de seu governo. 


\section{Referências}

Aryan, P.R.; Ekaputra, F.J.; Sunindyo, W.D.; Akbar, S., Fostering government transparency and public participation through linked open government data: Case study: Indonesian public information service. Data and Software Engineering (ICODSE), 2014 International Conference on , vol., no., pp.1,6, 26-27 Nov, 2014.

Batini, C.; Lenzerini, M.; and Navathe, S. 1986. A comparative analysis of methodologies for database schema integration. ACM Computing Survey 18(4):323\{364.

BRASIL. Constituição da República Federativa do Brasil de 1988. Out. 1998. Disponível em: $<$ http://www.planalto.gov.br/ccivil_03/constituicao/constituicao.htm>. Acesso em: $10 \mathrm{de}$ junho de 2015.

BRASIL. Lei complementar no. 101, de 4 de maio de 2000. Disponível em:

$<$ http://www.planalto.gov.br/ccivil_03/leis/lcp/lcp101.htm>. Acesso em: 10 de junho de 2015.

BRASIL. Lei Complementar no 131. Mai. 2009. Disponível em:

$<$ http://www.planalto.gov.br/ccivil_03/leis/lcp/lcp131.htm>. Acesso em: 10 de junho de 2015.

BRASIL. Lei no 12.527. Nov. 2011. Disponível em:

$<$ http://www.planalto.gov.br/ccivil_03/_ato2011-2014/2011/lei/112527.htm>. Acesso em: 10 de junho de 2015 .

Berners-Lee, T. Linked Data. 2006. Disponível em:

$<$ http://www.w3.org/DesignIssues/LinkedData.html $>$. Acesso em: 10 de junho de 2015.

Brito, K. S.; Silva Costa, M.A.; Cardoso Garcia, V.; Meira, R. L. S. Experiences Integrating Heterogeneous Government Open Data Sources to Deliver Services and Promote Transparency in Brazil. Computer Software and Applications Conference (COMPSAC), 2014 IEEE 38th Annual, vol., no., pp.606, 607, 21-25 July 2014.

Burkhead, J. Orçamento Público. Fundação Getúlio Vargas, 1971.

Craveiro, G. S.; Santana, M. T.; Albuquerque, J. P. Assessing open government budgetary data in Brazil. In: ICDS 2013. The Seventh International Conference on Digital Society. [s.n.], 2013. p. 20-27.

Eaves, David. The Three Laws of Open Government Data. 2009. Disponível em: $<$ http://eaves.ca/2009/09/30/three-law-of-open-government-data/>. Acesso em: 10 de junho de 2015.

Elmasri, R.; Navathe, S. B. Fundamentals of Database Systems. Addison Wesley; 6 edition (April 9, 2010), 2010.

Giacomoni, J. Orçamento Público. Editora Atlas, 16 a edição, 2012.

Hendler, J.; Holm, J.; Musialek, C.; Thomas, G., US Government Linked Open Data:

Semantic.data.gov. Intelligent Systems, IEEE, vol.27, no.3, pp.25, 31, May-June 2012 
Inmon, W. H. Building the Data Warehouse. John Wiley \& Sons, 2005. 4st.

Keen, P. G. W.; Morton, M. S. S. Decision Support Systems: An Organizational Perspective. Reading, MA: Addison-Wesley Publishing Company, 1978.

Kent, W. Data and Reality. First Books Library, 2000.

Kimball, R. Data Warehouse Toolkit. Tradução Mônica Rosemberg; Revisão Técnica Ronal Stevis Cassiolato. São Paulo: Makron Books, 1998.

Kimball, R. The Data Warehouse ETL Toolkit. John Wiley \& Sons, 2004. 1st Edition.

Larson, J. A.; Navathe, S. B.; and Elmasri, R. 1989. A theory of attribute equivalence in database with application to schema integration. IEEE Transaction on Software Engineering 15(4):449\{463.

Loureiro, M., Teixeira, M.; Prado, O. Construção de instituições democráticas no Brasil contemporâneo: transparência das contas públicas. Revista Organização \& Sociedade, 15 (47), 107-119.

Machado, A.L.; Parente de Oliveira, J.M., DIGO: An Open Data Architecture for eGovernment. Enterprise Distributed Object Computing Conference Workshops (EDOCW), 2011 15th IEEE International, vol., no., pp.448, 456, Aug. 29 2011-Sept. 22011

MINISTÉRIO DO PLANEJAMENTO, ORÇAMENTO E GESTÃO. SECRETARIA DE ORÇAMENTO FEDERAL. Manual Técnico de Orçamento MTO 2014. Brasília - DF, 2014. Disponível em: <http://www.orcamentofederal.gov.br/informacoes-orcamentarias/manualtecnico/MTO_2014.pdf>. Acesso em: 10 de junho de 2015.

MINISTÉRIO DO PLANEJAMENTO, ORÇAMENTO E GESTÃO. SECRETARIA DE ORÇAMENTO FEDERAL. O que é o orçamento público. Brasília - DF, 2014. Disponível em: < http:/www.planejamento.gov.br/servicos/faq/orcamento-da-uniao/conceitos-sobreorcamento/o-que-e-orcamento-publico>. Acesso em: 07 de Novembro de 2015.

OECD. OECD Best Practices for Budget Transparency. OECD Journal on Budgeting 1(2):714. 2002. Disponível em: < http://www.oecd.org/gov/budgeting/best-practices-budgettransparency.htm>. Acesso em: 10 de junho de 2015.

OGP - Open Government Partnetship. Declaração de Governo Aberto. Set. 2011. Disponível em: <http://www.opengovpartnership.org/>. Acesso em: 10 de junho de 2015.

OGWG - OPEN GOVERNMENT WORKING GROUP. Eight Principles of Open Government. Dez. 2007. Disponível em: <http://www.opengovdata.org/home>. Acesso em: 10 de junho de 2015.

Open Knowledge Foundation. Beyond Access: The Right to (Re)Use Public Information. 2011, pp. 8-9.

Paludo, A. V. Orçamento Público, Administração Financeira e Lei de Responsabilidade Fiscal. Editora Campus-RJ, $1^{\mathrm{a}}$ edição, 2013. 
Pieranti, O. P.; Rodrigues, S.; Peci, A.. Governança e New Public Management:

Convergências e Contradições no Governo Brasileiro. XXXI Encontro da ANPAD. Rio de Janeiro, 2007.

Sala, A.; Lin, C.; Ho, H. Midas for government: Integration of government spending data on Hadoop. In Proc. of the Int. WS on New Trends in Information Integration (NTII), 2010.

Santana, M. T. Uma proposta de publicação de dados do orçamento público na Web. Dissertação apresentada como parte da avaliação do programa de mestrado em Sistemas de Informação da Escola de Artes, Ciências e Humanidades - EACH. 2013.

Shadbolt, N.; O’Hara, K.; Berners-Lee, T.; Gibbins, N.; Glaser, H.; Hall, W.; Schraefel, M.C. Linked Open Government Data: Lessons from Data.gov.uk. Intelligent Systems, IEEE, 2012.

Theocharis, S.A.; Tsihrintzis, G.A., Open data for e-government the Greek case. Information, Intelligence, Systems and Applications (IISA), 2013 Fourth International Conference on , vol., no., pp.1,6, 10-12 July 2013

Santos, W. V. Sistema de Informação de Custos do Governo Federal: Modelo Conceitual, Solução Tecnológica e Gestão do Sistema. Secretaria do Tesouro Nacional. 2011.

SECRETARIA DO TESOURO NACIONAL. Manual de Contabilidade Aplicada ao Setor Público (MCASP). Brasília - DF, 2014. Disponível em:

$<$ http://www.tesouro.fazenda.gov.br/documents/10180/456785/CPU_MCASP+6\%C2\%AA\% 20edi\%C3\%A7\%C3\%A3o_Republ2/fa1 ee713-2fd3-4f51-8182-a542ce123773>. Acesso em: 05 de Outubro de 2015.

Simmhan, Y. L., Plale, B., Gannon, D. A Survey of Data Provenance Techniques. 2005. In: Technical Report TR-618: Computer Science Department, Indiana University.

Tan, W. C. Research Problem in Data Provenance. 2004. In: IEE Data Eng. Bull. 